Portland State University

PDXScholar

\title{
Lifeblood of the Earth: Nuwuvi (Southern Paiute) Hydrological Knowledge and Perceptions of Restoration in Two Southern Nevada Protected
} Areas

Kendra Lesley Wendel

Portland State University

Follow this and additional works at: https://pdxscholar.library.pdx.edu/open_access_etds

Part of the Indigenous Studies Commons, and the Water Resource Management Commons Let us know how access to this document benefits you.

\section{Recommended Citation}

Wendel, Kendra Lesley, "Lifeblood of the Earth: Nuwuvi (Southern Paiute) Hydrological Knowledge and Perceptions of Restoration in Two Southern Nevada Protected Areas" (2014). Dissertations and Theses. Paper 2027.

https://doi.org/10.15760/etd.2026

This Thesis is brought to you for free and open access. It has been accepted for inclusion in Dissertations and Theses by an authorized administrator of PDXScholar. Please contact us if we can make this document more accessible: pdxscholar@pdx.edu. 
Lifeblood of the Earth:

Nuwuvi (Southern Paiute) Hydrological Knowledge and Perceptions of Restoration in Two Southern Nevada Protected Areas

by
Kendra Lesley Wendel

A thesis submitted in partial fulfillment of the requirements for the degree of

\author{
Master of Science \\ in \\ Anthropology
}

Thesis Committee:

Jeremy Spoon, Chair

Michele Gamburd

Virginia Butler

Portland State University

2014 
(C) 2014 Kendra Lesley Wendel 


\begin{abstract}
In the arid landscapes of the southern Great Basin and northern Mojave Desert, issues surrounding water resource management are often politically contentious. Nuwuvi (Southern Paiute) have known and managed these resources for thousands of years prior to Euro-American arrival in the region. A variety of factors, including federal policies that resulted in the creation of reservations and forced placement in boarding schools, as well as contemporary resource commodification, have influenced Nuwuvi knowledge and practice.

In this thesis, I examined the character of Nuwuvi ethnohydrological knowledge, including management knowledge, of two protected areas: Spring Mountains National Recreation Area (SMNRA), managed by the U.S. Forest Service (USFS) and Desert National Wildlife Refuge (DNWR), managed by the U.S. Fish and Wildlife Service (USFWS). In addition, I investigated perceptions of water health and restoration among participants from the two managing agencies and six Nuwuvi Nations. I addressed these topics using the theoretical framework of political ecology and a methodology that included semi-structured interviews and demographic questionnaires with 16 Nuwuvi knowledge holders and four federal agency participants. I conducted text analysis of partial interview transcripts using the inductive coding method in order to identify recurring themes and concepts related to hydrology, management, and restoration.

My results illustrated that Nuwuvi ethnohydrological knowledge, which developed incrementally over time, conceptualized water as a sentient being that
\end{abstract}


required human interaction to remain healthy. There was also evidence that Nuwuvi knowledge of water was changing as a result of political, economic, and social forces. Furthermore, these findings suggest that Nuwuvi and agency approaches to hydrological management and restoration were built upon differing epistemologies, though there was convergence among specific management and restoration techniques. Based on these results, a report of findings from the Nuwuvi Knowledge-to-Action project, including recommendations for collaborative stewardship approaches, was delivered to participants in August 2013. 


\section{Acknowledgements}

I acknowledge the indispensable support and guidance of my adviser, Dr. Jeremy Spoon. I have benefited immensely from his expertise and leadership. I am also appreciative to Dr. Spoon and Richard Arnold for their invitation to join the Nuwuvi Knowledge-to-Action project. I also acknowledge my committee members, Drs. Michele Gamburd and Virginia Butler, for their thoughtful comments and for the time they have put into revisions. Their feedback has enriched my research and writing.

Thank you to all of my partners in the Nuwuvi Nations, USFS, and USFWS, The Mountain Institute, and to all of my consultants. I extend special thanks to the Nuwuvi Working Group, Amy Sprunger, and Judy Suing for their help in identifying interviewees.I offer special thanks to my fellow students in the Office of Applied Anthropological Research, especially Brian Lefler, Rachel Lahoff, Cerinda Survant, April Eagan, and Michael Kilman, for their encouragement and friendship. I also thank my friends: Whitney Frank, Katie Pickard, Katie Hallaian, Cheryl Freece, and Angie Ma for their cheerleading along the way.

Finally, thank you to my parents for their unwavering support and encouragement throughout my educational career.

This research would not have been possible without the financial support of the Southern Nevada Public Lands Management Act, and I acknowledge the Act's generous contribution and dedication to strengthening the relationship among 
Native American Nations and federal land management agencies in Southern Nevada. 


\section{Table of Contents}

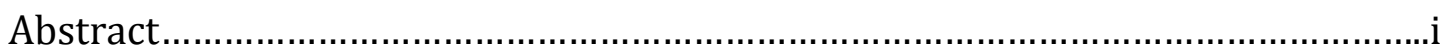

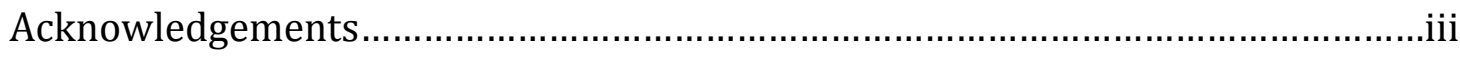

List of Tables.............................................................................................

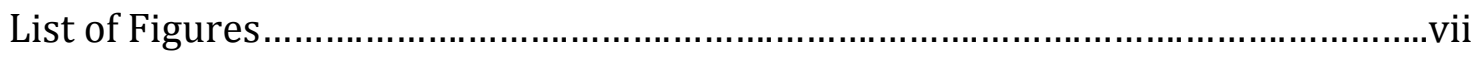

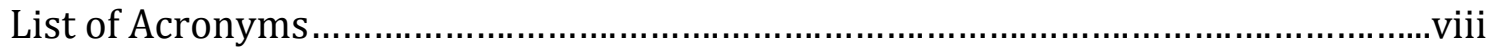

Chapter 1

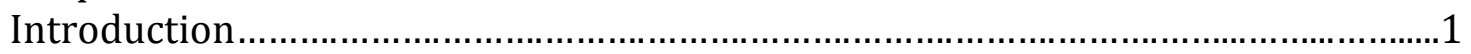

Chapter 2

Nuwuvi, the Great Basin/Mojave Desert, and Historical Drivers of Change in Southern Nevada........................................................................................ 16

Chapter 3

Nuwuvi Understandings of Water and Its Management......................................27

Chapter 4

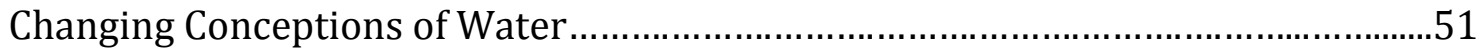

Chapter 5

Epistemologically Grounded Approaches to Hydrological Restoration.....................67

Chapter 6

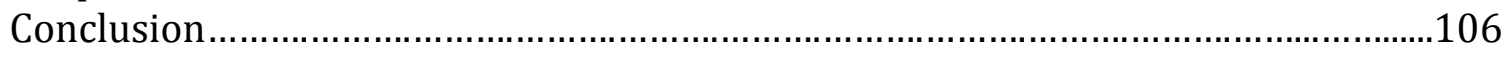

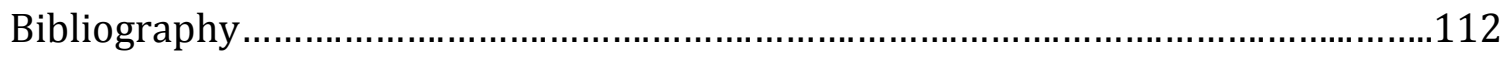

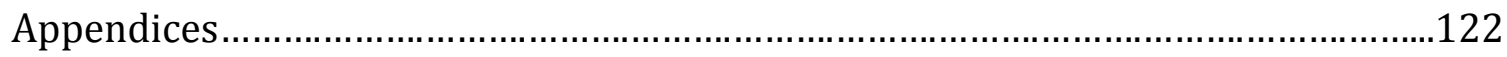

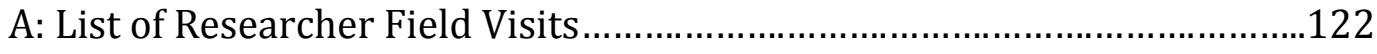

B: Nuwuvi Informed Consent Script..............................................................123

C: Agency Informed Consent Form.......................................................124

D: Interview Questions for Nuwuvi Participants......................................125

E: Interview Questions for Agency Participants.........................................127

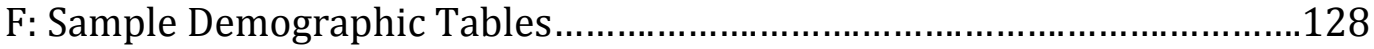

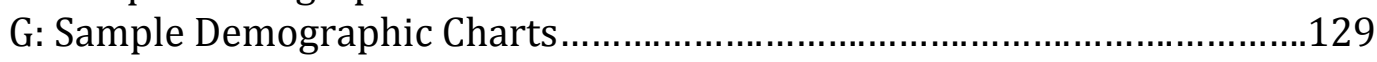




\section{List of Tables}

Table 1: Summary of Nuwuvi and Agency Perceptions of Hydrological Impacts......75

Table 2: Nuwuvi and Agency Perceptions of Restoration...........................................88 


\section{List of Figures}

Figure 1: Map of SMNRA and DNWR Within the Nuwuvi Ancestral Territory.........23

Figure 2: Photograph of Small Poh, SMNRA ......................................................... 47

Figure 3: Photograph of Corn Creek Restoration and Refugium Project, DNWR.....69

Figure 4: Photograph of Wild Horses, SMNRA ..................................................... 82 


\section{List of Acronyms}

CCC: Civilian Conservation Corps

DNWR: Desert National Wildlife Refuge

DNWRC: Desert National Wildlife Refuge Complex

FLPMA: Federal Land Policy and Management Act

IRA: Indian Reorganization Act

LEK: Local Ecological Knowledge

NAGPRA: Native American Graves and Repatriation Act

NEPA: National Environmental Policy Act

NGO: Non-Governmental Organization

NHPA: National Historic Preservation Act

NKTA: Nuwuvi Knowledge-to-Action

NWG: Nuwuvi Working Group

PSU: Portland State University

SMNRA: Spring Mountains National Recreation Area

SNAP: Southern Nevada Agency Partnership

SNPLMA: Southern Nevada Public Lands Management Act

SNRT: Southern Nevada Restoration Team

TEK: Traditional Ecological Knowledge

TMI: The Mountain Institute

USFS: United States Forest Service

USFWS: United States Fish and Wildlife Service 


\section{Chapter 1: Introduction}

Water is a vital resource for inhabitants of southern Great Basin and Mojave Desert arid landscapes. Political issues surrounding water are prevalent as regional populations continue to increase, especially in rapidly urbanizing areas such as Las Vegas (Hulse 2009, Wilkinson 2010). The original inhabitants of this region are Nuwuvi (Southern Paiute), or "the people," an indigenous culture group who built semi-permanent camps around available water sources across their ancestral territory, which spanned four contemporary U.S. states: Nevada, California, Arizona, and Utah. Due to a variety of political, economic, and other factors, their population currently numbers approximately 3,000 people, a significant reduction from precontact estimates (Fowler and Fowler 1971:37, Spoon et al. 2013:11). For Nuwuvi and other settlers, water has always been and remains a vital component of human habitation in these arid landscapes (Hulse 2009).

Nuwuvi consider themselves caretakers of the water resources found in their ancestral territory. Human management partially shaped land and water prior to Euro-American arrival in the region. Two sets of changes have caused the intensity of Nuwuvi water management to drastically decline over the past 200 years. Issues related to access have arisen as land has been privatized or put under federal, state, or local management. Additionally, the creation of Native American reservations, many of which are removed from culturally important landscapes and resources, has made visiting these areas more difficult. In addition to changes related to resource access, factors such as the creation of reservations, the boarding school 
educations imposed upon many Nuwuvi in the late $19^{\text {th }}$ and early $20^{\text {th }}$ centuries, and integration into the market economy have interrupted Nuwuvi cultural knowledge transmission. Beyond the lack of traditional management, drivers such as climate change, urban development, and increased recreation and tourism are currently placing regional hydrological resources under threat. Nuwuvi ecological knowledge about these resources needs to be documented and operationalized before dissolution.

In light of the threatened status of water resources and Nuwuvi ecological knowledge in this region, as well as the extent of hydrological restoration being carried out to combat resource degradation, this thesis evaluates the character of Nuwuvi knowledge of hydrological phenomena and water management and gauges perceptions of hydrological restoration in two southern Nevada protected areas. Much of the Nuwuvi ancestral territory now lies within state or federal lands. The two selected protected areas, Spring Mountains National Recreation Area (SMNRA) (316,000 acres) and Desert National Wildlife Refuge (DNWR) (1.6 million acres), represent significant hydrological resources to Nuwuvi, although they are governed externally by the U.S. Forest Service (USFS) and U.S. Fish and Wildlife Service (USFWS), respectively. In addition to the Nuwuvi perspective, I also engaged federal agency employees responsible for managing these landscapes to evaluate how approaches to hydrological management and restoration converged and differed among Nuwuvi and agency consultants. I argue that Nuwuvi ethnohydrological knowledge was changing as a result of political, economic, and social developments in the region, including the public ownership and management of much of the 
Nuwuvi ancestral territory, as well as the contemporary commodification of water in the western United States. I also argue that Nuwuvi and agency approaches to hydrological management and restoration were based on two distinct epistemologies, though there were areas of convergence and divergence in the management practices themselves. I use a political ecology lens to address how power dynamics influence land and water management in both SMNRA and DNWR. I have organized this into six chapters discussing various subjects related to the Nuwuvi relationship with water and federal agency perceptions of hydrological restoration in the two selected protected areas. The organization of the following chapters goes as follows: In Chapter 1, I describe the project and the methods that I use to address my research questions. Chapter 2 provides historical, cultural, geographic, and physiological context for Nuwuvi and their land. In Chapter 3, I describe Nuwuvi knowledge related to water and hydrological management and argue that this knowledge has developed incrementally over generations. In Chapter 4, I argue that the state of Nuwuvi knowledge continues to change as a result of external political, economic, and social forces. In Chapter 5, I compare Nuwuvi and federal agency (USFS and USFWS) approaches to hydrological management and restoration. I focus on how these perspectives converge and differ and using a political ecology framework, argue that management in these areas is developed through the favoring of positivist thinking based on western science. Chapter 6 concludes with a reiteration of the main arguments as well as a framework for collaborative resource stewardship developed as part of an associated applied project. 
This research was conducted as part of a broader initiative known as Nuwuvi Knowledge-to-Action Project (NKTA): a collaborative effort among seven Nuwuvi Nations, the U.S. Forest Service (USFS), and the U.S. Fish and Wildlife Service (USFWS), facilitated by the international non-governmental organization (NGO) The Mountain Institute (TMI). NKTA concluded with a report entitled Collaborative Resource Stewardship Plan: Nuwuvi (Southern Paiute), the Spring Mountains National Recreation Area and the Desert National Wildlife Refuge Complex (Spoon et al. 2013), which identified collaborative resource stewardship opportunities in two protected areas: Spring Mountains National Recreation Area (SMNRA) and Desert National Wildlife Refuge (DNWR), managed by the Forest Service and Fish and Wildlife Service, respectively. This thesis research thus informs the NKTA project and future collaborative stewardship efforts by engaging the hydrological, management and restoration knowledge of Nuwuvi and federal agency participants. The NKTA project seeks to foster relationships among participating groups and to support meaningful interactions between Nuwuvi and the DNWR and SMNRA landscapes through collaborative stewardship.

\section{Previous Research and Context of Project}

I have collaborated with Nuwuvi in various contexts since 2011. In total, I have been involved in twelve official meetings, site visits, and large-group events, in addition to my two months of independent fieldwork (see full list of activities in Appendix A). Seven of these events have been associated with NKTA. Other projects were conducted in partnership with USFS, USFWS, and other federal land 
management agencies. These trips allowed me to build rapport with the Nuwuvi Working Group (NWG) and with potential Nuwuvi and agency research participants whom I later worked with in the fieldwork phase of this project. Prior to data collection, I conducted a comprehensive literature review using relevant historical, anthropological, and ecological analyses of the region to establish context for the study.

As part of NKTA, this research contributes to both applied and academic outcomes. I designed the applied portion of this project in partnership with NKTA Principal Investigators Jeremy Spoon and Richard Arnold in order to ensure that this component met the requirements of the larger research plan. We submitted the final deliverable for the applied project to the U.S. Forest Service and U.S. Fish and Wildlife Service as part of the report Collaborative Resource Stewardship Plan: Nuwuvi (Southern Paiute), the Spring Mountains National Recreation Area and the Desert National Wildlife Refuge Complex in August, 2013.

\section{Research Questions}

This research project investigated three main questions pertaining to Nuwuvi and federal agency knowledge of water and perceptions of restoration in SMNRA and DNWR. I created these questions to guide the research to inductively consider both Nuwuvi and agency perceptions of hydrological phenomena, management and restoration, as well as how the two perspectives converge and differ. The research questions are as follows: 
1. What is the character of hydrological knowledge held by select Nuwuvi participants?

2. How do hydrological management strategies of Nuwuvi participants and USFS and USFWS managers converge and differ?

3. How do Nuwuvi and agency participants perceive hydrological restoration?

\section{Theoretical framework}

Political ecology

I draw heavily on the theoretical framework of political ecology for my analysis of the ever-changing relationship between Nuwuvi and hydrological resources in the research area. Political ecology emphasizes inequalities and social positioning related to access to and control of resources (Biersack 2006:22, Williams 2001). I also look at the ways in which processes of colonization, land privatization, and federal management of land in the Nuwuvi ancestral territory influenced hydrological knowledge, management practices, and perceptions of restoration among Nuwuvi participants. Escobar (1996) calls for analysis of how power shapes human-environment interactions. He also points out that groups and individuals construct nature in different ways depending on what forces influence them to do so. Furthermore, he argues that scholars must analyze these constructs of nature discursively. Political ecology is directly related to political economy, which seeks to understand the large-scale processes and links between economic and social phenomena (Giddens 1971:10). I will apply all of these considerations to 
my investigation of Nuwuvi ethnohydrological knowledge in light of the power relationships in the region. This assessment includes federal management policy and practice, the presence of private and commercial interests, and the diversion of water to other locations to suit the needs of growing urban populations.

Within the theory of political ecology, I draw from Forsyth's (2003) critical political ecology, which seeks to deconstruct ecological "laws" as perceived by the lens of Western science and to question dominant discourses surrounding natural phenomena. For example, western science once perceived shifting cultivation as having indisputably negative effects on the ecosystem, but scientists now acknowledge that certain types of shifting cultivation may promote certain types of biodiversity (Forsyth 2005:40). Forsyth's focus on ecological realities, while still acknowledging the major role of politics in environmental change, is also relevant to my work when considering ecological changes to the SMNRA and DNWR landscapes resulting from impacts from recreational activities and the effects of climate change.

Local Ecological Knowledge, Incremental Learning, and Knowledge Assemblages

By and large, most federal land management practices rely on western scientific principles and methods. Local ecological knowledge (LEK) provides an alternative perspective through which to look at environmental problems and potential solutions to those problems. Ecological knowledge provides positive environmental benefits in a variety of situations (e.g. Senos et al. 2006, Mulder and Coppolillo 2005, Smith and Wishnie 2000). A large part of my thesis describes Nuwuvi ethnohydrological knowledge, specifically that which pertains to water 
located in SMNRA and DNWR. Though the working definition of local ecological knowledge continues to evolve, I base my discussion on Berkes' (2008:7) definition, which describes LEK as "a cumulative body of knowledge, practice, and belief, evolving by adaptive processes and handed down through generations by cultural transmission, about the relationship of living beings (including humans) with one another and their environment." Using Berkes' definition as a base, I also employ some of Goodall's (2008:356) contributions, especially her challenge of the sometimes ahistorical characterization of indigenous knowledge, and her call to look at ecological knowledge as a process rather than an archive. I also consider Spoon's (2011) attention to heterogeneity of knowledge within cultural groups, which I use to highlight the dynamic nature of ethnohydrological knowledge. Turner and Berkes' (2006) concept of ecological understanding is also central to my discussion. I use this concept to explain and describe the development of Nuwuvi water knowledge. This model explains how ecological knowledge develops incrementally, refuting earlier assumptions that people derive conservation lessons solely from experiences with environmental crises. Turner and Berkes (2006:497) explain that the term ecological understanding embodies attributes including incremental learning, the development of an overarching belief system that supports a common understanding of the environment, the perpetuation of this belief system through stories and songs, and a development of institutions to consolidate environmental knowledge. While Nuwuvi water knowledge varies greatly, depending on subjects' age, gender, social position, personal interests, and geographic location, the overarching ways in which Nuwuvi 
relate to the land and its resources has developed over many generations, as evidenced by stories and anecdotes related by participants. The related concept of knowledge assemblages addresses the fact that the western scientific and local knowledge are often not as dichotomous as some of the literature suggests (Turnbull 1997, Watson and Herrington 2008). I utilize this concept to illustrate how many types of thinking influence Nuwuvi ethnohydrological knowledge (Spoon and Arnold 2012).

Spoon and Arnold (2012) discuss the concept of adaptive co-learning in relation to Nuwuvi perpetuation of ecological knowledge in the context of the current political landscape, which includes federal and private ownership of large segments of the Nuwuvi ancestral territory. The authors point out that public management of these lands, which includes DNWR and SMNRA, has fragmented ecological knowledge and place-based spirituality. At the same time, the federal management has also created an opportunity for collaboration, which makes possible some sort of reconciliation of the complex history of Euro-American occupation and governmental management of these lands.

\section{Ethnoecology and Ethnohydrology}

I refer to Nuwuvi hydrological knowledge as ethnohydrology, a term first used by Back (1981:258) to describe both observations and interpretations of phenomena, as well as the application of that knowledge to water use and management. While Back's study focused on the ways in which early Americans understood hydrological phenomena, later studies focused on the knowledge of 
contemporary peoples. In his work with Peruvian irrigation systems, Gelles (2000:55) described ethnohydrology in relation to "hydro-logics," meaning the local logic systems attached to hydrology. More recently, Gartin et al. (2010) demonstrated how urban ethnohydrological knowledge differed and converged among various demographic groups of residents in Phoenix, Arizona. Ethnohydrology builds on the concept of ethnoecology, a discipline which seeks to understand the relationships among organisms and the physical, biological, and social forces they come into contact with from an emic perspective (Gragson and Blount 1999:vii-viii, Johnson and Hunn 2012). This perspective informs my investigation of Nuwuvi perceptions of the interactions among water, plants, animals, and other natural features.

\section{Adaptive Management}

Nuwuvi-environment interactions both shape and are shaped by the land (Berkes and Folke 1998). The concept of adaptive management attempts to address the unpredictable outcomes that can occur as human-environment interactions change over time (Berkes et al. 2000). This approach to resource management necessitates that management practices must evolve to suit the needs of both the people and the ecosystem. Many Nuwuvi water management techniques result in hydrological disturbance, which can cause non-equilibrium in the system. Forsyth (2003) defines non-equilibrium ecology as an approach that emphasizes the importance of disturbance and change within the ecosystems, thus reinforcing the significance of human-environment interactions and disturbances in maintaining 
healthy ecosystem function. This view is essential in understanding the concepts of change and adaptation in relation to local management practices. The concepts of social-ecological systems and adaptive management are central to my discussion of Nuwuvi hydrological management.

\section{Methodology}

Sampling

Six Nuwuvi Nations participated in this research: Chemehuevi Indian Tribe; Chemehuevi representatives from Colorado River Indian Tribes; Kaibab Band of Paiutes; Las Vegas Paiute Tribe; Moapa Band of Paiutes; and Pahrump Paiute Tribe. ${ }^{1}$ These Nations joined the NKTA project because they have cultural affiliation to the two selected protected areas and expressed willingness to participate. The Nuwuvi Working Group - a group comprised of tribally designated representatives from each Nuwuvi Nation—recommended interviewees. I sought between two and three expert knowledge holders from each Nation for interviews. In total, sixteen Nuwuvi consultants ( 5 men and 11 women between the ages of 42 and 86; average age 62) participated in the study. This sample does not demographically represent the population from which it is drawn, but the specialized knowledge held by select consultants illustrates the broad character of Nuwuvi hydrological knowledge. The protocol for selecting interviewees ensures that participants were selected based on

\footnotetext{
1 There are nine Nuwuvi Nations, but only six Nations elected to participate and were available for my sample.
} 
their status as important keepers of Nuwuvi knowledge, possibly because of their age, social position, or personal background.

The Line Officers (e.g., Refuge Manager) from each agency recommended agency consultants. These interviews provided a greater understanding of agency perspectives on hydrological management, ecological restoration, and consultation with Native American Nations, so I sought interviewees who worked with hydrological management and/or restoration in either SMNRA or DNWR. In total, two participants from each agency (one man and one woman from each between the ages of 28 and 58) (See Appendix F for more detail).

Turner and Berkes (2006:504) note that not all old people should be considered elders and that some young people hold a level of knowledge great enough to be considered elders. This is part of the incremental learning process, which conceptualizes knowledge as something that is built on experience (Turner and Berkes 2006). This concept, along with the insider guidance of the NWG, supports the legitimacy of my sample.

\section{Data Collection}

This project relies mainly on qualitative data sourced from interview transcripts. I also use quantitative data in the form of descriptive statistics to illustrate participant demographics (see Appendix G). I collected primary data during a two-month fieldwork period in August and September of 2012. I carried out a series of semi-structured interviews during home visits with Nuwuvi participants, and at agency offices and field stations with agency consultants. 
Interviews contained a series of demographic questions covering participants' educational, professional, and cultural backgrounds. Topical questions on water, management, and restoration followed. I presented each consultant with an informed consent script prior to his or her interview. Interviews were recorded using a digital audio recorder and partially transcribed.

Nuwuvi interview questions examined definitions of different types of water (such as springs, streams, and subterranean water), as well as ecological interactions among water, humans, plants, animals, and other landscape features. Questions considered historical interactions with water sources as well as consultants' current relationships with water and the land (in general and within the two protected areas). I also asked participants to discuss current stressors affecting SMNRA and DNWR, such as increasing levels of recreation, tourism, and urban population growth. Finally, I asked participants for their opinions about present-day water health in the Spring and Sheep Mountains and about potential strategies for ecological restoration. I also presented maps to participants and asked them identify areas of personal or cultural significance (see Appendix C).

Agency interviews included a series of demographic questions focusing on the educational and professional background of participants. Additional questions focused on agency hydrological management strategies and restoration techniques. I asked participants to discuss current trends affecting water resources in SMNRA and DNWR, including climate change, growing urban populations, and increasing levels of tourism and recreation (see Appendix C). 


\section{Data Analysis}

In total, I recorded 32 hours of interviews over the course of two months of fieldwork, and created partial transcripts from these audio recordings. Analysis of this data followed Boeije's (2010) process of segmenting data into parts and then reassembling it in a way that reveals patterns that can be translated into research findings (Boeije 2010:76). The first step of this process involved coding text to illuminate and delineate overarching themes and concepts. Coding consisted of naming fragments of text that represent themes found present in the data (Boeije 2010:79). I based my thematic codes on close examination of the data that encapsulated the qualitative depth of the concept being discussed (Boyatzis 1998:30).

This project employed the inductive coding method, an important aspect of qualitative research that involves the investigation of data relating to a social phenomenon in order to find empirical patterns in that data (Boeije 2010:5). Boyatzis (1998) points out that inductive coding relies on the researcher to interpret the meaning in the words and syntax of the raw qualitative data. With this project, I specifically followed Bernard's (2002:464) inductive coding method. Based in grounded theory, this method aims to discover patterns through close analysis of texts. The inductive coding method involves deriving a set of important themes from the texts, identifying how those themes relate to one another, and linking the themes back to exemplar quotes (Bernard 2002:464).

For this project, I examined partial transcripts, applying codes as themes appeared in the text. Codes included concepts such as differing belief systems, 
climate change is human induced, and personification of water. I also included notes in the margins to indicate areas of topical interest, such as plants and specific place names. I used these notes in the development and organization of the project deliverable. After coding and annotating, I re-examined the transcripts to find exemplar codes for the themes, some of which I used in this thesis to illustrate and explicate some of the concepts being discussed. The themes generated through this coding process thus form the base of the findings outlined in this thesis.

\section{Ethics and Research Return}

The Human Subjects Research Review Committee at Portland State University reviewed this project and found it complied with policies and regulations covering the protection of human subjects. During fieldwork, I presented informed consent documents (verbally and in writing) that detailed the purposes of the project, the proposed use of the data to be collected, and a full explanation of participants' rights as research subjects (see consent forms in Appendices B and C). Upon project completion, project participants received the research in two ways: First, we held a meeting was held in December 2012 to present preliminary research findings to representatives from both agencies and members of the NWG. Secondly, we returned full reports, as well as audio recordings of interviews to project participants upon completion of the final report. 


\section{Chapter 2: Nuwuvi, the Great Basin/Mojave Desert, and Historical Drivers of Change in Southern Nevada}

Water plays a significant role in the ecology of the Great Basin and Mojave Desert, Euro-American settlement of the region, present-day political economic realities, and in Nuwuvi culture itself. The Great Basin watershed covers a large area of land, extending from Oregon in the north to southern Nevada in the south, and demonstrates a complex hydrology with many basins and internal drainage systems (Waring 2011:15). Hulse (2004:3) characterizes this area as the "land of interior drainage," because streams run inland toward sinks, rather than out to sea. As Waring (2011:7) describes, Great Basin water sources are the places "where living things congregate." South of the Great Basin hydrogeographic area lies the Mojave Desert, a large expanse of land spotted with mountains and valleys, and sites for several large-scale dam projects on the Colorado River, forming reservoirs such as Lake Mead and Lake Mohave (Hulse 2004:10). Springs comprise most of the natural water sources in the Great Basin and Mojave, though the Colorado River (south of the Great Basin proper), which runs for 1,450 miles through seven states, is a hugely important source of water in the region (Hulse 2004).

Nuwuvi, a Numic word meaning "the people," are a culture group comprised of nine federally and non-federally recognized Nations distributed across four states (Spoon et al. 2011:9). Nuwuvi ancestral territory extends throughout the southern Great Basin and northern Mojave Desert (Spoon et al. 2013). Both SMNRA and DNWR lie within Nuwuvi ancestral territories (see Figures 1 and 2), prompting the 
agencies to consult the Nations about potential management activities in the two protected areas.

Nuwuvi, like most culture groups in the Great Basin, speak languages from the Numic family (Knack 2001:13). Archaeological evidence justifies human settlement of the region for thousands of years (Madsen and Rhode 1994:213). In archaeological theory, the 1958 Lamb Hypothesis proposed a Numic expansion from southeast California around the year AD 1000 (Sutton 1993:111). Alternative and complementary theories were later developed, such as Bettinger and Baumhoff's (1982:485), which pointed to major dietary changes allowing for the replacement of pre-Numic groups in the area. However, some archaeologists point to holes in the archaeological record that refute Numic expansion theories (e.g. Sutton 1993). Furthermore, Nuwuvi oral history contradicts these hypotheses. The Nuwuvi Creation Story identifies Nuvugantu, or the Spring Mountains, as their place of creation, and indicates that they have inhabited this landscape since creation, when the world was new (Spoon et al. 2011, Stoffle and Zedeño 2001:229). The Creation Story explains that the entire ancestral territory was once covered with water, with only the mountaintops exposed. Animals were created before humans, who only populated the earth after there was enough land and resources to sustain them (Spoon et al. 2011:15, Kelly and Fowler 1986:385).

Throughout the pre-contact period, hunting and gathering of a wide variety of plant foods (such as roots, berries, and pine nuts), small game (including squirrels, mice, and wood rats), and large game (primarily mountain sheep) supported lifeways (Kelly and Fowler 1986:369, Spoon 2013a, Steward 1938). 
Nuwuvi also practiced some farming, including crops such as maize, squash, red and white flour corn, and winter wheat (Kelly and Fowler 1986:370). All of these subsistence activities occurred at different intensities over time depending on environmental, political, and economic factors. Access to key water sources, most notably springs, also supported survival (Knack 2001:2). Nuwuvi maximized the water available at "seeps" (springs lacking adequate water pressure to rise above ground) by digging into the ground and waiting until the hole was filled with water (Knack 2001:13). Prior to Euro-American contact, springs in the area were associated with particular individuals and passed down through families (Kelly and Fowler 1986:380). Nuwuvi historically travelled in small groups comprised of several families to utilize resources on a rotational basis (Knack 2001:20; Steward 1938). Upon Euro-American contact, many Nuwuvi activities involving water were drastically changed.

Early European arrivals began in the $18^{\text {th }}$ century as expeditions of friars (namely Escalante and Dominguez in 1776), fur trappers (beginning around 1820), traders, Mormon settlers, and immigrants entered on horseback (Knack 2001, Kelly and Fowler 1986, Fowler and Fowler 1971). In the mid 1800s, as the U.S. government attempted to "dispose" of public lands in the West through a national giveaway policy, Nuwuvi were relocated to reservations as required under the Dawes Act of 1887. This effectively made way for ranching and farming interests that required the most arable lands (Hulse 2009:1, Knack 2001, Spoon 2013a). Although many Nuwuvi reservations were located within the ancestral territory, the lands set aside for reservations were typically non-arable and lacked adequate 
access to water and other resources that would support livelihoods for local residents (Knack 2001:3). In addition to relocation, many Nuwuvi youths were placed in boarding schools run by the federal government or by religious groups (Calloway 2004, Knack 2001:138, Spoon and Arnold 2012).

The Indian Reorganization Act (IRA) was passed in 1934, allowing for local self-governance and tribal corporations for Native Americans living on reservations and terminating the Dawes Act (Calloway 2004: 400). Nuwuvi reservations are currently spread across four states: Arizona, Nevada, Utah, and California. Today, Nuwuvi live in both urban and rural settings, and tribal economies are largely fuelled by tribally owned businesses such as casinos, golf courses, gas stations, and tobacco shops, as well as other private enterprises (Spoon and Arnold 2012:479). Nuwuvi Nations comprise a culturally cohesive group that the federal government did not recognize as related until relatively recently (Bunte and Franklin 1987:4). Early disorganization on the part of government officials affected the way that the Nuwuvi Nations function politically and socially. An elder from the Las Vegas Paiute Tribe described his view of the political relationship among the Nuwuvi Nations:

All the different tribes have different policies that are governed by different ways. They have their own businesses and all that...So it's always divided. What I saw what goes on in this world...how we were put on different reservations. The government done that to us. You know, 'Take care of yourself, this is where you're gonna stay.' The Big Boss--that's what they call him.

Many elders involved in the NKTA project have weathered significant political and cultural changes in their lifetimes, which have come not only as a result of federal governance, but also due to the presence of missionaries and the cultural aftermath 
of boarding schools. Numerous Nuwuvi now identify as members of several

Christian denominations. An elder from the Chemehuevi Indian Tribe described the types of generational differences within her own family:

I don't know what it's going to be like when I kick the bucket [laughs]. Probably totally different...I think it would have to be because I was raised differently than my mother and [the rest of] them were-all the elders. Because I went to school-and I mean, she did too-but I went to church and I became a church member...you know. So I think I'm gonna have a different viewpoint on what should be done for me...I want somebody there from the church and I want some songs, and other people I know wouldn't like that, but that's my life, not theirs.

Anecdotes such as this reveal that Nuwuvi culture continues to change as some facets are maintained. Changes to Nuwuvi ecological knowledge are also likely as the broader culture continues to transform.

Anthropologists first took interest in Nuwuvi in the early $20^{\text {th }}$ century.

Perhaps most notable of the anthropological works produced was Julian Steward's influential cultural ecology text Theory of Culture Change: The Methodology of Multilinear Evolution (1955), which argued for the strong influence of environment in determining cultural evolution. Following Steward, anthropologists such as Isabel T. Kelly, Don and Katherine Fowler, Richard Stoffle, Jeremy Spoon and Richard Arnold also worked with Nuwuvi. My research builds and expands upon the work that these researchers have completed in the region.

\section{Water in the West}

Since settlement of the western United States, there has been a long history of diverting water from lakes, rivers, and springs to supply the needs of population 
centers in the region, particularly Las Vegas (Hulse 2004, Hulse 2009, Wilkinson 2010, Knack 2001). Partially due to rapid expansion from the 1940s-1980s, a period known as the Southern Nevada land rush, the population of Las Vegas expanded from 30 residents in the year 1900 to over 583,000 inhabitants in 2010 (Hulse 2004, Hulse 2009:55, U.S. Census Bureau). The Southern Nevada Water Project, which provided water from the Colorado River to the City of Las Vegas, was developed in 1948 to meet the needs of the region's growing population (Hulse 2004). As demand for water continues to grow, maintaining an adequate water supply remains a regional challenge.

Aside from the aforementioned pressures from population growth, new ecological challenges are currently presenting themselves in these protected areas due to the influence of increased human presence in the area (especially the effects of urbanization and tourism), as well as effects from climate change (U.S. Forest Service 2011:3). There have been documented changes in environmental factors such as decreased snowfall and annual precipitation, and increase in the frequency of wildfires (U.S. Forest Service 2011:3). These challenges require new approaches, thus this project seeks to identify areas where Nuwuvi knowledge can be integrated into water management solutions.

\section{Federal Land Management in Nevada}

The Great Basin, and Nevada in particular are notable for its large percentage of federally owned land, much of which was retained during the Federal Land Policy and Management Act of 1976 (FLPMA). Today, 83\% of land in Nevada is federally 
owned and managed (Hulse 2009, Glennon 2002). This can have positive and negative connotations, depending on whose opinion is being considered. Although federal management provides a wealth of jobs in the region, as well as a vast array of opportunities for recreation, many feel that federal land management detracts from local land rights, and the Sagebrush Rebellion of 1976 was just one major consequence of this reaction. Cattlemen and other locals led a movement for the State of Nevada to lay claim to millions of acres of land that were under the control of the Bureau of Land Management (Hulse 2009:9, Prescott 2003:13). Despite these protests, most of the lands in question remained under federal control and subject to regulations such as the Multiple-Use Sustained Yield Act of 1960, which directs USFS to manage for a range of activities including recreation and water resource conservation (Prescott 2003). Although Nevada has received little recognition for its "wilderness heritage," and has a history of resource exploitation related to mining, it contains fourteen designated wilderness areas and is the most mountainous state in the contiguous U.S. in terms of number of summits (Hulse 2004:16).

Federal ownership of land does have potential positive ramifications for Nuwuvi for two reasons. First, most Nuwuvi prefer federal ownership to private ownership, as it means that some restrictions are in place for development and other undesirable activities. Secondly, federal ownership means that tribes must be consulted as part of the National Environmental Policy Act (NEPA) process when any actions needing a permit are taking places on federal land. Other policies, such as the National Historic Preservation Act (NHPA) and the Native American Graves Protection and Repatriation Act (NAGPRA) also prompt consultation. Although 
much of the previous consultation with local tribes could be considered typical "check-the-box" collaboration, connoting shallow and meaningless consultation without any tangible results, projects such as NKTA seek to go beyond this minimal dialog and instead hope to build foundations for future collaborative stewardship of resources on Nuwuvi ancestral lands, which agencies such as USFS and USFWS now manage. The following section will provide an overview of my two research sites: the Spring Mountains National Recreation Area and Desert National Wildlife Refuge. Figure 1: Map of SMNRA and DNWR Within the Nuwuvi Ancestral Territory. Data from USFS Humboldt-Toiyabe National Forest and U.S. Fish and Wildlife Service.

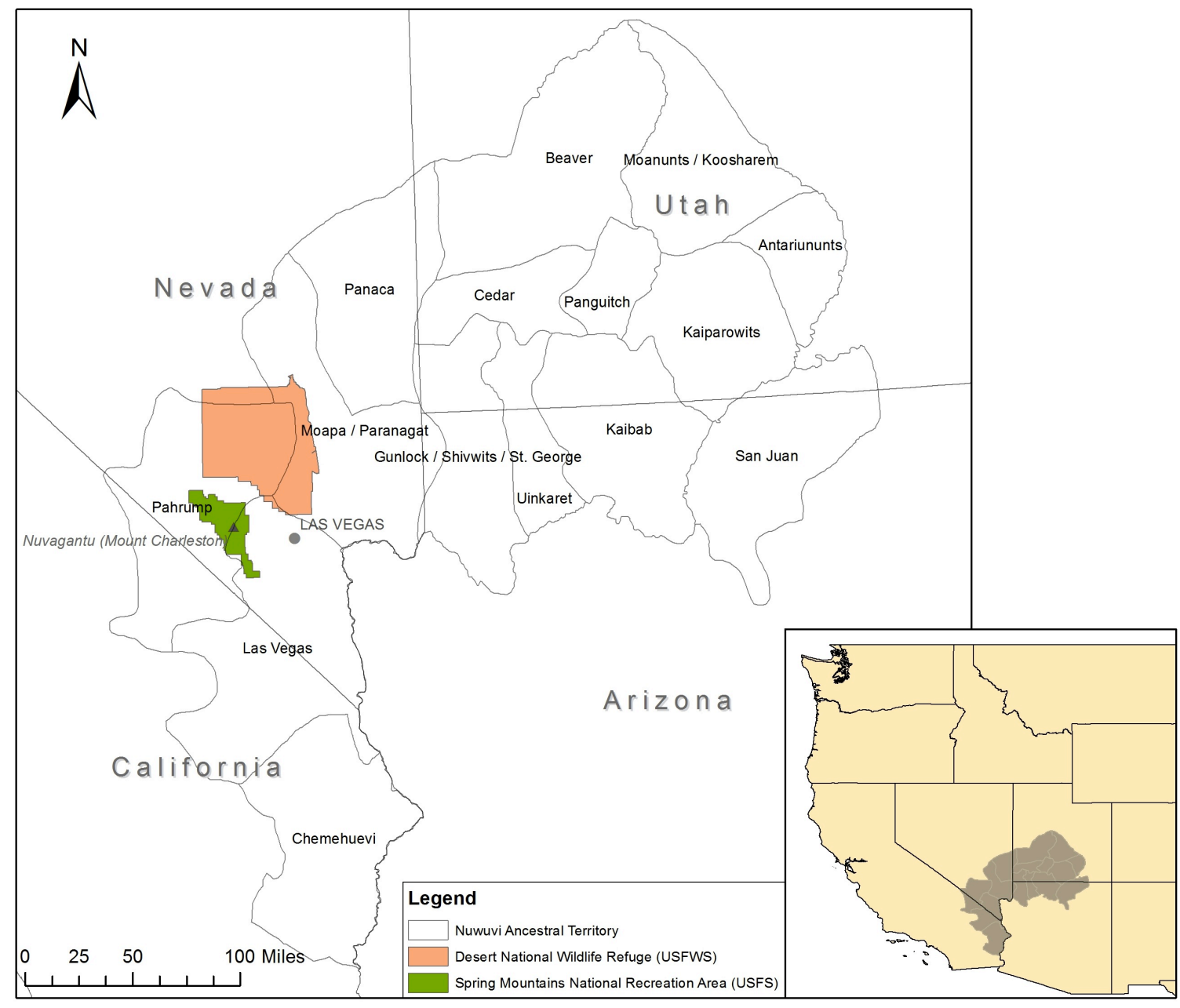


Spring Mountains National Recreation Area (SMNRA)

The Spring Mountain Range is located in Clark and Nye counties in southern Nevada. The range consists of six elevational vegetation zones that contain habitat for several endemic plant and animal species including the dark blue butterfly (Euphilotes enoptes ssp) and the rough angelica (Angelica scabrida) (U.S. Forest Service et al. 1998:D). The Spring Mountains National Recreation Area was established in 1993 for three purposes: 1) to preserve scenic, historical, natural, watershed, riparian, and other vales; 2) to ensure conservation and management of natural and recreation resources in the Spring Mountains; and 3) to develop recreation opportunities in the Spring Mountains (U.S. Forest Service et al. 1998:12). Water in the SMNRA can be divided into two hydrogeographic areas: the west side, which drains into the Great Basin, and the eastern slopes that flow into the Colorado River (U.S. Forest Service 2008:6). There are springs and seeps throughout the area, and water originates from aquifers supplied through seasonal precipitation from snow and thundershowers (U.S. Forest Service 2008:7). Some perennial and near-perennial streams can also be found in the SMNRA, but most are ephemeral (U.S. Forest Service 2008:7). A notable part of the area's original directive was to provide protection for watersheds, free-flowing streams, and the quality of ground and surface waters (U.S. Forest Service et al. 1998). As mentioned previously, the Spring Mountains are particularly significant to Nuwuvi as their place of Creation. 


\section{Desert National Wildlife Refuge (DNWR)}

DNWR is one part of a larger complex of four refuges in southern Nevada, totaling more than 1.6 million acres of land containing wetland, riparian, and montane ecosystems which are home to a number of endemic plant and animal species (U.S. Fish and Wildlife Service 2009:1-1). DNWR itself is a 1.6 million acre plot of land that is partially shared by Nellis Test and Training Range, making it the largest wildlife refuge in the United States (USFWS 2012). The Refuge is also notable for its role in protecting the desert bighorn sheep (Ovis canadensis nelsoni), which is the Refuge's primary management mandate. Once found in nearly every mountain range in the Nevada, the species can now only be found in a few ranges. One of the state's largest populations currently resides primarily within DNWR (USFWS 2009 1-16). Three mountain ranges occupy the space within the Refuge's borders: The Sheep, Las Vegas, and Pintwater ranges. According to USFWS records located in the Corn Creek Field Station, thirty-two springs have been surveyed within the Refuge.

\section{The Rush for Water Resources: A Land Influenced by a Multitude of Interests}

The southern Great Basin and northern Mojave Desert have been host to a significant amount of ecological, political, and social change. Nuwuvi maintain that they have managed these landscapes since time immemorial. When Euro-Americans began arriving in the region, they brought with them a desire for resource extraction of precious commodities such as gold, silver, and timber. Federal policies encouraged westward expansion, which in many cases displaced Native populations. Later, federal policies such as the Dawes Act (1887) and the Indian 
Reorganization Act (1934), further transformed Nuwuvi culture. Federal control over much of the lands in this region, including SMNRA and DNWR, at once protects the landscape from unbridled development and fails to address Native concerns about activities occurring on these landscapes that have historically been managed by Nuwuvi.

Water has played a central role not only in the geological shaping of this region, but also in the lifeways of its first peoples, Nuwuvi. Later, it became an essential tool for Euro-American miners and ranchers, and finally has facilitated the development of large cities such as Las Vegas, which is not only home to over half a million residents, but also to a steady stream of tourists who pour in from all over the world. Hydrological features also produce electricity for surrounding populations, through large-scale dam projects on the Colorado River such as the Hoover and Parker dams. Although water is relatively scarce in this region of the world, its cultural, economic, and political importance is powerful. 


\section{Chapter 3: Nuwuvi Understandings of Water and Its Management}

I do know that's [Mt. Charleston in the Spring Mountain Range] a sacred mountain to the Paiutes and the Chemehuevis. That's our creation land and the water is special there...To get some spring water there would be awesome....To bring it home and say 'I got this from the Spring Mountains,' from the creation lands...That would be great.

This statement by a Kaibab Band of Paiutes elder expresses the personal and cultural significance of water in these culturally important landscapes. This placebased view of water resources demonstrates the importance that many Nuwuvi place on waters that originate within the Nuwuvi ancestral territory. The Native perspective on water and hydrological management in SMNRA and DNWR is significant due to the long history of Nuwuvi management of these resources. Managers have largely ignored this perspective since the federal acquisition of these landscapes. In this chapter, I will outline the character of Nuwuvi ethnohydrological knowledge found among my sample of 16 subjects from six Nuwuvi Nations.

Nuwuvi ethnohydrological knowledge has experienced great changes over the past century, which will be addressed in another layer of analysis provided in the next chapter. In this chapter, my data analysis process revealed two major categories of Nuwuvi water knowledge. The first of these categories is hydro-logics, or explanations of how water functions (Gelles 2000). This category of water knowledge is divided into three sub-categories that describe how water shapes the land, supports biotic life, and is dependent upon human responsibility towards water. The second main category of Nuwuvi ethnohydrology is management of water resources, meaning both the overall management approach and specific 
techniques practiced by Nuwuvi. ${ }^{2}$ Spiritual components of water knowledge fit into both ethno-hydrological and management categories of Nuwuvi knowledge.

Ultimately, I argue that Nuwuvi hydrological knowledge generally viewed water as a sentient being that is integrated with all biotic and non-biotic aspects of the landscape, and which requires human interaction in order to remain healthy. It is thus appropriate to describe such human interaction with water, driven by necessity, as adaptive management.

As mentioned in Chapter 1, I recruited participants through discussions with the Nuwuvi Working Group (NWG). Although this sample is not representative of the population of these six Nuwuvi Nations as a whole, the individuals interviewed are acknowledged as knowledge holders within these communities, and may therefore signal the breadth and depth of knowledge expressed by members of the Nuwuvi Nations. It is important to note that factors such as age, gender, residential location, and occupation affect the type of knowledge that these participants hold. Most of the individuals in my sample (See Appendix F for details) are over 50 years of age. I asked questions about impressions of water in general as well as specific questions pertaining to SMNRA and DNWR, so this chapter contains both general water knowledge as well as knowledge specific to these two protected areas. By and large, I based my analysis in this chapter on data from my own interviews. Although the works of past researchers, notably Julian Steward and Isabel T. Kelly, contain

\footnotetext{
${ }^{2}$ A note about word use: although many Nuwuvi conceptualize the term water management to mean practices carried out by western land managers, I will sometimes refer to Nuwuvi stewardship of water as management. This will help illuminate the similarities between Nuwuvi and agency stewardship practices in later chapters.
} 
some valuable ethnographic data, I chose not to rely on them in my analysis due to some Nuwuvi concerns about their ethics and accuracy (including concerns about sample size and misleading informants).

\section{Hydro-logics: Physical and Cultural Properties of Water}

Water as a Force in Shaping the Earth

Gelles (2000) describes ethnohydrology in relation to "hydro-logics," meaning the logic systems attached to hydrology by local peoples. I interpret this concept to refer to both the physical role of water in the landscape as well as cultural understandings of how water functions. This type of knowledge composed much of the information gathered from my interviews with Nuwuvi knowledge holders. First and foremost, Nuwuvi considered water to be the "lifeblood of the earth," as subjects often phrased it. All interviewees acknowledged its central role in sustaining the life of plants, animals, and humans in the arid desert, and discussed at length how water connects and forms various parts of the landscape. From the Nuwuvi perspective, water played an especially important role in forming mountainous landscapes, such as those found in SMNRA and DNWR.

The power of water is of long standing significance to Nuwuvi. Much of the knowledge related to the power of water is told through stories, perhaps most notably in the Creation Story. My research took place outside of the winter storytelling months (approximately October through March), so consultants were not able to reveal details about the story and how it relates to water. However, many 
mentioned that the role water played in shaping the earth. An elder from the Moapa Band of Paiutes explained it this way:

From in the beginning of our Creation Stories, water played an important part. And it's sad I can't tell the Creation Story the way it is, because of the season-it's not the right time. But like I say, it's always been important to the Native Americans. We have a lot of stories on it.

Spoon et al. (2011) document a comprehensive telling of the Creation Story, which tells of a time when the earth was covered in water except for the mountains. Many animals fled to Nuvagantu (the Spring Mountains landscape) until the water retreated again. Around this same time, the Old Woman of the Sea formed humans from the elements and put them in a basket, from which they were scattered across the Paiute lands by Coyote. The central role of water in the Creation Story suggests its importance as a force behind the formation of the landscape. Descriptions of water in the Creation Story align with participants' descriptions of water's effects on the modern landscape. Many consultants described how water has continued to shape the land since the time of creation, as evidenced through present-day geological features such as caves, canyons, and mountains. Participants often mentioned high profile landscape features such as the Grand Canyon in Arizona, but some also described less well-known examples, such as Trout Canyon and Grasshopper Cave in the Spring Mountain Range. Here, an elder from the Colorado River Indian Tribes described her impressions of the Grand Canyon:

I think of the Grand Canyon and how it was created, and all the beautiful sites up there and everything, and that was created by the water...the force of the water. Because water...it's very beautiful. It's fragile, but it's very powerful. It's a powerful resource. And you think of the ocean and you look at the cliffs and how the waves come in and turn the rocks and create these little...these little coves and stuff like 
that... You see them up on our river, you can see how the rocks...after a while you can see new land showing where some of the power of that water just brought those rocks into the water, made them fall.

Nuwuvi view the relationship between mountains and water as multifaceted. Mountains, along with water, have been on this earth since the beginning of time, and are important forces in sustaining the precious resources that they hold. They attract rain and snowfall and then purify that water for use by plants, animals, and humans. Water that comes from mountains was seen by many consultants as being more pure than water that which comes from low-lying areas, although resources in the mountains can be affected and contaminated by activities elsewhere. A consultant from the Chemehuevi Indian Tribe referred to the porous nature of certain rock types, and described how it acts to purify the water that seeps through:

If you go into the caves far enough, there is generally water in there. I've been in a few of the caves, spelunking and stuff like that, and almost every one...even when it rains outside, there's no water coming in physically through the cave, but there's some seeping through the walls and stuff and creating pools of water down inside of there. And almost every cave I've been in, you see pools of water in there or remnants of water, depending on how recent the rainfall was.

Nuwuvi participants agreed that water generally flows downhill, but several participants qualified this statement by stating that water can sometimes reverse flow direction if it is not managed properly, or if humans disrespect it in a way that causes it to retreat. Consultants often spoke about springs and seeps as the first point where water comes above ground. Many consultants described them as being most pure at their point of origin, as underlying layers of geological strata acting as purifiers for the water. Once spring water is exposed, there is the potential for it to be contaminated by trash, chemicals, or nuclear waste. This complex set of 
interactions described by participants indicates of the importance of water in Nuwuvi culture. As evidenced by the centrality of water in the Creation Story and in perceptions of the physical role water plays in forming the landscape, water clearly occupied an important space in the Nuwuvi ecological knowledge domain.

Throughout the narrative created by these participants, there was a strong message that water was not acting purely as a physical force driven by gravity, but that it was a responsive being that has been closely connected with humans since the time of Creation. Just as one of the above participants personified water describing how it is "fragile" yet "powerful," many participants viewed water as an interactive resource that commands respect, and which threatens consequences for disrespect.

\section{Water as a Supporter of Biotic Life}

Among the different types of water, springs were by far the most discussed among consultants. Participants understood that some springs are ephemeral and some are available year-round. Springs have always been an extremely important source of water for Nuwuvi, and helped sustain people while traveling and camping. People could maximize water at low volume by digging a hole around the damp part of ground and letting it fill up with water. Springs were important not only to supply drinking water, but also as a place of cultivation, as some consultants described growing crops in or around springs. These crops included squash, corn, and beans, which families would plant during seasonal rotations. Families would return at a later point in time to harvest the crops. Some consultants expressed a resentment 
that Nuwuvi are often referred to as hunter-gatherers, when in fact gardens were an important part of their lifeway.

Water and geological features were connected in a number of physical ways. Nuwuvi consultants described various types of water, such as springs, streams, and ponds, as being connected through underground aquifers. Several consultants noted that water sources can be influenced by impacts to water located at other geographic points, and often attributed this connection to underground channels (see Chapter 5 for a detailed explanation). Historically, subterranean water was important to Nuwuvi as a source of drinking water obtained through methods such as seep-digging and well-building. Here, an elder from the Las Vegas Paiute Tribe described how Nuwuvi would utilize seeps:

...Oftentimes the people would see a seep...they would dig a hole...they always found a way to keep that water there.

Later, wells fulfilled a similar need in settlements and reservations. Many consultants recalled hauling water from wells in their youth. Another elder from the Las Vegas Paiute Tribe recalled a well once located on the Las Vegas Paiute Indian Colony in the city of Las Vegas:

That was a long time ago, there was no power, no sewage...you know, we had a well up here. We had to haul the water in. That was a very important thing, was that water. Because I had to take my tub bath, I remember that. Take my tub bath and get the heck scrubbed out of me.

Water is also considered an important habitat for certain spiritual beings. Here, an elder from the Pahrump Paiute Tribe described subterranean waterways as pathways for spirits: 
Culturally there [are] certain beings that are in the...supernatural beings, I guess, from other people's standards. But they're normal to us...that live in the water, travel in the water. And they can go from one area to another area...one spring to another spring through that. So we know that there are those pathways, and so we have stories about underground water systems that...typically correspond to different springs and different activities that happen in those springs.

Plants are a source of food, medicine, and construction materials for Nuwuvi. Consultants strongly associated certain plants with water, and knew they could be found primarily around seeps, springs, streams, rivers, or ponds. Nuwuvi consultants most commonly mentioned willow, cottonwood, mesquite, pinyon pine, and tamerisk. Other plants, including cactus species, contain high levels of moisture and some consultants explained that they can be utilized for hydration when water is scarce. For this reason, succulents are also often associated with water. Nuwuvi knowledge related to these plants can reveal a deep understanding of temporal and spatial water patterns. An elder from the Chemehuevi Indian Tribe described spring placement this way:

I think He (the Creator) strategically places everything...for everybody's use. You might be walking somewhere stranded in the desert, and all of the sudden, you're without water or whatever, and you come across a spring, and hey, it's there... I mean, how can you explain everything except to say that somebody knows what they're doing and they put things where they should be, you know, for people to use. That's the only way that I can explain it.

When prompted to describe the relationship between plants and water, consultants sometimes explained a complicated set of interactions that relate to the plant's lifecycle as well as cultural use of the plant. For instance, consultants discussed willow species (Salix spp.) in terms of several different associations with water. Culturally, willows are perhaps most important in the construction of baskets 
and cradleboards. Nuwuvi baskets were originally used for gathering activities, and basketry is still important today for family collections and sometimes as commodities sold in tribal businesses or museums (Knack 2001). In this case, ethnohydrological knowledge helps support an important Nuwuvi art form. These nuanced understandings of the ways water interacts with willow are an example of how knowledge of the species has been sustained, reinforced, and adapted over time to keep this craft alive (Garibaldi and Turner 2004).

Knowledgeable participants described the practice this way: basketmakers desire longer willow shoots, which are more readily available in the springtime, for basket construction. Many consultants mentioned that some years willow branches are brittle due to a lack of rainfall, and that the brittleness makes them difficult to work with. Before harvesting branches for use in basketry activities, it is important for people to ask the tree and the land for permission to take the branch. Harvesters should explain to the resource the purpose of their gathering and it is often appropriate to leave an offering for the tree and the land from which it comes. After branches are harvested, they are dried for storage. Basketmakers later apply water to the branches to make them pliable during the basketmaking process. This "brings the branches back to life." In the past, people used some types of willow baskets as water receptacles for hauling water. Multiple consultants described the "jugs," which were tightly woven, and then sealed with pine pitch and sand to make them watertight. Understandings of the many relationships between water and willow demonstrate the complexity of Nuwuvi knowledge of how water functions in both physical and cultural ways. 
Willows, along with cottonwoods, were also specifically mentioned as indicators of proximate water, and one method of locating nearby water sources is to spot large green plants such as these in the desert landscape. Plants can also be indicators of water health, and are strongly affected by the presence or absence of clean water (see Chapter 5 for more detail). Consultants often mentioned that greenery found around springs is a sign that the water spring was healthy. Seasonal variations in water availability and flow are also recognized. Water seeps, in particular, are recognized as important temporary sources of water. Here, an elder from Chemehuevi Indian Tribe describes the importance of seeps:

Yeah, cause that's where you know you're going to have limited water for a certain amount of time...because it's going to dry up or seep back into the earth. So you depend on them almost like a spring...but it's not a spring. Certain times of year...chances are there's going to be water in them...So when you're travelling, you know they're there. Yeah, I think there's some of them along some of the trails.

According to most Nuwuvi consultants, water is equally important to animals as it is to humans. The Creator put water on the earth for animals' use as well as humans'. For this reason, humans must share this important resource with the animals. Animals know where water sources are located and what times of year they are available. Many consultants mentioned relying on animals to indicate where water sources are and whether or not they are safe to drink from. Some animals are seen as being harmful to water sources, springs in particular. This is especially true of wild horses and cattle, which participants mentioned tend to trample springs as they drink. However, an elder from Chemehuevi Indian Tribes 
described his understanding of how to use the presence of animals to identify potable water:

You know what kinds of springs you drink out of? The ones that got little bugs in it. Yeah, if the bugs ain't living in there, you don't drink it. If the water looks too clear, then you'd better be a little leery.

Once again, these examples show how Nuwuvi perspectives viewed hydrological features interacting with the land in ways not typically seen through the lens of western science. Most consultants considered water to be sentient of how humans interact with it, and therefore acknowledged that a respectful relationship must be maintained in order for water to continue to support life in the desert. Consultants considered the placement of springs intentional to support life in the desert. Knowledge pertaining to hydrological interactions with plants and animals helps ensure human survival, but also ensures that important cultural practices such as basketmaking to continue.

\section{Human Responsibility Towards Water}

Springs, one of the most abundant sources of water in the region, have historically been important in maintaining human populations in the desert, and the development of cities such as Las Vegas were also dependent on these resources. Many consultants described the intentional and strategic placement of springs, and their naming by the Creator or by animals such as Coyote. While many consultants described Nuwuvi in the pre-contact area knowing the locations of many springs with the help of songs, stories, or petroglyphs, others described prayers used during times of travel that would ask the Creator for adequate water supply along the way. 
Historically, men and women also had varying relationships with water in some ways due to the different types of activities they participated in. One consultant from the Moapa Band of Paiutes noted: "While the women were cooking and preparing [lunch], [the men] would take their horses and water them at a spring." The knowledge of spring locations was historically important to sustaining Nuwuvi during seasonal migrations and for supplying camps during sedentary times. The ability to find water near trails was an integral part of survival in the desert, and as Goodall (2008:362) points out, ecological knowledge relating to survival is perhaps that which remains most unchanged through long-term oral transmission. Here, an elder from the Pahrump Paiute Indian Tribe described the use of songs to describe the placement of springs:

Culturally, when we talk about the world when it was new...the Creator had decided where certain springs were to be. We have songs that talk about the placement of those springs. There's certain animals that are responsible for making those springs as well. They then select where those springs would be. And then they...when the water flows, you see how it can change in other areas.

Several consultants mentioned that water from springs could have different properties depending on their placement. Certain locations are known for their spiritual power, and people often travel long distances to retrieve water from those sources. Stoffle et al. (2004) describe some of the ways in which Nuwuvi assign power to places, especially those associated with healing or ceremony. Kelly (1939) also explains how spirituality and place are connected in the context of Nuwuvi 
shamanism. ${ }^{3}$ Strang (2006:149) notes that water's universally central role in human life dictates that humans tend to assign powerful meanings to it, and often leading to its embeddedness in complex belief systems and values. Nuwuvi participants explained that water is often used in blessings or ceremonies. In addition to the meaningful placement of springs, one consultant explained that each spring has a unique character that makes it difficult to generalize about the needs of springs that may be in need of management or restoration.

The importance of water in Nuwuvi culture suggests that this knowledge has stemmed from and evolved out of necessity. Historically, knowledge of the physical location of water sources, signals of water health, and temporal variations in water flow and availability were essential to survival in the desert. With their work in the Pacific Northwest, Turner and Berkes (2006) discuss how stories and songs help perpetuate important information through intergenerational knowledge transmission. This knowledge maintains relevance today for Nuwuvi who engage in both recreational and management activities with water in these landscapes.

Nuwuvi understandings about the relationship between humans and water are central to their conceptualization of the ways in which water interacts with the landscape. Participants considered human interaction to be necessary for the maintenance of water health, and the belief in the sentience of water is central to this philosophy. Many consultants explained that water sources would know when they were neglected, resulting in ramifications that could include the withdrawal of

\footnotetext{
${ }^{3}$ Most of my discussion about Nuwuvi religion centers around the relationship between place-based spiritual values and environmental management. Additional analysis in relation to the anthropology of religion is outside the scope of my effort.
} 
the water or personal consequences for the mistreatment of water. Beliefs about the relationship between humans and water also influences Nuwuvi approaches to water management, which will be outlined in the following section.

\section{Nuwuvi Management of Water Resources}

Prior to Euro-American arrival in the region, Nuwuvi were the sole human caretakers of these resources, and many individuals continue to uphold these responsibilities today. Management knowledge of water, which encompasses knowledge related to both physical and spiritual interactions with water, makes up a significant portion of Nuwuvi ethnohydrological knowledge. Nuwuvi management of water resources can be considered adaptive, meaning that the interactions between people and nature are constantly evolving to suit the needs of both the people and the ecosystem (Armitage 2005, Berkes et al. 2000, Berkes and Folke 1998, Folke et al. 2010).

From a Nuwuvi perspective, people must maintain a respectful connection with water through the perpetuation of cultural taboos related to the resource. Subjects described a number of taboos surrounding water, including going near water after dark, contaminating water, the general waste of water (especially drinking water), and hunting animals near water sources. Participants spoke of several potential repercussions for the mistreatment or disrespect of water. Water sources are sometimes protected by entities called water beings (also known as water babies). Water beings, along with Nuwuvi, were considered to be the keepers of this resource. Nuwuvi consultants described water beings as sentient, though 
separate from the water itself, which was also assigned sentience. The penalties for breaking taboos associated with water are often carried out by water beings, and stories are told to children that warn of retaliation from these entities if they approach certain bodies of water. Water beings are often a source of fear for humans-especially children. If water is mistreated, beings will sometimes retaliate by drowning or kidnapping children, or causing them to get lost. They may also cause ill-effects on the rest of the environment, or the water sources themselves can dry up. Here, an elder from the Colorado River Indian Tribes speaks of the power that water beings hold:

[Nuwuvi] have great respect for the water because it's the home of what we call the water [beings], and the water [beings], they live in the water and they have all the channels of the waterways that are underground, and they know how to go from here, from there...maybe to see a certain person or to cause havoc, or...just to travel somewhere. And they have their special places that they like to go and stay, and they're also used as discipline...Indian families used to always tell their young kids, 'you'd better behave or the water babies are gonna come out and get you.' Which is true, because sometimes the water babies would be mean and they would drown a child or they would cause some kind of havoc, like a person to get disoriented and get lost. So...they were something that all Indian families knew you didn't mess around with. And that was how my sisters and my mother, how they went and disciplined us kids...they never whipped us. That was powerful for us. Used to scare the living daylights out of us!

Notably, water beings can affect both the water source itself as well as the personal lives of anyone who disrupts this resource. Many participants also expressed a fear of water unrelated to water beings, but still reinforcing the sense of strength that Nuwuvi attribute to water. Here, a participant from the Kaibab Band of Paiutes described her reservations about the recreational use of water: 
We were always taught that for us as Paiute people, water wasn't recreation. Water wasn't boating and skiing and all of those things...that's not what water was for. And if we abuse water in that sense and in that fashion, then we would suffer the repercussions of that. Of almost abusing the water, you know. And whereas, sometimes I think wow, those teachings are true because you hear of drownings that happen all the time and boating accidents and things like that, you know, that occur. And...your Paiute way of thinking goes back to 'Wow, that's really true...the abuse of water.' So I think in that sense, to me as a Paiute, recreation with water was-it never existed for us. Never was a part of life.

Although Nuwuvi water management strategies consist of a wide range of interactions with the resource, Nuwuvi adaptive management of hydrological resources can be described with three examples: the cleaning of springs, prayers and songs expressed to keep the resource healthy, and the cleaning of water catchments. All three of these Nuwuvi management practices have been incrementally developed over time to support both the social and ecological systems in question.

\section{Cleaning Springs: An Adaptive Approach to Ensure Water Health}

Subjects discussed a number of different water management methods, mainly relating to springs. From a Nuwuvi perspective, springs require human interaction to remain healthy, but in their interactions, humans must respect the water and recognize it as a living thing. Most importantly, participants saw strong waterflow as a key aspect of healthy spring function. Springs that become stagnant are considered by Nuwuvi to be unhealthy. If water is stagnant, or if waterflow becomes blocked, it is difficult for humans and animals to utilize the resource. Consequently, one of the most important aspects of taking care of the springs 
involves stimulating and maintaining the flow of the spring. Most importantly, humans should remove debris including dead plants from around the source of the spring. The removal of excess vegetation is also important to make sure that springs maintain an adequate flow, but some vegetation must remain in the area because lush plant life is an indicator of spring health. Additionally, some consultants mentioned plants and their roots being beneficial to soil and water health. An elder from the Kaibab Band of Paiutes described the reasoning behind this practice:

Yeah, keeping them clear of debris, that's one of the main things you have to do. You have to clean out that water where the water's coming out, take all the icky stuff out. Because if you don't do that, the water will become stagnant and really ugly and you can't use it anymore. ...We've got springs here that have been covered up because no one looked after them anymore and we don't have use of them today.

Spring restoration practices described by participants are an example of adaptive management in that their approach is based on adaptive decision making in the face of ecological conditions and variable factors that impact the springs. Mulder and Coppolillo (2005:64) describe adaptive management as a system in which managers learn from past mistakes, improve their understanding of ecosystems, and alter the plan of action as necessary. Nuwuvi participants explained that individuals or groups should clean springs when they deem it necessary through informal monitoring. Various impacts to these resources, including soil effects from ungulates or motorized vehicles, make adaptive management necessary to keep springs healthy.

Some interviewees expressed that they still practice this management technique today when visiting springs (typically on public lands), but others also 
said that it was difficult due to physical and time constraints. Here, an elder from the Kaibab Band of Paiutes expresses regret over some of the changes that are taking place in relation to this practice:

It's the job of the people to take care of the water... It's our job to take care of the springs too, but we don't do that anymore, you know, because we don't go to all these different springs. Our cattlemen are the ones who are taking care of the springs today. Simply because they're watering their cows off from those springs. Some are better than others at taking care of the springs.

This revealing example shows how social interactions surrounding water are shifting, both for Nuwuvi as well as other interest groups in the region. Changing approaches to management and restoration will be discussed in depth in the following section.

Prayers and Songs: Necessary Practices to Maintain Relationships

Prayers and songs are another important part of interacting with the water and ensuring that it maintains its health. Stories and songs are not only important for explaining how water interacts with plants, animals, rocks, and the broader landscape, they are also indispensible for their instructions on appropriate ways to interact with water and warnings of repercussions for disrespecting it. Although these practices do not fall under traditional western scientific definitions of management, a large part of water management from the Nuwuvi perspective simply involves utilizing water resources in a respectful way. One participant explained that water sources were historically important because they provided a place to make camp, but that it was not (and still is not for recreational campers) 
considered appropriate to camp right next to water sources. Instead, campers could travel the short distance to the water and "make your offerings and your prayers before you got your water. Talking to the water. And you know, the spirits in the water too." This statement again highlights the distinction between the sentience of water beings and the sentience of the water itself. Prayers and offerings are an important way of communicating the respect that is central to the Nuwuvi relationship with water. Once again, this management activity is carried out when deemed necessary by individuals or groups who will care for the resource. This relatively informal, yet agreed upon, approach makes this another example of adaptive management.

\section{Poh Management: A Unique System to Maximize Water Availability}

Water catchments, also known as tinajas, or by their Southern Paiute name, pohs, play an important part in ensuring adequate water supplies for animals and humans in the arid environments of the southern Great Basin and Mojave Desert. Pohs are depressions formed in bedrock by rainfall, wind, seepage, or other flowing water. These depressions fill up during rainfalls and act as an ephemeral source of water during these periods. Participants explained that there are some large pohs (five feet and over in diameter), but consultants typically referred to smaller catchments. Trails and camps were often located in close proximity to pohs so that groups traveling through the desert could utilize the water they hold. An elder from the Pahrump Paiute Tribe described the use of pohs: 
There was one over there on the Wheeler side [of the Spring Mountains], I mean the road you go from Pahrump, where you go the switchback...They used to have to haul lumber from Lee Canyon, Sawmill Canyon... there's a rock on the right side as you go up... One time we came up from Ash Meadows, we went pine nut hunting. We got late to get into Wheeler...we slept overnight. My daddy went up, took the two horses up there. There's a rock, I guess, probably got a hole down about this deep [gestures] maybe, hold the water from rainwater a long time ago, and daddy took them horses team up there, give it water...That's where the deer, or the animals get water, or the birds, [or] lizards...

Over time, wind, rainfall, or other waterflow cause catchments to become filled with sediment. Nuwuvi consultants explained that the Creator tasked humans with the responsibility of clearing out this sediment to help maximize the capacity of the catchment. Some consultants described pohs that were positioned along trails and within close proximity of rock shelters. People would clean out and utilize these pohs as they travelled along such trails. This technique also depends upon informal monitoring of resources and a flexible approach towards management, in which the manager considers the current condition of each individual poh in its present condition. This is an example of what Mulder and Coppolillo (2005:64) would describe as adaptive management. 
Figure 2: Photograph of Small Poh, SMNRA

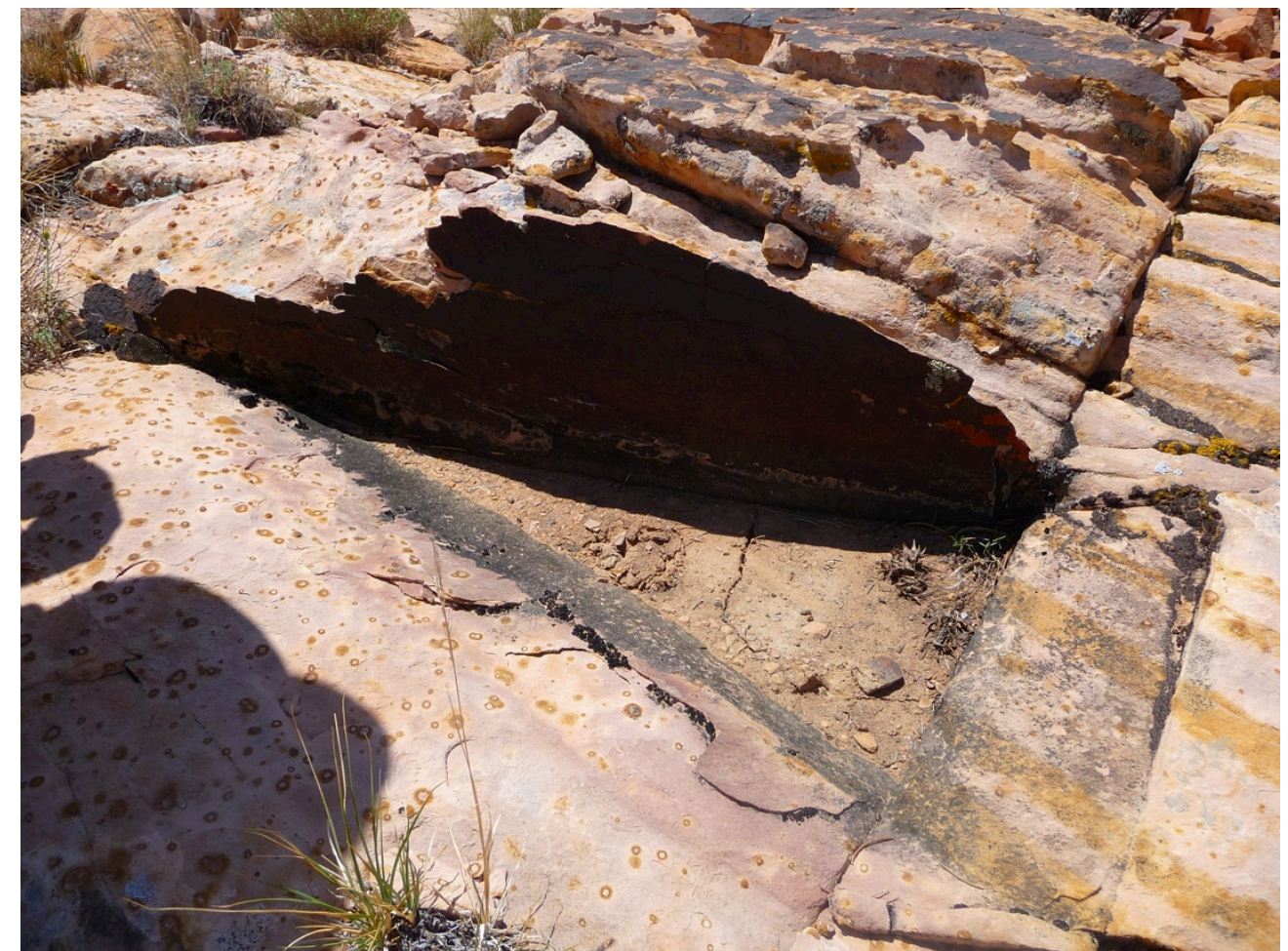

A dry poh filled with sediment, southern Spring Mountains, August 2012 (Image: K.L. Wendel)

In addition to cleaning out the pohs, several consultants explained that

Nuwuvi sometimes placed rock "lids" over the catchments to stunt evaporation.

These lids were designed to allow small animals to access the water while still

blocking out most of the sunlight. An elder from the Pahrump Paiute Indian Tribe explained the use of rock lids on pohs:

There's ways of managing those...even the evaporation of them. So...sometimes you may have, like on the deep ones, you can have a rock, rock lids on them that retard the evaporation. But sometimes you leave little holes in them, so if the animals need to get in there...or there's ways to channel the water. So that it also kind of runs out for some of the plants, but it still maintains...some of the water.

One consultant also described the importance of introducing water to a depression where water catchment is desired. 
There was some deviation in the way that Nuwuvi viewed this practice. Notably, one consultant expressed concern about the idea of cleaning out pohs in unfamiliar areas, or areas that might be managed by other people. This respondent noted that pohs were often associated with certain groups or individuals, and that for an individual to clean out a poh with which he or she lacks a connection is considered offensive to those who are associated with it. However, this consultant concluded that the cultural significance of the Spring Mountains as the Creation Site for Nuwuvi makes it appropriate for Southern Paiutes to manage pohs located in that area.

Folke, Berkes, and Coding (1998:432) argue that smaller, locally run institutions are generally faster and better at adapting to change than large centralized institutions. It can be argued that informal institutions such as the ones that make up the Nuwuvi approach to water management are well suited for managing a scarce and vulnerable resource such as water in these arid landscapes. Folke et al. (2005) discuss how the adaptive governance of social-ecological systems can lead to greater resilience against abrupt change and disturbance. The cleaning of pohs is one small-scale human disturbance that helps ensure the maintenance of the resource for plants, animals, and humans during times of water scarcity. The cleaning of springs is another example of stewardship that ensures the continual availability of resources. 


\section{Nuwuvi Ethnohydrology: Understandings of Water Function and Stewardship}

Nuwuvi ethnohydrological knowledge can be organized according to the two broad categories presented in this chapter: 1) hydro-logics, or the physical and cultural properties of water and an understanding of how it engages with the rest of the landscape, and 2) knowledge pertaining to water management, which includes three major practices: clearing springs, performing prayers and songs, and cleaning pohs. Nuwuvi believe that water is a sentient being that requires respectful human interaction to remain healthy. Nuwuvi conceptions of hydrological stewardship for the betterment of plant and animal species, as well as for the survival of humans, require the use adaptive management practices.

The term ethnosphere refers to the entirety of institutions and beliefs that make up cultures around the world. Garibaldi and Turner (2004) point out that just as the ethnosphere is born out of the biosphere from which it produced, the ethnosphere also modifies and manages that biosphere. Even as Euro-Americans arrived in the perceived "wilderness" of the west, there was evidence of longpracticed Nuwuvi hydrological management can be seen on the landscape today (Garibaldi and Turner 2004). Small-scale alterations such as corn, beans, and squash planted near springs went largely unnoticed by settlers, who perceived Nuwuvi to be a hunter-gatherer society. While Nuwuvi life-ways and ecological management strategies have changed over time, practices such as the cleaning of springs, the performance of stories and songs, and poh stewardship remained relevant and necessary in the eyes of most Nuwuvi participants. The Nuwuvi perception of water 
as sentient prescribes that individuals abide by common understandings about how people should take care of water. 


\section{Chapter 4: Changing Conceptions of Water}

You live in two worlds in that way. You have to remember your Indian ways...whereas when you're at home, you don't think about it because the water's coming out of the tap. And when you're out there...walking around in those willows and you see that spring, you're more in tune with what you're supposed to be doing.

This account by an elder from the Kaibab Band of Paiutes exemplifies a feeling expressed by many participants that new developments and lifestyles have caused many changes to Nuwuvi culture over the past two centuries. Static conceptions of indigenous knowledge undermine the significance of the many influences that continue to affect indigenous populations in ongoing ways. As Nuwuvi experience changes in political, economic, environmental, and social conditions, the Nuwuvi body of knowledge is undergoing related changes. While the previous chapter presented the character of Nuwuvi ethnohydrological knowledge, this chapter explores Nuwuvi conceptions of water that go beyond what Nuwuvi elders considered to be traditional notions of water and its role in Nuwuvi culture. In this chapter, I demonstrate how Nuwuvi ethnohydrological knowledge became fragmented and changed at a rapidly accelerated rate as a result of some of the products of Euro-American colonization of the region, which include urban development, federal land management, and the regional commodification of water. As Goodall (2008) points out, local ecological knowledge is not static, but is actually an ongoing process. In keeping with this concept, my data analysis revealed that water appeared to be gaining significance as an economic and political symbol among Nuwuvi participants. 
I argue that Nuwuvi ethnohydrological knowledge is 1) incrementally learned through the ecological understanding process outlined by Turner and Berkes (2006); 2) an assemblage that was influenced by both new and old conceptions of the role that water plays in Nuwuvi culture, as well as in the broader regional socio-economic fabric; and 3) fragmented as a result of political, economic, and social drivers. Several elders also described how Nuwuvi views of and interactions with water were experiencing generational shifts. Ultimately, I suggest that knowledge of certain Nuwuvi hydrological management practices are currently under threat due to factors such as the spacing initiated by the creation of reservations beginning in the 1850s, as well as the cross-generational effects of forced placement into boarding schools and contemporary integration of the Nuwuvi Nations into the market economy (Biolsi 2007, Knack 2001, Spoon and Arnold 2012). All of these influences acted as barriers to intergenerational knowledge transmission, as well as served as agents of cultural change (Spoon and Arnold 2012, Strang 2005, Goodall 2008).

Nuwuvi knowledge of water has always been changing and evolving as a result of shifting environmental and social conditions. However, the changes that have come with Euro-American arrival in the region, and with the developments associated with colonization of the western United States in the last two centuries have had profound impacts on Nuwuvi understandings of natural resources in the region (Spoon and Arnold 2012). Today, activities such as agriculture, tourism, and recreation are dependent upon access to this valuable resource, making water rights 
a major source of contention among regional stakeholder groups. Many consultants expressed concern over the future of water resources in the area. This fear is not only due to the cultural significance of water, but also because of this recently ensconced political and economic importance of water in the region.

The newfound role of water in tribal economies makes economic success in many ways dependent upon access to water resources. Historically, there was some early agricultural use of water from the Muddy River in alfalfa crops located on the Moapa reservation (Knack 2001:177). Access to water is even more important in tribal economies today, as a number of tribal businesses such as the Las Vegas Paiute Golf Resort and several farms that are owned by the Colorado River Indian Tribes are also dependent upon water rights. The relatively recent commodification of water as an economic resource has influenced perceptions of water and the responsibility humans have toward the resource. While some Nuwuvi participants recognized the importance of economic value of water to the tribes, others expressed displeasure over the commodification of water.

Some consultants expressed personal displeasure over what they saw as wrongdoings on the parts of land management agencies in the region, including disputes over water rights, which often changed hands as land was acquired by the agencies. Multiple participants previously resided within the present-day boundaries of SMNRA, and still resented their forced removal from the land. Private non-tribal residences located in SMNRA are also a source of umbrage for many Nuwuvi, who saw their use of the mountain's resources as wasteful and their lack of historical connection with the land inappropriate. 
Residents of two residential subdivisions located inside the boundaries of SMNRA enjoy water sourced from the Spring Mountain Range. Interestingly, the Las Vegas Paiute Tribe also maintains water rights to use water from the Spring Mountains to support the tribe's Golf Resort. Spoon (2013b) describes knowledge adaptations that have arisen as a result of the integration of an indigenous group into the market economy, including the transformation of local livelihoods to rely on newly prevalent tourism industry in the area. This topic is also pertinent in the Great Basin and Mojave Desert, where Nuwuvi views about water shift as access to water (or lack thereof) affects the economic wellbeing of their Nations. Access to and control over water signals power in these desert climates; contention surrounds issues of access and consumption. This is especially true with water sourced from elite locations such as the Spring Mountains.

\section{The Incremental Learning Process and Ecological Understanding}

Turner and Berkes' (2006) concept of ecological understanding helps describe how ecological knowledge develops over time. The authors recognize that environmental knowledge is sometimes derived through experiences with resource crises, a theory known as the depletion crisis model (Berkes and Turner 2006, Smith and Wishnie 2000). However, the authors also argue that ecological knowledge can be built through long-term incremental learning, known as the ecological understanding model (Turner and Berkes 2006). The concept of ecological understanding embodies four major attributes: 1) incremental learning as a result of observations about the natural world; 2) the development of co-held belief 
systems that help avert potential resource crises; 3) the encoding, communication, and dissemination of practical concerns and ideologies related to the belief system; and 4) the development of institutions to regulate interactions with the environment and its resources (Turner and Berkes 2006:497). I suggest that selections from my interview data embody these four attributes of ecological understanding. The connection between the ecological understanding model and consultants' descriptions of knowledge development and transmission helps illustrate how knowledge is continuing to change under contemporary political, economic, and social conditions, which are rapidly changing.

The first attribute of ecological understanding is incremental learning based on activities such as sampling, experimentation, and evaluation, which culminates in a body of knowledge that has been developed over multiple generations (Turner and Berkes 2006:497). Many Nuwuvi participants described the importance of inter-generational knowledge transmission to the perpetuation of Nuwuvi culture and ecological knowledge, and some recognized that this is becoming more difficult due to the relatively newfound influences of the market economy, and by cultural disruptions stemming from the effects of boarding schools (Spoon and Arnold 2012). Turner and Berkes (2006:497) explain that incremental learning is based on detailed observations and experiences with natural variations. As evidenced Chapter 3, Nuwuvi knowledge of water includes an understanding of how water is incorporated into the desert environment in both temporal and spatial senses. Knowledge of water availability during specific seasons and along important trails 
was historically vital to survival, and remains relevant to individuals who continue to practice traditional management techniques.

Turner and Berkes' (2006) second attribute of ecological understanding involves a co-held belief system that serves practically to avert resource crises. Several researchers have debated over whether or not indigenous resource use systems can be classified as resource conservation. Although many of the Nuwuvi water management practices and taboos outlined in this chapter function to conserve or preserve water resources during certain times or in specific places, the question still remains as to whether or not these practices qualify as intentional conservation.

Scholars such as Smith and Wishnie (2000) have suggested that intentionality is an essential property in defining a system of the concept of conservation. However, Berkes and Turner (2006) argue that case studies from around the world show that de facto conservation regimes exist and are developed through means other than intentional conservation. Nuwuvi seem to practice both intentional and indirect conservation strategies. While some taboos are justified expressly for the purpose of conserving resources, such as the taboo surrounding the amount of water one consumes, others seem more indirect, such as the belief system surrounding water babies. There are both intentional and unintentional types of Nuwuvi conservation, and many participants recognize that these taboos and cultural rules surrounding water serve to conserve the resource for human, animal, and plant use. Values such as sharing water with the animals serve as this type of de facto conservation that Berkes and Turner (2006) describe. Rappaport 
(1968) describes en example of the ritual regulation of resource use in New Guinea. Similarly, some Nuwuvi practices serve to regulate resource use through the imposition of spiritual guidelines.

Turner and Berkes' (2006) third attribute of ecological understanding, which is that both practical and ideological aspects of the belief system are culturally encoded, communicated, and disseminated, is well supported by data patterns which reveal a co-held belief system surrounding water. This system of belief is complex, and mainly comprised of a reverential respect for water and the role that it has in keeping humans, animals, and the rest of the landscape thriving. Much of this framework originates at the time of Creation, when the landscape was formed partially by hydrological forces. Although the intensity and character of Nuwuvi water management has changed through the years, respect for water remains vital and relevant today, and many Nuwuvi see management practices as essential to the continual availability of water resources.

Though this belief system seems to be long-held, there is also evidence that certain beliefs surrounding water are changing. Just as Goodall (2008) demonstrated how Australian aboriginal understandings of water have continued to shift since colonization, it is clear that water is taking on new meanings within Nuwuvi and broader society as an economic as well as an ecological resource as regional understandings of hydrology and the decline of available water resources. Although Nuwuvi understandings of water are changing, responses were still mainly focused on traditional knowledge that has developed over generations. A member of 
the Colorado River Indian Tribes explained how she was taught to interact with water:

Water is very precious to the people...you know, as we grew up...Paiute people or any different tribes, they respected. They didn't waste it. They used it in the right way.

In keeping with Turner and Berkes (2006) third attribute of ecological understanding, ecological knowledge related to water is encoded into Nuwuvi culture in ways that sustain oral transmission of this knowledge. Stories and songs are important means to transfer knowledge to future generations, as they contain descriptions of how and why water sources exist, as well as instructions about where to find and how to interact with water, and songs that describe possible repercussions for disrespecting it. Here, an elder from the Chemehuevi Indian Tribe tells of how stories are used to describe the physical locations of water sources, as well as their significance:

Typically springs are not man-made, but can be enhanced by manmade manipulation, and springs...are tied to the culture. There's certain stories and songs that we have that how they were created, why they were created, where they're located, which plays into their significance.

Participants discussed the importance of stories and songs in perpetuating this knowledge to future generations. At the same time, many elders acknowledged that there are fewer opportunities for transmission today than there were in the past.

Lastly, Turner and Berkes' (2006) fourth attribute of ecological understanding references institutions set in place to govern resource use. This is evidenced in the data through the existence of informal institutions that govern group behaviors. According to Colding and Folke (2001:585), informal institutions 
are comprised of self-imposed and monitored conventions or norms. Nuwuvi have developed informal institutions including customs surrounding water use, and repercussions for misuse range from immediate bodily harm to the disappearance of the resource itself. Much of this comes back to the overarching belief system that water is to be respected and not wasted, as well as shared with the animals and plants. Here, an elder from the Pahrump Paiute Indian Tribe expresses the importance of following customs for water use:

It's a very important resource. People-meaning the animals-need that for survival. And all of them have to use it in an appropriate way, and in a way that's not too excessive...Water can make you sick as it can make you feel good and quench your thirst. If a person were to go and take too much water, for example, and you're out there in the hot and you just drink too much, you can get sick from it. So it's a powerful thing, and you need to know how to regulate that. The animals that do that...they know where the springs are...they know where the water sources are...they can sense that. We as humans, in our form, we also reply upon those same resources, so consequently, we then will stay away from a lot of areas where animals might go, because they need the water, because you don't want to go and bother them or scare them away.

All of the examples in this section illustrate Turner and Berkes' (2006) concept of ecological understanding. Nuwuvi knowledge of water appears to be developed through the long-term process of incremental learning, culminating in a co-held belief system based on a common ecological understanding. This knowledge continues to develop today under rapidly changing political, social, and economic conditions. I will discuss this concept in the following sections. 


\section{Developing a Knowledge Assemblage}

Traditional ecological knowledge has often been conceptualized as the antithesis to western scientific knowledge. The dualistic thinking associated with these concepts is based on positivist views of western knowledge as systematized and therefore the converse of that (traditional, or local knowledge) is disordered and therefore lacking in legitimacy (Vermeylen et al. 2008, Watson and Huntington 2008). However, a number of researchers (e.g. Turnbull 1997, Vermeylen et al. 2008, Watson and Huntington 2008) argue that this distinction is a false dichotomy. The concept of knowledge assemblages addresses this criticism. Turnbull (1997) describes a knowledge assemblage as a merging of multiple knowledge spaces with different devices and strategies for assembling the knowledge. Forsyth (2003:91) also describes this phenomenon as the co-production of knowledge.

While one could argue that Nuwuvi ethnohydrological knowledge has changed (or lost detail) to the point where it can no longer be considered "indigenous," the concept of assemblages helps to explain some of the developments in the knowledge domain. Understandings of water are in some ways co-produced with other user groups in the region, which include political factions, businesses that utilize and consume local natural resources, and non-Native locals who might value landscapes for their ecological or economic value (Forsyth 2003:91). Strang (2005) argues that various user groups encode meanings and values into water and that the diverse range of understandings over what constitutes "productivity" often leads to both ecological and social tension. In this case, there was not only conflict between Native and non-Native users of water resources, but also sometimes among 
Nuwuvi themselves. While some participants felt that it was important for the Nuwuvi Nations to secure water rights and utilize the resources to support tribal businesses, others felt that it was inappropriate. This contrast illustrates how conflict can arise concerning how water should be valued, among Nuwuvi Nations as well as in of the broader regional social framework and policy.

\section{The Contemporary Fragmentation of Knowledge}

As noted in the previous chapter, Nuwuvi ethnohydrological knowledge is heterogeneous and held at varying degrees based on factors such as the individual's age, residential location, and occupation (Spoon 2011). An elder from the Pahrump Paiute Indian Tribe described the phenomenon in this way:

Clearly the challenge...of our people...with the culture and the way that it has been influenced by outside forces, whatever that may be, then sometimes you get a real disparity of knowledge from people...Some people that may know within... their life experience [is] what helps define the water and how it's used.

As previously evidenced, Nuwuvi ecological knowledge embodied all four attributes of ecological understanding posed by Turner and Berkes (2006). Although a common system of understanding of water was present among subjects, there was also a notable lack of knowledge about water in relation to certain specific locations. The Nuwuvi reservations are dispersed across four states, and the physical distance from SMNRA and DNWR has clearly affected some participants' understanding of these areas. Access to DNWR is especially difficult, and Nuwuvi individuals do not always have the time, ability, or resources to visit these landscapes, despite the culturally significance of landscapes such as Nuvagantu (the Spring Mountains 
landscape). The privatization and federal acquisition of land parcels have resulted in a fragmentation of this landscape, which was once all considered Nuwuvi territory. Knowledge transmission became more difficult as opportunities for interactions with ancestral lands are sparse for many who live on reservations or in urban areas. One elder from the Kaibab Band of Paiutes expressed dismay at the dwindling opportunities for children to experience the land and learn from elders:

As toddlers, with your mother, you would hear those songs. Then you would learn them...by listening to them and hearing them every time you went out. It was just natural, you know, to learn it that way. Today we have to have a class to learn those songs, because nobody goes out to do that-it's not the normal thing to do anymore.

This statement also highlights the important fact that many Nuwuvi individuals did not participate in traditional and cultural management practices on a regular basis. Some areas are difficult to access and with integration in the market economy means that distant travel is made more difficult due to work obligations. Many individuals also visit these landscapes to participate in non-traditional activities such as mountain biking. Spoon and Arnold (2012) discuss the fragmented nature of Nuwuvi ecological knowledge, which is a result of the parcelization of the landscape because of the relatively recent public and private acquisition of land. From the Nuwuvi perspective, human interactions with the landscape were essential to keep the land in balance. Although most consultants expressed this sentiment, many recognized that they did not have a great deal of opportunities to return to these landscapes and conduct management activities. Here, one elder spoke of her awareness of the difficulty of keeping up with responsibilities to the land: 
It's the job of the people to take care of the water...It's our job to take care of the springs too, but we don't do that anymore... because we don't go to all these different springs... But they're very important, because it we don't do that, they're gonna go away, that's what I've always been told-if you don't take care of the water and if you don't take care of the plants then they're going to go away, and you'll no longer have the knowledge of them. And so it's important to manage them...But for us it's just simply taking care of them and making use of them and keeping them clean and showing a lot of respect for that source...that water source.

The majority of my sample was comprised of elders from six Nuwuvi tribes (see Appendix F for more details). These elders have witnessed major political and social transformations in the region over the course of their lifetimes, and along with these societal changes have come new understandings about water and its role in Nuwuvi culture. Urban population increases and development in cities such as Las Vegas have greatly influenced the political significance of regional water issues, which occupy considerable attention in popular news media. Larger societal shifts regarding water have also manifested in new knowledge among Nuwuvi about the ecological, social, and economic roles of water in the region, and the implications of these changes for the Nuwuvi Nations.

Elders often emphasized the differences between how water was utilized in their childhoods versus how young people interact with it today. Changes over time in how water is utilized are indicative of the evolving role of water in the social fabric of the region. For instance, underground water obtained through wells was an essential resource to Nuwuvi for generations. Many consultants recalled hauling water from wells in their youth, while today, Nuwuvi growing up both on and off 
reservation have plentiful access to treated water. Here, two elders from the Kaibab

Band of Paiutes described some of the changes brought about by this development:

We don't rely on them for water and things like that anymore, because it comes through the tap and into our house...we don't take care of them and look after them like we used to. But...they're very important, because it we don't do that, they're gonna go away. That's what I've always been told.

I think in the old days, people were more conservative with the water and did less wasting than what we did today, because... water was very precious...because you had to go from spring to spring to get your water. But today we take water for granted and we don't give offerings to the water that comes out of the tap...We just take it for granted...oh there's the water, you drink it and bathe in it and that kind of thing. And that's the way I am too unless I'm at a spring or gathering my plants.

The idea that youth interact with water differently than generations past was prevalent among elders. Strang (2006) argues that experiences, images, and metaphors can arise from people's interactions with water. The examples above show how generational understandings of water transform as individual experiences with it change. Some participants expressed the sentiment that respect for water has become more difficult to instill in young people as it has become such a ubiquitous resource. An elder from the Kaibab Band of Paiutes explained it this way:

So many of us take for granted that when we flush the toilet, it's going to flush, and when we turn the water fountain on...water's gonna come out. None of us have been taught that maybe one day when you turn the water fountain on, or the water spout, it may not come on... and so I think what could happen and what needs to take place within our communities is really having that knowledge of the water...being taught, again, the importance of water and how we need to view water and not take advantage of it...not waste it...Having those teachings in place again, how important water is and teaching that to our children. 
Spoon and Arnold (2012) argue that the fragmentation of land and social marginalization that Nuwuvi have experienced since the nineteenth century have drastically accelerated the rate of change and adaptation of ecological knowledge. In this chapter, I examined some new understandings of the role of water within Nuwuvi culture and the larger political and social climate. Goodall (2008) discusses how Australian indigenous knowledge related to water has evolved in in response to the effects of colonialism, arguing that water played and continues to play a major role in the colonization of Australia. Similarly, access to and control of water has been essential in the settlement of the western United States (Hulse 2004, 2009). The effects of colonization and development have clearly influenced perceptions of the resource held by various regional stakeholder groups, including Nuwuvi. Water in the Great Basin and Mojave Desert has arguably replaced precious minerals as the region's top natural commodity (Hulse 2009).

\section{Generational Knowledge Shifts and Changing Valuations of Knowledge}

This chapter argued that Nuwuvi ethnohydrological knowledge was incrementally learned, resulting in knowledge assemblages that have been developed over time, and that are becoming fragmented, while being co-produced with other understandings of water. While there was a generally agreed upon cultural framework for acceptable use of water, as outlined in Chapter 3, there was also dissention among participants as to whether or not water should be considered an economic resource. Participants made it clear that generational attitudes towards water and hydrological management are drifting farther apart. These 
changes are a result of factors such as the integration of Nuwuvi Nations into the market economy, and historical agents of change such as the long-reaching effects of boarding schools and the creation of reservations. Changes to the ways in which youth are interacting with hydrological resources seems to be a threat to the continuing performance of traditional management practices such as spring stewardship. This makes the documentation and operationalization of Nuwuvi ethnohydrological and management knowledge imperative. 


\section{Chapter 5: Epistemologically Grounded Approaches to Hydrological Restoration}

As SMNRA and DNWR lie within Nuwuvi ancestral territory, the degradation of hydrological resources in these areas is a concern for both land managers and Nuwuvi. Ecological restoration comprises a significant amount of the water management being planned and performed by managers in these protected areas. By and large, Nuwuvi and federal agency participants described similar impacts to water resources in SMNRA and DNWR in their interviews. I argue that although Nuwuvi and agency approaches to restoration are based on diverging epistemologies, both approaches consider certain types of disturbance to be vital to water health. The practices associated with these two distinct approaches exhibit areas of convergence, as well as difference. Using a political ecology framework, I also suggest that the power differential that exists between these two broad groups influences which management and restoration practices are applied to management plans in SMNRA and DNWR.

Ecological restoration has become an important part of hydrological management in SMNRA and DNWR as water resources in these areas have been and continue to be impacted by a number of historical and contemporary activities. In this chapter, I first will explain why ecological restoration is of interest for the purposes of this project. I will then outline perceptions of water health in SMNRA and DNWR held by Nuwuvi and agency participants as well as a description of restoration approaches and techniques used by Nuwuvi and agency groups. Finally, 
I will discuss both sets of restoration approaches in the context of my political ecology framework and in the larger cannon of restoration scholarship.

\section{Social Science Perspectives on Ecological Restoration}

My focus on ecological restoration is pertinent due to its importance in land management plans in the U.S., and more specifically, its prevalence as a management technique used in SMNRA and DNWR. One such project is the Desert National Wildlife Refuge Corn Creek Restoration and Refugium project, which aims to restore habitat for the endangered Pahrump poolfish (Empetrichthys latos latos) and the endemic snail, Corn Creek pyrg (Pyrgulopsis fausta), which has been underway since 2002 . The springs and outflow channels were negatively affected by the historic water diversion and piping for agricultural purposes. The Pahrump poolfish refugium was completed in 2002, while smaller restoration projects, as well as the construction of interpretive material continue at Corn Creek. ${ }^{4}$ The restoration of the oxbow at Black Canyon in the Pahranagat NWR (one of the four Refuges that comprise DNWRC) is another notable large-scale hydrological restoration project that seeks to return water to the Canyon and revegetate the surrounding riparian habitat. ${ }^{5}$ SMNRA also has several restoration projects that are currently underway, including the Archery Range project, which is aiming to restore soils and vegetation damaged by human activity (primarily recreation) in the area.

\footnotetext{
${ }^{4}$ See http://www.otisbay.com/projects/nevada/corncreek/corncreek.html for more information on the project

${ }^{5}$ See http://www.otisbay.com/projects/nevada/pahranagat/blackcanyon/blackcanyon.html for more information on the project.
} 
Figure 3: Photograph of Corn Creek Restoration and Refugium Project, DNWR

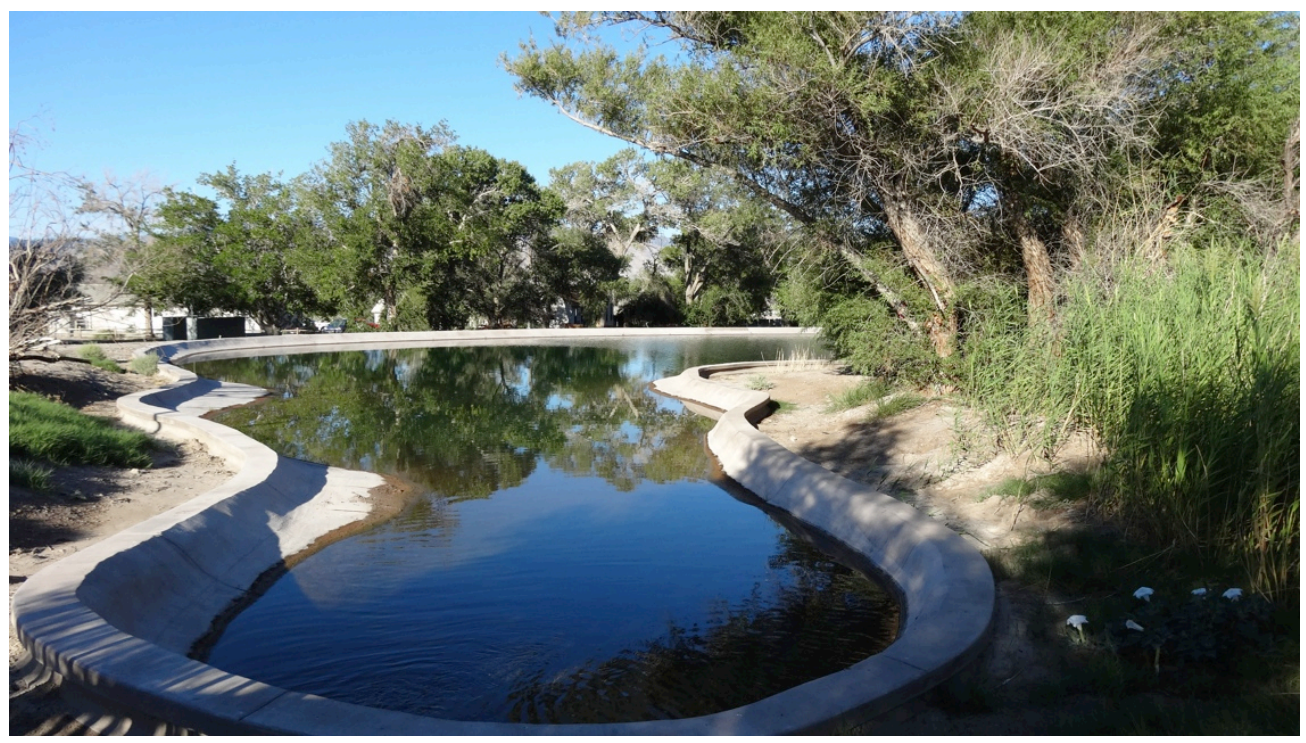

Corn Creek Restoration Project, August 2012 (Image: K.L. Wendel)

In the United States, ecological restoration has arisen from the early $20^{\text {th }}$ century as one of the primary means for managers to manipulate environments in the pursuit of management goals. Today, most American land managers and environmental advocates agree that restoration is a vital part of maintaining a healthy human-environment relationship (Jordan and Lubick 2011). Jordan and Lubick (2011:2) point out that ecological restoration is often motivated by aspects of human curiosity, scientific, historic, and aesthetic interests, and nostalgia. While other forms of environmental management can be described as meliorative land management (improving the land for human inhabitants), ecological restoration is more aptly labeled as ecocentric restoration (focused on a re-creation of land and resources). 
Although the current ecological restoration trend is a worldwide phenomenon, it has uniquely American roots. In the 1930s, the Civilian Conservation Corps (CCC) focused many efforts on tree planting, especially focusing on agricultural trees to be used in timber extraction (Jordan and Lubick 2011, Bratton 2000). Bratton (2000) argues that early restoration projects fit into one of two models: The economic model (such as the CCC projects), and the wilderness model, which included Muir-inspired projects meant to return nature to a state before humans' interference. Although several authors (Bratton 2000, Tomblin 2009, Jordan and Lubick 2011) have discussed alternative restoration movements, mainstream restoration projects remain largely based on either economic or wilderness models.

Over the past thirty years, social scientists have become increasingly interested in the social aspects of ecological restoration. Several authors have discussed restoration paradigms in relation to social-ecological systems. Reuss (2005) discusses the history of dominant western scientific discourse surrounding ecological restoration in the United States. Reuss (2005:34) sees ecology as "as much, and perhaps more, social science than physical science." Reuss takes a social and historical view of restoration, outlining the ideological roots of ecology and demonstrating how restoration discourse currently relies heavily on technological solutions and cost-benefit analyses. Additionally, restorationists have to reconcile two disparate objectives: defense of the environment and satisfying a broad range of human needs (Reuss 2005:31). 
Reuss is one of many researchers who have analyzed dominant restoration discourse. Others, however, have discussed alternative restoration paradigms that are arising to challenge hegemonic models of ecological restoration that favor western science. Tomblin (2009:188) discusses epistemic cultures in relation to ecological restoration: Holistic Restoration Culture and Indigenous Restoration Culture. While ecological restoration has traditionally demonstrated a race, class, and gender bias, being primarily designed and driven by white male land managers, these new movements seek to address some of the issues stemming from that bias (Tomblin 2009:185). Tomblin (2009:192) defines holistic restoration as "community-based, grassroots restoration projects that attempt to return damaged ecosystems to historic classic landscapes." This distinction acknowledges the plurality of perspectives on restoration, and connects directly to my discussion of the epistemological bases of Nuwuvi and agency approaches to restoration. Furthermore, these alternative movements deliver challenges to the dominant restoration paradigm, a concept that will be relevant to my discussion on possible venues for collaboration among USFWS, USFS, and Nuwuvi Nations as part of the NKTA project.

In addition to challenging the dominant restoration paradigm, social science has also considered the value of alternative knowledge systems in restoration work. Scholarly evidence of the value of local ecological knowledge (LEK) in restoration plans is essential understanding the value of this research. Several studies have already demonstrated the utility of such knowledge in restoration projects. For example, Senos et al. (2006) provide several key cases of the successful utilization of 
LEK in restoration projects in the Pacific Northwest. The authors argue that the tendency to use western science as the "default" guiding knowledge of restoration limits their efficacy and alienates those who do not share the dominant restoration epistemology (Senos et al. 2006:394). The authors argue that LEK-based restoration has the potential succeed in not only restoring ecosystems, but "also in fostering the interrelationships of people and place" (Senos et al. 2006:393). Higgs (2003) also argues for the integration of alternative cultural, ethical, and philosophical perspectives into restoration, which he argues will ultimately bring community participants together and reestablish human relationships with the land.

\section{Two Perspectives on Hydrological Impacts in SMNRA and DNWR}

As mentioned in previous chapters, water in the southern Great Basin and northern Mojave is a precious resource that has played an essential role in facilitating both historic and contemporary human habitation of the region. Chapter 2 of this thesis outlined the ways in which water contributed to the development of the city of Las Vegas. This chapter will demonstrate how historical economic drivers including mining, ranching, and residential development have impacted regional water resources, from the perspective of Nuwuvi and agency participants. These activities required large-scale tapping of limited regional water resources, which both Nuwuvi and agency participants see as a harmful development.

While Nuwuvi and agency perspectives on hydrological impacts are largely similar, they stem from differing worldviews and methods for understanding ecological change. Nuwuvi participants have experienced changes in regional water 
resources throughout the course of their life events, and have also learned about such changes through stories passed down from parents and grandparents. Participants often revealed these experiences to me as personal anecdotes in interviews. Here, one participant from the Colorado River Indian Tribes recalled her father's perception of how Colorado River water quality has changed over time:

My dad was here last Thursday, and he was talking-I don't know how we even got on the subject-but he was talking about the [Colorado] River and he was saying 'we used to drink that river, we used to drink that river!'...I thought, oh, that's so gross! We were laughing around about it, because we thought it was a joke. And my dad was going, 'no, I'm serious-we drank the river - ' and I said, 'you did not...you drank river water?' and the more he talked, he was saying, 'well the river way back then wasn't like what it is now...it was natural and it was clear. When we went swimming in the river, you could see the bottom. You could see the moss, you could see the weeds, you could see the rocks.' He goes, 'you used to be able to see that. So we would always just scoop it up and drink it.' He says, 'not like it is now. Not like it is with the boats' pollution...people polluting it. People urinating it and all that, you know what I mean? People throwing their trash in it.' He goes, 'not like that. I wouldn't drink river water now.'

Many participants initially described modern day water resources as being "healthy," but those descriptions were often followed by stories such as the above. Although this response referred to the Colorado River, other responses were geared towards water resources located in SMNRA and DNWR. These responses make it clear that from a Nuwuvi perspective, there was a need for hydrological restoration in these two protected areas. In the following section, I will describe impacts to hydrology in SMNRA and DNWR, as perceived by Nuwuvi and agency consultants. Qualitative data from interviews with indigenous peoples have proven useful in a number of restoration projects that employ applied historical ecology methods. 
Historical ecology is a multi-disciplinary field developed to suit the needs of restoration ecologists seeking to reconstruct historic landscapes. Methods ranging from soil distribution analysis to ecological field experiments to tree ring dating have all been used in historical ecology research (Egan and Howell 2001: 75). Sociocultural anthropology methods have also proven useful in this field, enabling researchers to understand historic environmental conditions. Historical memory related to human-environment interactions come across in a number of Nuwuvi interviews, with the potential to provide restorationists with an understanding of how water sources in these two protected areas, and on a larger regional scale, have changed over time. Data from Nuwuvi elders may be similarly helpful in determining past ecological conditions and examining the extent of ecological change over the past few generations.

Interviews with both Nuwuvi and agency consultants make it clear that water health in this region has been compromised through a number of historic and contemporary influences. Agency consultants and the majority of Nuwuvi participants agree that restoration is possible in most cases, but the effects from these impacts require human intervention to correct them. From the Nuwuvi perspective, this is part of their cultural responsibility towards the land. For agency representatives, it is part of their legal obligation as land managers.

This chapter is organized to describe Nuwuvi and agency perceptions of five sets of impacts: 1) recreation; 2) climate change; 3) increased human presence within the protected areas; 4) non-native plant and animal species; and 5) historic 
improvements installed to hydrological features. These categories arose through the coding process as overlapping concerns (to varying degrees) of both agency and

Nuwuvi participants. The following table summarizes the general Nuwuvi and agency perceptions of these five impacts, and identifies similarities and differences

between the two perspectives:

Table 1: Summary of Nuwuvi and agency perceptions of hydrological impacts

\begin{tabular}{|c|c|c|c|c|}
\hline Impact & Nuwuvi & $\begin{array}{c}\text { Federal Agency } \\
\text { (USFS/USFWS) }\end{array}$ & Similarities & Differences \\
\hline Recreation & $\begin{array}{l}\text { ATV use, horses, } \\
\text { and other } \\
\text { recreational } \\
\text { activities nega- } \\
\text { tively impact } \\
\text { springs }\end{array}$ & $\begin{array}{l}\text {-ATV use, horses, } \\
\text { and other } \\
\text { recreational } \\
\text { activities } \\
\text { negatively impact } \\
\text { springs } \\
\\
\underline{\text { USFS }} \\
\begin{array}{l}\text { Recreation is an } \\
\text { essential activity } \\
\text { in SMNRA }\end{array}\end{array}$ & $\begin{array}{l}\text { - Camps should be } \\
\text { located away from } \\
\text { water sources so } \\
\text { that animals can } \\
\text { utilize the resource } \\
\text { - Recreational } \\
\text { activities can have } \\
\text { negative impacts on } \\
\text { the land } \\
\text { - Hiking is the most } \\
\text { desirable/ least } \\
\text { ecologically } \\
\text { harmful form of } \\
\text { recreation }\end{array}$ & $\begin{array}{l}\text { - Agencies } \\
\text { providing } \\
\text { recreational } \\
\text { opportunities } \\
\text { is an important } \\
\text { goal in these } \\
\text { areas }\end{array}$ \\
\hline $\begin{array}{l}\text { Climate } \\
\text { Change }\end{array}$ & $\begin{array}{l}\text { - Climate change } \\
\text { has altered } \\
\text { seasonal weather } \\
\text { patterns in the } \\
\text { region }\end{array}$ & $\begin{array}{l}\text { - Increased } \\
\text { summer } \\
\text { temperatures } \\
\text { and decreased } \\
\text { snowfall have the } \\
\text { potential to } \\
\text { change ecological } \\
\text { conditions in } \\
\text { both areas }\end{array}$ & $\begin{array}{l}\text { - Climate change } \\
\text { poses a threat to } \\
\text { water resources in } \\
\text { the region }\end{array}$ & - $\mathrm{N} / \mathrm{A}$ \\
\hline $\begin{array}{l}\text { Population } \\
\text { Growth }\end{array}$ & $\begin{array}{l}\cdot \text { Urban population } \\
\text { growth means } \\
\text { that more people } \\
\text { are using regional } \\
\text { resources } \\
\cdot \text { Houses in SMNRA } \\
\text { use too many } \\
\text { resources }\end{array}$ & $\begin{array}{l}\text { Population } \\
\text { growth affects } \\
\text { the ecology } \\
\text { through } \\
\text { increased } \\
\text { recreation and } \\
\text { tourism }\end{array}$ & $\begin{array}{l}\text { - Population } \\
\text { growth has affected } \\
\text { the land and will } \\
\text { continue to affect it } \\
\text { into the future } \\
\text { - More education is } \\
\text { needed to prevent } \\
\text { further damage to } \\
\text { the land and its } \\
\text { resources }\end{array}$ & - N/A \\
\hline $\begin{array}{l}\text { Non-Native } \\
\text { Species }\end{array}$ & $\begin{array}{l}\cdot \text { Non-Native } \\
\text { species such as }\end{array}$ & $\begin{array}{l}\text { - Invasive plants } \\
\text { are drawing up }\end{array}$ & $\begin{array}{l}\text { - Non-Native plant } \\
\text { species can }\end{array}$ & - N/A \\
\hline
\end{tabular}




\begin{tabular}{|c|c|c|c|c|}
\hline Impact & Nuwuvi & $\begin{array}{l}\text { Federal Agency } \\
\text { (USFS/USFWS) }\end{array}$ & Similarities & Differences \\
\hline & $\begin{array}{l}\text { Salt Cedar draw } \\
\text { up large amounts } \\
\text { of groundwater, } \\
\text { negatively } \\
\text { impacting native } \\
\text { plant species such } \\
\text { as Cottonwoods }\end{array}$ & $\begin{array}{l}\text { water } \\
\text { - Non-Native } \\
\text { animal species } \\
\text { trampling } \\
\text { springs }\end{array}$ & $\begin{array}{l}\text { negatively impact } \\
\text { native species }\end{array}$ & \\
\hline $\begin{array}{l}\text { Historic } \\
\text { improve- } \\
\text { ments }\end{array}$ & $\begin{array}{l}\text { - Mechanical } \\
\text { improvements to } \\
\text { springs negatively } \\
\text { affect them }\end{array}$ & $\begin{array}{l}\text { Most historic } \\
\text { improvements to } \\
\text { springs are } \\
\text { detrimental to } \\
\text { ecological health } \\
\text { and should be } \\
\text { removed } \\
\text { - However, some } \\
\text { are protected } \\
\text { under NHPA }\end{array}$ & $\begin{array}{l}\text { - Historic } \\
\text { improvements to } \\
\text { springs, such as } \\
\text { piping to supply } \\
\text { horse troughs, } \\
\text { negatively impact } \\
\text { springs and should } \\
\text { be removed }\end{array}$ & $\begin{array}{l}\text { - Agencies are } \\
\text { obliged to } \\
\text { protect some } \\
\text { sites under } \\
\text { NHPA }\end{array}$ \\
\hline
\end{tabular}

Impacts from Recreation: Erosion, Pollution, and Noise

Recreation is one of the primary sets of activities that take place in both SMNRA and DNWR. Recreational activities have a major impact on the way water sources are managed in both areas, but particularly in SMNRA, which is a popular site for hikers, campers, horseback riders, and participants in a multitude of other recreation activities. All-terrain vehicles (ATVs) are especially detrimental to water sources, as these vehicles cause soil erosion around water sources and scare off wildlife. Both agency and Nuwuvi participants acknowledged the potential negative impacts that these activities can have on water resources, but agency consultants (especially those from USFS) viewed it as a necessary impact that can only be mitigated through education, while some Nuwuvi suggested more large-scale bans on recreational activities around water. Here, two participants from the Pahrump 
Paiute Tribe and the U.S. Forest Service (respectively), expressed similar concerns over off road vehicles:

Yeah, the four wheelers, I think, probably more detrimental than any of them, from what I've seen. Cause they don't care-they make their own roads and obviously they leave trash out there and you can see parts laying out there and you can see where they've spilled oil, because you know, they've punched a hole in something.

Trying to keep people on designated routes so they're not driving all willy-nilly everywhere. So you don't have roads driving through water sources or sensitive plant species or sensitive wildlife species habitat areas, nesting areas, or stuff like that...or ATVers and dirtbikes, since they're smaller, they can go anywhere they want to. So working with them, education, letting them know why these areas are important other than just because we're curious and wanted to go trailblazing. You've got to take a step back and realize that you're not the only species using these areas.

Overall, participants discussed recreation more than most other impacts to water resources, most likely because it is one of the most visible activities in these areas. Providing recreational opportunities for local residents is one of the primary mandates for managers at SMNRA. Both of these areas are within close proximity to the city of Las Vegas, meaning that they are easily accessible for a people seeking to practice a wide range of recreational activities. Some Nuwuvi participants explained that they participate in practices such as hunting, mountain biking, and camping, and appreciate opportunities to engage in these pursuits on federally managed land themselves.

Large-Scale Impacts from Climate Change

Both Nuwuvi and agency participants agreed that the effects of climate change, which include increasing summer temperatures and decreased snowfall, are 
negatively affecting regional hydrological resources on a large scale. Agency consultants explained that they expect that these problems could become much more pronounced in coming years, which would drastically impact water resources in SMNRA and DNWR. One consultant from USFWS explained the effects of climate change on the Refuge:

I think the aquifer itself is fairly insulated, and is going to attenuate a lot of the climate change signal. It's going to take a long time to see it in the aquifer...water levels potentially declining. Certainly the major impact down there...a couple of major impacts. One would be more rain and less snow in the winter, and maybe that would be more susceptible to loss from evaporation or transferration and not captured or not recharging the aquifer.

The scientific consensus is that these mountainous regions are vulnerable to the effects of climate change (see USFS 2011). Many Nuwuvi also recognized this threat, often because they had witnessed these effects themselves over the course of their lifetimes. Here, two generations from the Pahrump Paiute Tribe discuss their perception of the impact of changing climates on water resources:

Participant 1: It seemed like they had more water in those days. Participant 2: More snow too.

Participant 1: Cause I know our property up in the mountains there, the water used to run a good half-mile farther than it does today.

These types of observations from long-term residents (the property these two participants refer to is located on the western side of the Spring Mountains) can be incredibly valuable in developing an account of what these areas looked like in the past, evidenced by several researchers who integrated oral history into their historical landscape analyses (e.g. Senos et al. 2006). Because the agencies view climate change as a major threat to water resources in SMNRA and DNWR, the 
Nuwuvi example provided above shows the value of such observations to confirm environmental changes that have taken place over the last century. While Nuwuvi and agency methods for observing and understanding ecological change are stemming from differing epistemologies, the conclusions they draw are quite similar.

Increased Human Presence

Nuwuvi consultants mentioned several activities that they saw negatively affecting water sources in the Spring and Sheep Mountains. This list included trash from recreationists, soil erosion created by horses and motorized vehicles, and soil erosion and pollution resulting from traffic on mountain roads, Agency consultants saw many similar impacts to water in these areas. Contamination from nuclear testing conducted at the Nevada Test Site in the $20^{\text {th }}$ century is also a source of concern for both Nuwuvi and agency participants. According to Nuwuvi hydrologics, water sources can be influenced by events elsewhere on the landscape, meaning that water resources in both SMNRA and DNWR are endangered by impacts at the Nevada Test Site.

Groundwater extraction is one of the main concerns related to regional population growth. Historically, the city of Las Vegas depended on groundwater during its construction and growth. As well, water from the Colorado River continues to be drained every year for use by the city of Las Vegas, and supply becomes more problematic each year, so the tapping of groundwater is an option as water levels in large bodies such as the Colorado River and Lake Mead decline 
(Hulse 2009:69). Both agencies saw the preservation of groundwater levels as being extremely important for maintaining ecosystem health now and in the future.

Here, consultants from USFWS discussed current threats to water resources that lie underneath DNWR:

There have been attempts-and not by us-to look at the aquifers that lie under the refuge for potential extrapolation of the resource, which we, of course, would not permit. And you know, we're always concerned about the water and how long it's going to be here.

In that context, really talking about managing groundwater, because the springs that appear at the surface are all dependent on the groundwater. And there's a lot of pressure to develop the groundwater in the sense of pumping, you know, for Las Vegas water supply. And if you don't do that, if you're not very careful about how you do that, you could impact springs. You could lower water levels and impact springs...essentially dry them up...It's very much keeping springs sustained while managing groundwater development. It's also restoring and enhancing the habitat in the springs and the streams that come from the springs.

Several Nuwuvi elders also mentioned witnessing threats to groundwater, noting that modern-day wells need to go deeper than they did in the past to reach water, suggesting that water tables have lowered. An elder from the Pahrump Paiute Tribe discussed the difference this way:

There used to be a lot of water coming up before they started drilling wells below, you know, everywhere. That water went down.

Robertson and McGee (2003:275) demonstrate how the use of TEK elicited through oral history gathering informs restorationists of historical species frequencies and distributions, as well as serving the duel purpose of articulating community concerns to environmental planners. Interview excerpts included in this chapter 
provide strong examples of the ways in which the life experiences and observations of Native elders can be utilized in restoration projects.

Non-Native Species: Threats to Ecological Balance

From a Nuwuvi perspective, water fills an essential role in sustaining plant and animal life. However, agency consultants saw certain species as being detrimental to water quality and availability. For instance, invasive plant species such as tamarisk require large amounts of water, making them detrimental to native plant species such as cottonwood and willow. Many Nuwuvi also named tamarisk as one of the plants that are most invasive and detrimental to native plants. Non-native animal species, especially horses and burros, were brought up even more frequently than plants. These animals often eat large amounts of riparian vegetation and trample springs in such a way as to reduce waterflow. Both Nuwuvi and agency participants acknowledged the impact of wild horses on soil and water resources in SMNRA and DNWR, and studies have also pointed to the major ecological impact of horses in the Great Basin (e.g. Beever and Herrick 2006). Horses were essential to the settlement of the region, and although they are still a symbol of the West today, they are also known to be a significant source of ecological disturbance (Beever 2003, Beever and Herrick 2006). Although Nuwuvi recognized the impacts that horses and other ungulates have on springs, they were also sympathetic to the position of the horse, having been brought in as a tool of Euro-American settlers. 
Participants from the Moapa Band of Paiutes and USFS (respectively) discussed the impacts of wild horses this way:

A stream runs clear...it's got to be clean. You can tell, you know, when it's clean. But you can see, like I said, nowadays it isn't clean, cause they have different cattle and whatever...cause of the cattlemen and all that...horses and goats and all that...you name it, they got 'em.

From a natural resource management perspective, [horses] do a lot of harm to the Spring Mountains when they exceed their appropriate management levels-AML--and we have AMLs and they've exceeded them. And they're having a lot of impact.

Wild horses have become such a symbol of the region that they can be seen on a special edition Nevada license plate, but it is clear from both the Nuwuvi and agency perspectives that they are causing problems for springs in these protected areas.

Figure 4: Photograph of Wild Horses, SMNRA

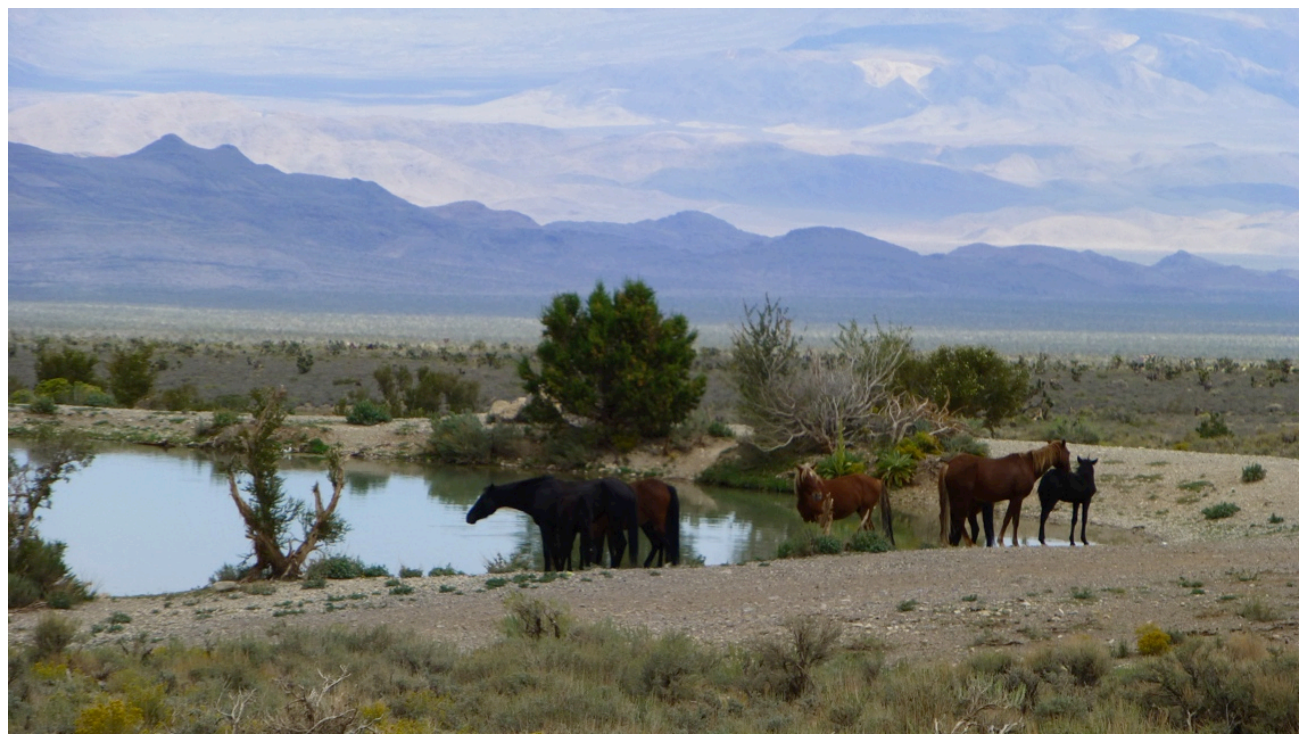

Wild horses seen near Cold Creek in the eastern Spring Mountains, September 2012 (Image: K.L. Wendel) 
Historic Improvements: Remnants of Times Past

Early settlers who used available water sources to irrigate fields, water livestock, and provide water for activities such as mining and logging drastically altered many springs and streams in these areas. The "dewatering" of mines, which involves the draining of water that accumulates when open-pit mining operations dip below the water table, has been a common occurrence in the state of Nevada, which was settled partially due to its abundance of gold and silver (Glennon 2002:175). Many participants mentioned historic improvements related to these activities as having impacted water sources and the Nuwuvi relationship with those resources. When ranchers and others effectively springs, it not only excluded Native use of those resources, it also prevented the ordained Nuwuvi stewardship of those resources. This is perceived to be an extremely negative effect of the Euro-American settlement of the region. Here, an elder from the Las Vegas Paiute Tribe described his grievances about the way water has been utilized by Euro-Americans:

The non-Native people, when they came into the area, they would try to make things better, but actually make things worse when they try to fix a stream or a... spring. A lot of that has happened where people come out and mess it up and it stops flowing. It would just stop. And I know sometimes things happen where it stops because no one's using it. But sometimes when people-like Native people, if they understand what's going on, they can actually make it come back. Some of those things could happen...or it could go away because it doesn't know you...or come back... so there are certain things that people can do...in some stories, I mean...that has happened. It went away because no one used it and they can call it back to be used.

Agency consultants also recognized the negative impacts that mechanical alterations such as the piping water sources to fill horse troughs or aggressively 
digging out springs to maximize water flow can have. The removal of such improvements will be described as a common restoration technique in the following section of this chapter. Based on an investigation of these five impacts, it is clear that there are many similarities in the ways that Nuwuvi and agency consultants perceive hydrological impacts to resources in SMNRA and DNWR.

\section{A Common Perspective on Impacts to Hydrological Resources}

Although in many cases Nuwuvi and agency consultants described the same impacts to water sources in these areas, they often arrived at these conclusions in different ways. For instance, Nuwuvi perceptions tended to be based on either cross-generational perspective gained through inter-generational knowledge transmission or through personal observation. Agency perceptions are also often gained through personal observation, especially for employees who had worked in the region over a long time frame. However, agency perceptions of impacts were also often products of monitoring projects aimed at measuring these changes. This is a common distinction made between western scientific and indigenous knowledge (e.g. Berkes 2008), and represents differing approaches to the measurement of impacts on hydrological resources in SMNRA and DNWR, revealing the diverging epistemologies at the root of these perspectives. 


\section{Nuwuvi and Agency Restoration Approaches and Techniques}

USFWS and USFS: Approaching Restoration with a Manager's Eye

Restoration projects account for much of the active management conducted in these areas by the USFS and USFWS. Agency consultants, who included one restoration ecologist, discussed various approaches to restoration, all of which are based on western scientific models. Impacts from historic activities such as mining and ranching, as well as present-day recreational activities, have rendered hydrological restoration necessary in these ecosystems. Monitoring and surveying are two important tools for determining whether or not water sources are in need of restoration. Managers often employ techniques that compare samples from various water sources to determine the relative health of a given source and base conditions for restoration. Several large-scale restoration projects have taken place in SMNRA and DNWR, including the restoration of Corn Creek, which included rechannelization and revegetation activities. Restoration projects in SMNRA are often completed collaboratively through the Southern Nevada Restoration Team (SNRT).

Current agency restoration practices include removing historic improvements and restoring natural channels, clearing invasive plant species and replanting native vegetation, and exclusion measures, which includes the building of fences around water sources and the bouldering of user-created roads. One agency consultant spoke specifically about taking the non-equilibrium approach to hydrological management and restoration, which encourages some amount of disturbance to the ecosystem. 
Nuwuvi: Working to Restore Balance

As mentioned in the previous chapter, many Nuwuvi consultants assert that water in these areas is less healthy now than it was in the past. Nuwuvi informants saw factors including recreational activities and climate change as responsible for the impacts to hydrology. Many Nuwuvi view hydrological restoration as a necessary step forward since many water sources in the region are considered to be unhealthy. Part of the necessary present day human management of water includes practices meant to bring the land back into balance. The concept of balance is central to the Nuwuvi understanding of ecological health. Here, a representative from the Kaibab Band of Paiutes describes the concept of balance:

But we as man are creating an imbalance. So that's when everything starts to change. That's what we were told, you know. So that's why it's so important as Native people to fight the battles. To conserve and to protect the land, and yeah, you know, expansion or all of this stuff must take place, but yet we believe-some of us believe-that [humans are] creating that imbalance. You're messing with life, you know, and that's where turmoil starts to take place.

The concept of balance is related to the complex set of interactions detailed in the hydro-logics section in Chapter 3. The land remains in balance as long as all parts of the ecosystem (including humans) are occupying their role. This is why, when one part of the landscape becomes unhealthy, other landscape features can be impacted.

An elder from the Pahrump Paiute Tribe described it this way:

When the spring is healthy, the land is healthy. When the land is sick, the springs are sick...if you have those sick areas and they're not being properly managed, then they start to accumulate different things. And 
so if you get some, let's say some animal dies in the water or something like that, and so it starts to contaminate that water, and you get an overgrowth of different plants that can make the spring unhealthy...you might get areas that have different things...that have happened that might make it better. For example, you have people who are...they have managed the spring and they kept things out and I've seen have been done culturally, naturally, and artificially, that sometimes things would be managed in a way where...let's say wild horses. Wild horses came in and some people tend to think that...a lot of the ones that you see here, were native here and have of course been here for hundreds of years, but they were really brought in. but they can...they're really hard on springs.

Most Nuwuvi consultants agreed that restoration of impacted resources is both possible and desirable to bring the land back into balance.

Through the coding process, I identified three major practices surrounding Nuwuvi management and restoration of hydrological resources: debris removal from springs, respecting the springs through prayers and songs, and the cleaning out of pohs, or bedrock depressions (see Chapter 3). These management practices are all considered restoration techniques to bring the land back into balance. Since the land is seen by many Nuwuvi to be out of balance, the only way to right the imbalance is for humans to interact with hydrological resources in a respectful way, which involves practicing these techniques.

\section{Comparing the Two Approaches}

As the impacts described by agency and Nuwuvi consultants were relatively similar, these two disparate approaches to restoration beg comparison and analysis. I suggest that agency and Nuwuvi approaches to restoration stem from different epistemologies, although there is a good deal of alignment and complementarity in 
the restoration practices described from consultants from both groups. Below is a summary of Nuwuvi and agency perceptions of restoration concepts, and a discussion of the similarities and differences identified in these approaches. In the text that follows, I utilize three practices as examples of overlap and divergence: spring stewardship, poh restoration and guzzler (tanks used to provide water for animal populations) installation, and the construction of exclusions. Ultimately, these distinctions serve to illuminate how the two groups' approaches to restoration have developed epistemologically.

Table 2: Nuwuvi and Agency Perceptions of Restoration

\begin{tabular}{|c|c|c|c|c|}
\hline $\begin{array}{l}\text { Management } \\
\text { or } \\
\text { Restoration } \\
\text { Theme }\end{array}$ & Nuwuvi & $\begin{array}{l}\text { Federal Agency } \\
\text { (USFS/USFWS) }\end{array}$ & Similarities & Differences \\
\hline $\begin{array}{l}\text { Management } \\
\text { (general) }\end{array}$ & $\begin{array}{l}\text { - Taking care of } \\
\text { the water is } \\
\text { an important } \\
\text { human } \\
\text { responsibility }\end{array}$ & $\begin{array}{l}\text { Management } \\
\text { strategies are } \\
\text { guided by agency } \\
\text { plans and missions }\end{array}$ & - $\mathrm{N} / \mathrm{A}$ & $\begin{array}{l}\text { Nuwuvi } \\
\text { - The word } \\
\text { "management } \\
\text { " is often } \\
\text { associated } \\
\text { with Euro- } \\
\text { American } \\
\text { control of } \\
\text { resources }\end{array}$ \\
\hline $\begin{array}{l}\text { Restoration } \\
\text { (General) }\end{array}$ & $\begin{array}{l}\text { - It is possible } \\
\text { for water } \\
\text { health to be } \\
\text { restored } \\
\text { - Opinions vary } \\
\text { on the } \\
\text { timeline for } \\
\text { restoration }\end{array}$ & $\begin{array}{l}\text { - Restoring water } \\
\text { sources to historic } \\
\text { conditions } \\
\text { - Monitoring and } \\
\text { surveying common } \\
\text { methods used in } \\
\text { preparation for } \\
\text { restoration projects } \\
\text { - Extended timeline } \\
\text { is necessary } \\
\text { - Disturbance } \\
\text { sometimes } \\
\text { encouraged }\end{array}$ & $\begin{array}{l}\text { - Restoration can } \\
\text { have a positive } \\
\text { effect on the } \\
\text { land } \\
\text { - Humans can } \\
\text { facilitate } \\
\text { restoration }\end{array}$ & $\begin{array}{l}\text { Nuwuvi } \\
\text { - Before a } \\
\text { disturbance, } \\
\text { humans need } \\
\text { to explain to } \\
\text { water why it } \\
\text { is being } \\
\text { altered }\end{array}$ \\
\hline Springs & $\begin{array}{l}\text { - Springs need } \\
\text { human } \\
\text { interaction to }\end{array}$ & $\begin{array}{l}\text { - Popular recreation } \\
\text { sites } \\
\text { - Monitoring of water }\end{array}$ & $\begin{array}{l}\text { - Management/st } \\
\text { ewardship } \\
\text { involves }\end{array}$ & $\begin{array}{l}\text { Nuwuvi } \\
\text { - Humans must } \\
\text { recognize }\end{array}$ \\
\hline
\end{tabular}




\begin{tabular}{|c|c|c|c|c|}
\hline $\begin{array}{l}\text { Management } \\
\text { or } \\
\text { Restoration } \\
\text { Theme }\end{array}$ & Nuwuvi & $\begin{array}{l}\text { Federal Agency } \\
\text { (USFS/USFWS) }\end{array}$ & Similarities & Differences \\
\hline & $\begin{array}{l}\text { remain } \\
\text { healthy } \\
\text { - Indictors of } \\
\text { healthy } \\
\text { water: green } \\
\text { vegetation, } \\
\text { wildlife in the } \\
\text { area, strong } \\
\text { water flow }\end{array}$ & flow & $\begin{array}{l}\text { cleaning debris } \\
\text { from springs } \\
\text { - Consistent } \\
\text { water flow a } \\
\text { sign of spring } \\
\text { health }\end{array}$ & $\begin{array}{l}\text { springs as } \\
\text { living things } \\
\text { in order to } \\
\text { show respect }\end{array}$ \\
\hline $\begin{array}{l}\text { Streams and } \\
\text { Ponds }\end{array}$ & $\begin{array}{l}\text {-It is important } \\
\text { for stream } \\
\text { flow to } \\
\text { continue } \\
\text { - If water is } \\
\text { disrespected, } \\
\text { it may stop } \\
\text { flowing or } \\
\text { the flow may } \\
\text { reverse }\end{array}$ & $\begin{array}{l}\text { - Popular sites for } \\
\text { recreation }\end{array}$ & $\begin{array}{l}\text { An important } \\
\text { and striking } \\
\text { part of the } \\
\text { landscape }\end{array}$ & $\begin{array}{l}\text { Nuwuvi } \\
\text { Flowing water } \\
\text { susceptible to } \\
\text { change if } \\
\text { disrespected }\end{array}$ \\
\hline $\begin{array}{l}\text { Water } \\
\text { Catchments/ } \\
\text { Guzzlers }\end{array}$ & $\begin{array}{l}\text {-Sediment } \\
\text { should be } \\
\text { cleared out } \\
\text { •Rock "lids" } \\
\text { sometimes } \\
\text { used to stunt } \\
\text { evaporation }\end{array}$ & $\begin{array}{l}\text { - Guzzlers an } \\
\text { important part of } \\
\text { wildlife } \\
\text { management in } \\
\text { both areas } \\
\text { USFWS } \\
\text { - Especially important } \\
\text { for the } \\
\text { preservation of } \\
\text { desert bighorn } \\
\text { sheep, consistent } \\
\text { with the agency } \\
\text { mission }\end{array}$ & $\begin{array}{l}\text { - Animals need } \\
\text { reliable water } \\
\text { sources in order } \\
\text { to survive }\end{array}$ & $\begin{array}{l}\text { Nuwuvi } \\
\text { Humans have } \\
\text { responsibility } \\
\text { to clean out } \\
\text { pohs (water } \\
\text { catchments) }\end{array}$ \\
\hline $\begin{array}{l}\text { Flowing } \\
\text { Water }\end{array}$ & $\begin{array}{l}\text {-Historical } \\
\text { alterations } \\
\text { to flowing } \\
\text { water have } \\
\text { negatively } \\
\text { impacted the } \\
\text { resource } \\
\text { - Restoring } \\
\text { water flow, } \\
\text { avoiding } \\
\text { stagnation, } \\
\text { removing } \\
\text { trash from } \\
\text { water source } \\
\text { all impor- } \\
\text { tant parts of }\end{array}$ & $\begin{array}{l}\text { - Historic impacts } \\
\text { such as piping are } \\
\text { often targeted for } \\
\text { removal }\end{array}$ & $\begin{array}{l}\text { - Historic } \\
\text { modifications are } \\
\text { often seen as } \\
\text { detrimental to } \\
\text { water health }\end{array}$ & $\begin{array}{l}\text { Nuwuvi } \\
\text { respect for the } \\
\text { water source is } \\
\text { a vital } \\
\text { component to } \\
\text { restoration }\end{array}$ \\
\hline
\end{tabular}




\begin{tabular}{|c|c|c|c|c|}
\hline $\begin{array}{c}\text { Management } \\
\text { or } \\
\text { Restoration } \\
\text { Theme }\end{array}$ & Nuwuvi & $\begin{array}{l}\text { Federal Agency } \\
\text { (USFS/USFWS) }\end{array}$ & Similarities & Differences \\
\hline & $\begin{array}{l}\text { restoration } \\
\text {-Springs may be } \\
\text { able to } \\
\text { restore } \\
\text { themselves, } \\
\text { but human } \\
\text { management } \\
\text { activities } \\
\text { prompt } \\
\text { restoration }\end{array}$ & & & \\
\hline $\begin{array}{l}\text { Sub- } \\
\text { terranean }\end{array}$ & $\begin{array}{l}\text { - Subterranean } \\
\text { water is espe- } \\
\text { cially } \\
\text { vulnerable to } \\
\text { impacts from } \\
\text { nuclear and } \\
\text { chemical } \\
\text { pollution }\end{array}$ & $\begin{array}{l}\text { Lowering water } \\
\text { tables are a } \\
\text { concern }\end{array}$ & $\begin{array}{l}\text { - Regional } \\
\text { groundwater } \\
\text { development } \\
\text { projects are a } \\
\text { potential } \\
\text { problem }\end{array}$ & - $\mathrm{N} / \mathrm{A}$ \\
\hline Exclusion & $\begin{array}{l}\text { - May be } \\
\text { detrimental } \\
\text { to animal life } \\
\text { and prevents } \\
\text { human stew- } \\
\text { hardship of } \\
\text { water sources } \\
\text { - Helps protect } \\
\text { water from } \\
\text { destruction } \\
\text { by horses and } \\
\text { ATVs }\end{array}$ & $\begin{array}{l}\text { - A common } \\
\text { approach to } \\
\text { ecological } \\
\text { restoration } \\
\text { - Excludes sources of } \\
\text { disturbance } \\
\text { (horses, vehicles, } \\
\text { etc.) }\end{array}$ & $\begin{array}{l}\text { - Exclusions can be } \\
\text { an effective } \\
\text { method against } \\
\text { damage }\end{array}$ & $\begin{array}{l}\text { Nuwuvi } \\
\text { Reservations } \\
\text { are restricted } \\
\text { access to water } \\
\text { sources }\end{array}$ \\
\hline
\end{tabular}

Areas of Convergence: Watering Animals and Cleaning Springs

As mentioned earlier, both agency and Nuwuvi individuals take a nonequilibrium approach to ecology, in which human disturbance can play a positive role in ecosystem health. Although many of the human activities discussed in the impacts section were considered to be detrimental to water health, other activities, such as the cleaning of springs and pohs and the construction of guzzlers (large 
tanks placed along animal migration routes to ensure adequate water supply), are seen as positive enhancements to the ecosystem.

One important consideration is that simple human interaction with water is a central aspect of the Nuwuvi approach to management and restoration. Over time, springs are considered unhealthy if lax stewardship causes the water source to become blocked by plants, rocks, or other debris. This is when Nuwuvi find it necessary to restore the spring by removing debris from the area and recommencing the human relationship with the resource. This restores waterflow and helps the spring be healthy again.

This practice is remarkably similar to restoration techniques carried out by both USFS and USFWS. Clearing excess vegetation, particularly non-native species, is one important technique for water sources including springs. Additionally, revegetating the area with native species reduces erosion and restores wildlife habitat. The similarities between these two sets of practices are striking, and provide an obvious avenue for collaboration among these groups.

Another area of convergence is in the importance placed on animal health, specifically in ensuring that animals have reliable access to water sources. USFS, USFWS, and Nuwuvi are all interested in supporting the animals that frequent these areas, and ensuring a continuous water source is one way to do that; however, Nuwuvi and the agencies have slightly different approaches to this issue. While Nuwuvi manage pohs to help ensure that their volume is maximized for future rainfall (see Chapter 3 for a detailed description of the practice), agencies install water guzzlers to help maintain wildlife populations. Guzzlers are large metal tanks 
that are strategically placed in both SMNRA and DNWR to provide animals with dependable sources of water along migration routes. This ensures that populations will survive through harsh summers, and aid hunters in locating game. Guzzlers are especially vital to the mission of DNWR, which is centered on the preservation of the desert bighorn sheep. Consultants from both agencies indicated that not many new guzzlers are being constructed in SMNRA and DNWR, but that many are already dispersed throughout both areas. Although the maintenance of pohs and the construction and maintenance of guzzlers are very different practices, their ultimate aim is the same in ensuring adequate water supply for the animals that inhabit these landscapes.

In both practices of spring stewardship and poh restoration, humans occupy important roles in ensuring the health of water resources, as well as the plants and animals that depend on the water. Several researchers (Alcorn 1981, Posey 1985, Stevens 1997, Berkes 1998, Bugalho et al. 2011) have shown that humans can have positive impacts on ecosystems from a western scientific perspective, enhancing biodiversity through anthropogenic activity. Others (Folke et al. 1998:422) have demonstrated that human-initiated disturbances can enhance ecological resilience towards future large-scale disturbances. These Nuwuvi management and restoration practices similarly show how humans can cause very small-scale disturbances to landscape features such as springs and seeps and ensure that they have the capacity to sustain water resources for plants, animals and humans through future unpredictable ecological and meteorological conditions. 
Areas of Divergence: Exclusions and Human Interaction with Water

Both Nuwuvi and agency consultants acknowledged that human activities can have either detrimental or positive effects on water health. In order to mitigate destructive human impacts to water, agencies have utilized exclusions as one of the most common restoration techniques. Exclusions can include additions such as bouldering placed at the heads of user-created roads and fences put around springs to prevent ATVs, horses, and other forces that are deemed destructive from accessing these areas. According to agency informants, exclusionary measures allow the ecosystem time to recover from these impacts, thus passively prompting restoration.

Many Nuwuvi consultants described fences and other exclusionary measures that they had seen near or around springs in SMNRA and DNWR, and some expressed mixed feelings about them. While many participants saw value in preventing non-Native animals such as horses, burros, and cattle from accessing springs, they also expressed concerns over the impacts on these animals themselves, who are unable to reach water sources because of the barriers. Equally important is the fact that exclusions act as a form of control over these resources, as they effectively restrict public access to the water. Although Nuwuvi support the restriction of access for certain recreationists and others who are likely to treat water sources with disregard, many have negative reactions to fences due to the fact that they also restrict respectful and necessary interactions with the land and water.

This key area of divergence is indicative of the larger discrepancy in the ways that agency and Nuwuvi consultants viewed the role of humans in these ecosystems. 93 
Although both agreed that disturbance could have positive impacts on water resources, which had broader implications for Nuwuvi. For instance, prayers and songs were considered to be necessary for the restoration of these water sources that have been mistreated for many years. While exclusions prevent many destructive forces from affecting springs, they also prevent constructive and supportive human interactions, including the cleaning of springs and the practices of praying and singing for the water. One elder from the Pahrump Paiute Tribe described his conflicting feelings about the practice of constructing exclusions:

[Wild horses are] really hard on springs. I mean they'll trample over those things really bad because they're trying to get the water too. And so they don't understand what they're doing to keep the other animals out. And so I've seen it where the springs have actually been protected...where they're blocked off at the source so that way then some of the animals can't get to it. So you may have like a chain link fence. So now they can't get to where the spring is, but the water's still flowing through. So you're able to at least let the water flow through there. The downside, sometimes, is that it's artificial. And so even on some of...the songs and the prayers and things that we do...even though the chain link is open, sometimes things still can't get through the chain link. It's like an obstacle or a little barrier. It becomes a filter of sorts. So I think that's one of the things that's...also how we manage it. But...It's all those things: The songs, the stories, the interactions, the things that are beyond us. I mean, that's...why they were placed there.

This interview excerpt captures the sentiment of many Nuwuvi, who seek to protect water resources from destructive impacts while allowing for necessary human interaction. The lack of need for restoration techniques not supported by western scientific evidence (such as prayers and songs) is one of the key differences between agency and Nuwuvi approaches to restoration. 
Although agency consultants explained that some disturbance was considered beneficial to these ecosystems, especially vegetative disturbance caused by native animals, practices such as exclusions effectively serve to prevent many agents of disturbance that historically existed in the ecosystem (other than from very small animals and large-scale events such as fires). Exclusions prevent types of human disturbance that occurred prior to EuroAmerican arrival in the area, as well as other types of management deemed necessary by Nuwuvi, such as prayers and songs intended to keep the land in balance. While preventing disturbances of larger magnitudes such as ATVs and horses, exclusions also prevent some actions seen as beneficial from a Nuwuvi perspective.

\section{Epistemic Communities and Western Scientific Hegemony}

As evidenced above, the two approaches practiced by Nuwuvi and agency groups are very different in their epistemological grounding. Forsyth (2011:32) describes the word science as a set of technological knowledge developed through a systemized array of techniques. Management should not be considered entirely synonymous with science. Management encapsulates a broad range of goals, including supporting human health and welfare and environmental quality (Randolph 2004:3). However, it is clear that agency approaches to restoration are based on a western scientific approach. This type of knowledge development differs from the ecological understanding model outlined in Chapter 4. Though Nuwuvi and agency conclusions about hydrology and restoration may have been reached in 
different manners, there is still much overlap in the ultimate goals of Nuwuvi, USFS, and USFWS.

Land management agencies face a difficult set of circumstances when striving to achieve restoration goals. Reuss (2005) takes a social and historical view of restoration, outlining the ideological roots of ecology and demonstrating how restoration discourse currently relies heavily on technological solutions and costbenefit analyses. The expansiveness of DNWR, along with the agency's small staff, necessitates that cost-benefit analyses are an important decision-making tool for managers. Additionally, agency respondents confirmed that restorationists often seek technological solutions to environmental problems (Higgs 2003, Reuss 2005). Restorationists have to reconcile two disparate objectives: defense of the environment and satisfying a broad range of human needs (Reuss 2005:31). The Multiple Sustained Yield Act of 1960 legally obligated USFS to cater to the needs of a diverse range of interests ranging from recreation to timber (Prescott 2003). All of these considerations significantly complicate the circumstances of the managing agencies.

Nuwuvi had distinctly mixed feelings towards federal management of these landscapes. While some Nuwuvi expressed dismay that these landscapes are federally governed, and therefore subject to rules and regulations that did not exist in the past, many were grateful that the land was under public ownership and therefore protected from unbridled private development. Many participants appreciated agency efforts to restrict public access to certain areas, especially springs. Though this is contradictory to the idea that these springs need human 
interaction to remain healthy, it is clear that many Nuwuvi feel that common recreational interactions with these springs, which often involve dogs, horses, ATVs, and swimming, are inappropriate. Many Nuwuvi suggested education as a possible mitigation technique for impacts occurring as a result of culturally inappropriate uses of the land. An elder from the Kaibab Band of Paiutes conceded that education is perhaps the best available tool in the fight against ecological destruction in SMNRA:

Even in an area in the Spring Mountains where there's a lot of people going up there hiking and stuff like that. Those places, you know, could be protected, you know, even signs could be put up saying 'take your trash out...' You know, different kinds of measures like that could be done to protect those springs, to keep 'em flowing freely. Those people who take care of the mountains like the Forest Service people...could make sure that those places are cleaned. You know, go up there...especially if they're open to the public...they know a lot of people hike up there to see this spring. And those people today are the caretakers of those springs, cause Indian people are no longer the caretakers, because they're the National Forest now...Indian people can go up there and make their offerings and prayers and maybe pick up trash too, but the main caretakers nowadays are those who work for the government. So if they would take care of them that would really be something good.

Some of the techniques discussed by Nuwuvi participants point to an underlying non-equilibrium ecology approach to management. Interactions with springs include human-prompted disturbance of the surrounding riparian area around springs. Essentially, this is very similar to the agency approach, which is also based on a disturbance approach. Though the Nuwuvi concept of balance may seem unclear in the context of the non-equilibrium approach, it should be noted that the Nuwuvi concept of balance includes human interference with the land. Spoon and Arnold (2012) refer to this as a non-linear adaptive approach to management, 
meaning that the strategy is to bring the land back into balance when it is necessary. These ideas, which are in many ways consistent with western science, mean that there is some convergence in epistemology.

Jordan and Lubick (2011:2) describe the western ecological restoration approach as ecocentric management, or management focused primarily on recreating land and resources. The Nuwuvi approach positions humans in a more central role in restoration. Human (specifically Native American) interaction with the land is considered necessary for ecological restoration to happen. An elder from the Pahrump Paiute Tribe argued:

It can't be done without us. Tribes need to be actively and intimately involved from the very beginning...We were here in the beginning. We were the ones that showed people how to interact with it, how to use it. And if now, people will say...it's ours and you don't have a role in that, I think would be a real disservice. I think that the tribal people rely upon the information that was given to us. I mean, it's thousands of years old. From the beginning of time, we've interacted with the resources out there. And so for people to understand...they would have to include us.

Understanding social-ecological systems that have influenced water resources in these areas over time is another important part of reconstructing historic conditions for use in restoration projects. The Native voice can add tremendous value to restoration projects through a long-term perspective on water resources in the region; however, most restoration projects are not conducted collaboratively, but rather through the standard government-to-government consultation process required of federal agencies. Ecological restoration has been called into question by social scientists as being an example of the hegemony of western science in environmental management practices. However, given the 
common environmental goals identified by Nuwuvi and agency consultants, there is space for collaboration. Forsyth (2003:239) writes, “Acknowledgement of expertise does not...imply that all individuals have equal knowledge or training about specific risks, but that the experience and framing of risks by 'lay' people is crucial for the understanding of risks." This supports the legitimacy of Nuwuvi perceptions of land and water health in these protected areas. This type of data could be vital for land managers seeking to understand how the land has changed over time.

Federal agency consultation with Native American Nations occurs under Executive Order 13175, a measure that encourages the consideration of Native voices in land management and development plans (Stoffle et al. 2004:1). Collaboration becomes more difficult, however, when the perspectives involved can differ so radically on certain issues. For instance, Nuwuvi understandings of water, rocks, and mountains as living beings do not align well with positivist thinking that supports western scientific discourse of ecology (Chmara-Huff 2006:79). Escobar's (1996) focus on discourse and its ability to reveal underlying biases highlights this disconnect between Nuwuvi and agency approaches to hydrological management and restoration.

The relative values that individuals assign to various parts of the ecosystem vary considerably, and often manifest themselves as different engagements with water, which could be recreational, economic, managerial, or spiritual interactions (Strang 2005). Land management agencies have to consider the different engagements with water that occur within their borders. Considerations from habitat protection to recreational use all must be taken into account. This disparity 99 
of management considerations often dilutes the Native perspective, which is also supposed to be respected when developing management plans. The situation is further complicated when the values assigned to water differ not only among these various user groups, but also sometimes among Nuwuvi themselves. While some view water rights as an important political tool for the Nuwuvi Nations, others disagree with "buying into" the commodification of water. Although the Nuwuvi perspective is considered during the consultation process, more often than not, management plans are based partially on western scientific knowledge of the ways in which natural resources interact.

\section{Management versus taking care}

The way that Nuwuvi consultants conceptualized the relationship between humans and water was apparent in the way they described stewardship activities. As mentioned previously in Chapter 3, many Nuwuvi consultants disassociated the word "management" from the types of cultural practices they think are important to maintaining water resources. This distinction illustrates some of the key differences between Nuwuvi and agency approaches to water management and restoration. Nuwuvi participants often interpreted "management" to refer to Euro-American control of resources, including the current pipeline projects such as the Southern Nevada Water Authority pipeline project from Ely, Nevada or the Lake Powell Pipeline Project in Utah. Activities along the Colorado River, such as the building of dams (especially the Hoover and Parker Dams), and the diversion of water to cities such as Los Angeles, California and Phoenix, Arizona were also widely discussed. 
Here, an elder from the Las Vegas Paiute Tribe described her impressions of water management in the region:

I guess water management, like in this valley here-our water district...clear up Pahranagat Valley, up into Ely, is buying all the water. Shipping it all down here, and Harry Reid is getting fat, too. He's a fat cat. And you know, Coyote Springs...all the wells that they've dug up there. But you know, they're buying all that water all the way up. Just like they did-what they did in Kern County-Bishop and stuff where they've got that aqueduct running all the way down to Los Angeles, they've taken from those springs up here, the springs up in Bishop area and up that way. Well we're doing the same thing...they're taking the water, and all of the ranchers and all of the Mormon people are getting fat. They're getting paid a lot of moneythey're being paid millions for all that water that they're buying. And that water is...like down in Caliente, down in the lower half over there, the water just seeps out of the ground.

Much can be said of the political economic dimensions of water in these arid environments, but it was not my main focus. Nevertheless, it was clear that many participants recognized the links between power and economics in relation to regional water politics.

Nuwuvi participants were hesitant to describe practices such as the clearing of springs as water management. Nuwuvi management practices often came up in other portions of the interview, and participants described them as "taking care" of the water, rather than water management. This distinction can be partially attributed to the Nuwuvi conceptualization of the relationship between humans and water as symbiotic. In addition, it is evidence of the hegemony of western scientific discourse that permeates once-unique understandings of the world. Forsyth (2003:238) points out that orthodox science is built upon a division between "expert" and "lay" knowledge. "Epistemic communities" arise through the 
maintenance of this dichotomy. Epistemic communities are worldwide groups of professionals that share common values and tend to frame problems as simple cause-and-effect relationships that can be handled with policy (Jansen and Roquas 2005:143). Some researchers (e.g. Murphy 1994, Smith 1996) have argued that epistemic communities are reinforced through bureaucratic policies and the rationalization of so-called "expertise."

Among Nuwuvi consultants, there was a clear trend towards separating local, cultural, or personal understandings of water from the so-called "expert" managerial approach that most Nuwuvi see as synonymous with western management of these landscapes. However, many researchers have argued that the tendency to form a binary distinction between "local" and "expert" knowledge does a disservice to proponents of local knowledge. For instance, Agrawal (1995) points out that referring to local knowledge as a stark opposition to western science implies that "local" knowledge must always come from a subaltern group, effectively reinforcing already-present power relations. In this project, it was clear that many Nuwuvi participants themselves marked the divide between and western science and management and their own knowledge of the environment. There were often negative connotations to water "management" as described by Nuwuvi participants.

Participants often defined management as a way of making sure there were enough resources for the future, using the framework of Western science, and using terms such as "sustainable." Some of this discourse was applied to discussions of Nuwuvi management practices as well, suggesting that language may be used in a way to lend a perceived sense of legitimacy to the Nuwuvi approach to water 102 
management. It was also clear that participants equated land management privileges with social power. Although many Nuwuvi management techniques can technically be practiced on public lands, it is clear that the fact that these culturally important landscapes are being placed under federal control drastically alter the way that Nuwuvi relate to the land. Political ecology emphasizes inequalities and social positioning related to access to and control of resources (Biersack 2006:22, Williams 2001). This is particularly relevant to questions about knowledge valuations as represented in discourse. Here, a participant from the Kaibab Band of Paiutes explained her perspective on water management:

You know what? I will tell you the truth. Water management to me, as a Paiute, living here on the Kaibab Indian Reservation...it really means the white man's control of the water, and them overseeing the water, them controlling the water. And you as a Paiute, you having any say...water management-you're really cut out of the picture. That excludes you from the whole picture. Whereas, if you were to say preserving the water resources or documenting the water resources for the importance of your people...that's a whole different approach. But water management, I think, to me is really losing that source completely, and it being overtaken by another-like you say Fish and Wildlife or National Park Service, or-whatever the entity may be, it's really losing all rights and power over the water.

Although not all responses were so political in nature, many participants saw water management as something built around rigid laws and restrictions, and practiced by white land managers. Nuwuvi often saw their own management practices as personal interactions with the resource, rather than those governed by formal policies and regulations. This aligns with Colding and Folke's (2001) view of informal institutions differing from formal institutions due to their lack of written regulations and third-party enforcement. Rather, Nuwuvi institutions are built upon 
a complex set of beliefs and taboos that ensure proper care of hydrological resources. Many consultants described the Nuwuvi relationship between humans and water as symbiotic, which perhaps explains why many participants view official regulations and restrictions as somewhat distasteful.

Many participants also perceived of political control of water resources as greedy. Here, an elder from the Chemehuevi Indian Tribe explained her perspective on water managers:

I think they're trying to ensure that there is water-that it's gonna last for a long, long time... And that it's good water and clean water...try to keep it clean for as long as possible, but in this day and age, I think it's kind of impossible sometimes. But mainly...I think it does need to be managed, but for the right reasons, I think. You can't be greedy with it, that's for sure.

These two different approaches to water management were obviously noted by Nuwuvi participants, who viewed western management as a power-laden, sometimes greedy enterprise. At the same time, there was a clear acknowledgement of the legitimacy of western techniques, as evidenced through the integration of western scientific concepts into descriptions of Nuwuvi management regimes.

\section{Finding Points of Convergence in Two Disparate Approaches to Restoration}

By and large, Nuwuvi and agency participants described similar impacts to water resources in SMNRA and DNWR. A comparison of management and restoration approaches shows both similarity and divergence in the ways in which Nuwuvi and agency personnel seek to bring about hydrological restoration in these landscapes. Practices such as the clearing of springs and removal of historic 
improvements, as well as the cleaning of pohs as a supplement to the construction of guzzlers carried out by both agencies are quite complimentary. Other practices such as the construction of exclusions are more controversial from the Nuwuvi perspective.

Although there were several areas of overlap in the ways in which Nuwuvi and agency participants viewed hydrological management and restoration, the approaches that they took to management were based on very different epistemologies. Some Nuwuvi viewed the managerial approach practiced by "experts" working for both agencies as distasteful, especially in light of controversial large-scale piping projects currently taking place in the region. The power inequalities between the agencies and Nuwuvi Nations were also prevalent, as western scientific hegemony clearly influenced management plans in both SMNRA and DNWR. 


\section{Chapter 6: Conclusion}

As people continue to tap water from these desert landscapes, documenting Native understandings of the land and its resources becomes increasingly important. Nuwuvi relationships with the land have undergone significant transformation since the Euro-American colonization of the west, and Nuwuvi ecological knowledge has experienced associated changes. These developments pose a threat not only to the water resources themselves, but also to the perpetuation of Nuwuvi hydrological and management knowledge. The Nuwuvi Knowledge-to-Action project has offered a great deal of insight into the breadth and depth of ecological knowledge held by members of Nuwuvi Nations. As I show in previous chapters, the character of ethnohydrological knowledge and the ways in which it has changed over time provides an example of the effects of colonization and large-scale development of the Great Basin on a knowledge domain and its related practices.

Data from interviews with 16 Nuwuvi knowledge holders and four agency participants presented a number of meaningful patterns that supported the arguments throughout this thesis. Chapter 3 explored the first level of analysis of Nuwuvi ethnohydrological knowledge, which was split into two categories: "hydrological" knowledge and management knowledge. Hydro-logical knowledge pertained to hydrological interactions with geology, biology, and the human relationship with water, while management knowledge was sub-divided into three significant adaptive management practices: clearing springs, practicing prayers and 
songs, and stewarding pohs, or bedrock depressions (Gelles 2003). I argue that Nuwuvi viewed water as a sentient being that requires human interaction in order to remain healthy, thus necessitating the management practices described. In Chapter 4, I further dissect this body of knowledge, analyzing how it 1) developed incrementally; 2) could be described as an assemblage; and 3) became fragmented over time. Chapter 5 explores how perceptions and approaches to hydrological impacts and restoration converged and differed among Nuwuvi and agency participants. I argue that although the overall perceptions of restoration were based on differing epistemologies, there were areas of convergence among individual practices described by both groups, especially in the common acceptance of a nonequilibrium approach to ecology. The common practices that I identify lay groundwork for potential collaboration among Nuwuvi and these land management agencies.

\section{The Potential for Collaborative Resource Stewardship in Southern Nevada}

Goodall (2008:365) argues that water holds a symbolic role in addition to its obvious ecological and economic roles. The Nuwuvi case bears this point out, as seen in participants' discontent with private residents using water resources from the Spring Mountains. It is evident that water is an economic commodity, and that access to and control of resources indicates who has power in the region. Here, an elder from the Moapa Band of Paiute Indians described her perception of homes located in the Rainbow Subdivision in the Spring Mountains: 
And...I see the mountains and I see the progress that's come there, and I'm thinking how is it gonna survive-the mountains? Because people are building these gigantic homes and I always said...when you say 'I have a home up in the mountain' I think of a little cabin. Maybe one, two, three room. And I said there isn't too much....water there in...the Kyle Canyon area, and...I said, this place can't take anymore homes.

The allocation of water in these landscapes is clearly a sensitive issue. The significance of the Spring Mountains landscape as the Nuwuvi Creation Site makes issues of access and control especially pressing.

In this thesis, I demonstrate the breadth and depth of Nuwuvi ethnohydrological knowledge, including management knowledge. I show evidence of continuity as information was passed down generationally through stories and songs. However, knowledge was becoming more fragmented, and the intensity of Nuwuvi water management in these landscapes has dramatically changed as a result of increased integration into the market economy, the distance of reservations from these important cultural landscapes, and knowledge loss stemming from the effects of federally-funded boarding schools. Despite these changes, Nuwuvi participants expressed a strong desire to continue traditional hydrological management practices, which they perceived as necessary to maintain water health. The stewardship models we presented as part of NKTA provide examples of the types of collaborative approaches that can be taken to ensure that necessary Nuwuvi water management practices continue in styles that can be complimentary to agency goals, and to provide opportunities for intergenerational knowledge transmission, thus slowing 108 
the loss of hydrological knowledge that has become threatened as a result of the political, economic, and social forces described in this thesis.

\section{Applied Outcomes: Management Recommendations from the NKTA Project}

The Nuwuvi Knowledge-to-Action project seeks not only to build rapport among Nuwuvi Nations, USFS, and USFWS, but to also provide recommendations for collaborative resource stewardship among these groups. We presented these recommendations in the document Collaborative Resource Stewardship Plan: Nuwuvi (Southern Paiute), the Spring Mountains National recreation Area and the Desert National Refuge Complex (2013). My research identifies two major areas for potential co-stewardship of hydrological resources: spring stewardship, and poh restoration (Spoon et al. 2013:89). Spring stewardship would reinstate certain Nuwuvi techniques that currently neglected in agency management plans. Practices such as clearing debris from springs, restoring strong waterflow, and conducting traditional prayers and songs that would help to bring the spring back into health would be particularly suitable for this collaborative activity. The second type of proposed activity, poh restoration, would involve individuals or groups identifying pohs and clearing out any sediment that has accumulated over time, consequently reducing the volume of water that the poh can contain. Many Nuwuvi consultants explained that conducting prayers and songs supports the success of other management techniques.

I selected these two management activities as suggestions for co-stewardship not only due to their importance to Nuwuvi, but also because of the parallels that 
can be drawn between Nuwuvi and agency management approaches in these areas. Agency approaches to spring management include many similar types of activities, including the clearing of debris, the replanting of native plant species, and the removal of historic spring improvements. In addition, pohs deliver a complimentary ecological service to guzzlers, which are currently installed by agencies to provide water sources for migrating animal populations.

Three models for collaboration were also provided in the stewardship plan (Spoon et al. 2013). The models provide three different approaches take depending on the type of management activity and the number of people involved. The first configuration is for individuals and families, in which small groups can practice spiritual or physical resource management activities on a small and informal style. The second model is for specialist groups, which would typically include a select group of individuals who have a specialized set of knowledge or skills who can practice monitoring or stewardship activities, or work on planning activities. This work can be carried out in tandem with USFS and USFWS representatives. The third type of collaboration takes place in the form of large-scale events. These events provide opportunities for intergenerational knowledge transmission and to teach Nuwuvi resource stewardship practices to individuals who are unfamiliar with them. Both types of proposed hydrological co-stewardship can be carried out in any of these three formats.

The NKTA Project works with Nuwuvi Nations and land management agencies to encourage Nuwuvi interaction with these landscapes (Spoon and Arnold 2012). These types of collaborative projects serve to reinitiate adaptive co-learning 
on the part of both agency and Native participants. The concept of social-ecological systems compliments the idea of coinciding ecological and social enrichment (Folke et al. 2005). Berkes and Folke (1998:340) link social and ecological systems in a very literal way, endorsing a "creative model of co-management in which scientific and traditional modes of taking care of a forest are combined, and in which the recovery of forest health parallels the recovery of human health, socially and individually." Multiple researchers (e.g. Higgs 2003, Tomblin 2009, Yibarbuk et al. 2001) have also pointed out that collaborative approaches to restoration can serve to reestablish relationships between humans and the land, which would address objectives created as part of the Nuwuvi Knowledge-to-Action project. This collaborative approach to resource stewardship seeks to support ecological health from a Nuwuvi perspective, and has the potential not only to improve relationships among participating groups, but also to empower Nuwuvi to take care of the land and resources towards which they feel important stewardship responsibilities. 


\section{Bibliography}

Agrawal, Arun

1995 Dismantling the Divide Between Indigenous and Scientific Knowledge. Development and Change 26(3):413-439.

Armitage, Derek

2005 Adaptive Capacity and Community-Based Natural Resource Management. Environmental Management 35(6):703-715.

Alcorn, Janice B.

1981 Huastec Noncrop Resource Management: Implications for Prehistoric Rainforest Management. Human Ecology 9(4):395-417.

Back, William

1981 Hydromythology and Ethnohydrology in the New World. Water Resources Research 17(2):257-287.

Beever, Erik

2003 Management Implications of the Ecology of Free-Roaming Horses in Semi-Arid Ecosystems of the Western United States. Wildlife Society Bulletin 31(3):887-895.

Beever, Erik and J.E. Herrick

2006 Effects of Feral Horses in Great Basin Landscapes on Soils and Ants: Direct and Indirect Mechanisms. Journal of Arid Environments 66:96112.

Berkes, Fikret

1998 Indigenous Knowledge and Resource Management Systems in the Canadian Subarctic. In Fikret Berkes and Carl Folke, eds. Pp.98-128. Cambridge: Cambridge University Press.

2008 Sacred Ecology. 2nd Edition. Philadelphia, PA: Taylor \& Francis.

Berkes, Fikret and Carl Folke

1998 Linking Social and Ecological Systems for Resilience and Sustainability. In Linking Social and Ecological Systems: Management Practices for Building Resilience. Fikret Berkes and Carl Folke, eds. Pp.1-26. Cambridge: Cambridge University Press.

Berkes, Fikret and Nancy J. Turner

2006 Knowledge, Learning, and the Evolution of Conservation Practice for Social-Ecological System Resilience. Human Ecology 34(4):479-494. 
Berkes, Fikret, Johan Colding, and Carl Folke

2000 Rediscovery of Traditional Ecological Knowledge as Adaptive Management. Ecological 10(5):1251-1262.

Bernard, H. Russell

2002 Research Methods in Anthropology: Qualitative and Quantitative Methods (Third Edition). Walnut Creek, CA: AltaMira Press.

Bettinger, Robert L. and Martin A. Baumhoff

1982 The Numic Spread: Great Basin Cultures in Competition. American Antiquity 47(3):485-503.

Biersack, Aletta

2006 Reimagining Political Ecology: Culture/Power/History/Nature. In Reimagining Political Ecology. Aletta Biersack and James B.

Greenberg, eds. Pp.1-40. Durham, N.C.: Duke University Press.

Biolsi, Thomas

2007 Race Technologies. In A Companion to the Anthropology of Politics. David Nugent and Joan Vincent, eds. Pp.400-417. Oxford: Blackwell Publishing.

Boeije, Hennie

2010 Analysis in Qualitative Research. Los Angeles: Sage Publications.

Boyatzis, Richard E.

1998 Transforming Qualitative Information: Thematic Analysis and Code Development. Thousand Oaks, California: Sage Publications.

Bratton, Susan Power

2000 Alternative Models of Ecosystem Restoration. In Environmental restoration: Ethics, theory, and practice. William Throop, ed. Pp. 5368. Amherst, NY: Humanity Books.

Bugalho, Miguel N., Maria C. Calderia, Joao S. Pereira, James Aronson, and Juli G. Pausas

2011 Mediterranean Cork Oak Savannas Require Human Use to Sustain Biodiversity and Ecosystem Services. Frontiers in Ecology 9(5):278286.

Bunte, Pamela A. and Robert J. Franklin

1987 From the Sands to the Mountain: Change and Persistence in a Southern Paiute Community. Lincoln: University of Nebraska Press. 
Calloway, Colin G.

2004 First Peoples: A Documentary Survey of American Indian History. Boston: Bedford/St. Martin's.

Chmara-Huff, Fletcher P.

2006 A Critical Cultural Landscape of the Pahrump Band of Southern Paiute. Master's thesis, Department of Geography, University of Arizona.

Colding, Johan and Carl Folke

2001 Social Taboos: "Invisible" Systems of Local Resource Management and Biological Conservation. Ecological Applications 11(2):584-600.

Egan, Dave and Evelyn A. Howell

2001 The Historical Ecology Handbook: A Restorationist's Guide to Reference Ecosystems. Washington D.C.: Island Press.

Escobar, Arturo

1996 Construction Nature: Elements for a post-structuralist political economy. Futures 28(4):325-343.

Folke, Carl, Fikret Berkes, and Johan Colding

1998 Ecological Practices and Social Mechanisms for Building Resilience and Sustainability. In Linking Social and Ecological Systems:

Management Practices for Building Resilience. Fikret Berkes and Carl Folke, eds. Pp.414-436. Cambridge: Cambridge University Press.

Folke, Carl, Thomas Hahn, Per Olddon, and Jon Norberg

2005 Adaptive Governance of Social-Ecological Systems. Annual Review of Environmental Resources 30:441-473.

Folke, Carl, Steve Carpenter, Brian Walker, Marten Scheffer, Thomas Elmqvist, Lance Gunderson, and C.S. Holling

2010 Regime Shifts, Resilience, and Biodiversity in Ecosystem Management. In Foundations of Ecological Resilience. Lance H. Gunderson, C.R. Allen, and C.S. Holling, eds. Pp.119-150. Washington, D.C.: Island Press.

Forsyth, Tim

2003 Critical Political Ecology. New York: Routledge.

2011 Politicizing Environmental Explanations: What Can Political Ecology Learn from Sociology and Philosophy of Science? In Knowing Nature: Conversations at the Intersection of Political Ecology and Science Studies. Mara J. Goldman, Paul Nadasdy, and Matthew D. Turner, eds. Pp. 31-46. Chicago: University of Chicago Press. 
Fowler, Don D. and Catherine S. Fowler

1971 Anthropology of the Numa; John Wesley Powell's Manuscripts on the Numic Peoples of Western North America, 1868-1889. Washington: Smithsonian Institution Press.

Garibaldi, Ann and Nancy Turner

2004 Cultural Keystone Species: Implications for Ecological Conservation and Restoration. Ecology and Society 9(3):1[online] URL: http://www.ecologyandsociety.org/vol9/iss3/art1.

Gartin, Meredith, Beatrice Crona, Amber Wutich, and Paul Westerhoff

2010 Urban Ethnohydrology: Cultural Knowledge of Water Quality and Water Management in a Desert City. Ecology and Society 15(4):35 [online] URL: http:// www.ecologyandsociety.org/vol15/iss4/art36/.

Giddens, Anthony

1971 Introduction and Selections on Marx. In Capitalism and Modern Social Theory. Pp.xi-xvi, 1-64. Cambridge: Cambridge University Press.

Gelles, Paul H.

2000 Water and Power in Highland Peru: The Cultural Politics of Irrigation and Development. New Brunswick: Rutgers University Press.

Glennon, Robert

2002 Water Follies: Groundwater Pumping and the Fate of Americas Fresh Waters. Washington D.C.: Island Press.

Goodall, Heather

2008 Riding the Tide: Indigenous Knowledge, History, and Water in a Changing Australia. Environment and History 14:355-84.

Gragson, Ted L. and Ben G. Blount

1999 Ethnoecology: Knowledge, Resources, and Rights. Athens, GA: University of Georgia Press.

Higgs, Eric

2003 Nature by Design: People, natural processes, and ecological restoration. Cambridge: MIT Press.

Holling C.S.

2010 Resilience and Stability of Ecological Systems. Annual Review of Ecological Systems 4:1-23.

Hulse, James W. 
2004 The Silver State: Nevada's Heritage Reinterpreted. Reno: University of Nevada Press.

2009 Nevada's Environmental Legacy: Progress or Plunder. Reno: University of Nevada Press.

Jansen, Kees and Esther Roquas

2005 Absentee Expertise: Science Advice for Biotechnology Regulation in Developing Countries. In Science and Citizens: Globalization and the Challenge of Engagement. Melissa Leach, Ian Scoones, and Brian Wynne, eds. Pp.142-154. London: Zen Books.

Johnson, Leslie Main and Eugene S. Hunn

2012 Landscape Ethnoecology: Concepts of Biotic and Physical Space. In Landscape Ethnoecology: Concepts of Biotic and Physical Space. Leslie Main Johnson and Eugene S. Hunn, eds, Pp. 1-11. New York: Berghahn Books.

Jordan, William R. and George M. Lubick

2011 Making Nature Whole: A History of Ecological Restoration.

Washington D.C.: Island Press.

Kelly, Isabel T.

1939 Southern Paiute Shamanism. Berkeley, CA: University of California Press.

Kelly, Isabel T. and Catherine S. Fowler

1986 Southern Paiute. In Handbook of North American Indians: Volume 11, Great Basin. William C. Sturtevant and Warren L. D'Azevedo, eds. Pp.368-397. Washington: Smithsonian Institution.

Knack, Martha

2001 Boundaries Between: The Southern Paiutes, 1775-1995. Lincoln, NB: University of Nebraska Press.

Madsen, David B. and David Rhode

1994 Across the West: Human Population Movement and the Expansion of the Numa. Salt Lake City: University of Utah Press.

Mulder, Monique Borgerhoff and Peter Coppolillo

2005 Conservation: Linking Ecology, Economics, and Culture. Princeton, NJ: Princeton University Press.

Murphy, Raymond

1994 Rationality and Nature: A Sociological Inquiry into a Changing Relationship. Boulder, CO: Westview Press. 
Posey, Darrell A.

1985 Indigenous Management of Tropical Forest Ecosystems: The Case of the Kayapo Indians of the Brazilian Amazon. Agroforestry Systems 3:139-158.

Prescott, Samuel T.

2003 Federal Land Management: Current Issues and Background. Hauppauge, New York: Nova Science Publishers.

Randolph, John

2004 Environmental Land Use and Planning. Washington: Island Press.

Rappaport, Roy

1968 Pigs for the Ancestors: Ritual in the Ecology of a New Guinea People. New Haven: Yale University Press.

Reuss, Martin

2005 Ecology, Planning, and River Management in the United States: Some Historical Reflections. Ecology and Society 10(1): 34-44.

Robertson, Hugh A. and Tara K. McGee

2003 Applying local knowledge: the contribution of oral history to wetland rehabilitation at Kanyapella Basin, Australia. Journal of Environmental Management 69:275-87.

Senos, Rene Frank K. Lake, Nancy Turner, and Dennis Martinez

2006 Traditional Ecological Knowledge and Restoration Practice. In Restoring the Pacific Northwest: the art and science of ecological restoration in Cascadia, Dean Apostol and Marcia Sinclair, eds. Pp. 393-426. Washington D.C.: Island Press.

Smith, Richard J.

1996 Sustainability and the Rationalization of the Environment. Environmental Politics 5(1):25-47.

Smith, Eric A. and Mark Wishnie

2000 Conservation and Subsistence in Small-Scale Societies. Annual Review of Anthropology 29: 493-524.

Spoon, Jeremy

2008 The Heterogeneity of Khumbu Sherpa Ecological Knowledge and Understanding in Sagarmatha (Mount Everest) National Park and Buffer Zone, Nepal. Human Ecology 39(5):657-672. 
2011 Tourism, Persistence, and Change: Khumbu Spirituality in Sagarmatha (Mount Everest) National Park and Buffer Zone, Nepal. Journal of Ecological Anthropology 15(1):41-57

2013a Different Ways of Knowing, Shared Goals: Applied Sustainability projects in the Nepalese Himalaya and the Great Basin. In Social Sustainability: A Multilevel Approach to Social Inclusion. Veronica Dujon, Jesse Dillard, and Eileen M. Brennan, eds. Pp.211-232. London: Routledge.

2013b From Yaks to Tourists: Sherpa Livelihood Adaptations in Sagarmatha (Mount Everest) National Park and Buffer Zone, Nepal. In Continuity and Change in Cultural Mountain Adaptations: From Prehistory to Contemporary Threats. Ludomir R. Lozny, ed. New York: Springer.

Spoon, Jeremy and Richard Arnold

2012 Collaborative Research and Co-Learning: Integrating Nuwuvi (Southern Paiute) Ecological Knowledge and Spirituality to Revitalize a Fragmented Land. Journal for the Study of Religion, Nature and Culture 6(4):477-500.

Spoon, Jeremy, Richard Arnold, and the Nuwuvi (Southern Paiute) Working Group 2011 Nuwu Kanee, Nuwu Tooveenup (Our Home, Our Story): Nuwuvi (Southern Paiute) and the Spring Mountains. Portland: The Mountain Institute and Portland State University.

2012a Consultation Handbook: Nuwuvi (Southern Paiute), the Spring Mountains National Recreation Area and the Desert National Wildlife Refuge Complex. Portland: The Mountain Institute and Portland State University.

2012b Nuwu-Vots (Our Footprints): Nuwuvi (Southern Paiute) and the Pahranagat Valley. Portland: The Mountain Institute and Portland State University.

Spoon, Jeremy, Richard Arnold, Brian Lefler, Kendra Wendel, the Nuwuvi (Southern

Paiute) Working Group, the U.S. Forest Service, and the U.S. Fish and Wildlife Service 2013 Collaborative Resource Stewardship Plan: Nuwuvi (Southern Paiute), the Spring Mountains National Recreation Area and the Desert National Wildlife Refuge Complex. Portland: The Mountain Institute and Portland State University.

Stevens, Stanley 1997 Conservation through Cultural Survival. Washington DC: Island Press.

Steward, Julian

1938 Basin-Plateau Aboriginal Sociopolitical Groups. Washington: U.S. Government Printing Office. 
1955 Theory of Culture Change: The Methodology of Multilinear Evolution. Urbana: University of Illinois Press.

Stoffle, Richard W. and Marina Nieves Zedeño

2001 Historical Memory and Ethnographic Perspectives on the Southern Paiute Homeland. Journal of California and Great Basin Anthropology 23(2):229-248.

Stoffle, Richard W., Fletcher P. Chmara-Huff, Kathleen A. Van Vlack, Rebecca S. Toupal

2004 Puha Flows from It: The Cultural Landscape Study of the Spring Mountains. Tucson, Arizona: Bureau of Applied Research in Anthropology, University of Arizona.

Strang, Veronica

2005 Water Works: Agency and Creativity in the Mitchell River Catchment 16(3):366-381.

2006 Fluidscapes: Water, Identity, and the Senses. Worldviews 10(2):147154.

Sutton, Mark Q.

1993 The Numic Expansion in Great Basin Oral Tradition. Journal of California and Great Basin Anthropology 15(1):111-128.

Tomblin, David C.

2009 The Ecological Restoration Movement: Diverse Cultures of Practice and Place. Organization \& Environment 22(2):185-207.

Turnbull, David

1997 Reframing Science and Other Local Knowledge Traditions. Futures 29(6):551-562.

Turner, Nancy and Fikret Berkes

2006 Coming to Understanding: Developing Conservation through Incremental Learning in the Pacific Northwest. Human Ecology 34(4):495-513

U.S. Census Bureau

2010 City Quickfacts: Las Vegas. Retrieved May 30, 2012 from http://quickfacts.census.gov.

U.S. Fish and Wildlife Service

2009 Desert National Wildlife Refuge Complex: Ash Meadows, Desert, Moapa Valley, and Pahranagat National Wildlife Refuge: Final 
Comprehensive Conservation Plan and Environmental Impact Statement.

2012 FY 2012 FWS Land Statistical Data Tables.

U.S. Forest Service

2008 Final Report Landscape Analysis. Chapter 1: Characterization of the Spring Mountains National Recreation Area. August 2008.

2011 Humboldt- Toiyabe National Forest Climate Change Vulnerability Report April 2011.

U.S. Forest Service Intermountain Region, State of Nevada, Department of Conservation and Natural Resources, U.S. Fish and Wildlife, Pacific Region

1998 Conservation Agreement for the Spring Mountains National Recreation Area Clark and Nye Counties, Nevada. URL: http://www.clarkcountynv.gov/Depts/dcp/Documents/Library/othe r\%20reports/collab/ConservationAgreementForTheSpringMountains NRA_April_1998.pdf

Vermeleyen, Saskia, George Martin, and Roland Clift

2008 Intellectual Property Rights Systems and the Assemblage of Local Knowledge Systems. International Journal of Cultural Property 15:201-221.

Walker, Brian and David Salt

2006 Resilience Thinking: Sustaining Ecosystems and People in a Changing World. Washington D.C: Island Press.

Watson, Annette and Orville H. Huntington

2008 They're Here-I Can Feel Them: The Epistemic Spaces of Indigenous and Western Knowledges. Social \& Cultural Geography 9(3):257-281.

Waring, Gwendolyn L.

2011 A Natural History of the Intermountain West: Its Ecological and Evolutionary Story. Salt Lake City: The University of Utah Press.

Wilkinson, Charles F.

2010 Indian Water Rights in Conflict with State Water Rights: The Case of the Pyramid Lake Paiute Tribe in Nevada, US. In Out of the Mainstream: Water Rights, Politics, and Identity. Rutgerd Boelens, David Getches, and Armando Guevara Gil, eds. Pp.213-222. London: Earthscan.

Williams, Brett

2001 A River Runs Through Us. American Anthropologist 103(2):409-431. 
Yibarbuk, D., P.J. Whitehead, J. Russell-Smith, D. Jackson, C. Godjuwa, A. Fisher, P. Cooke, D. Choquenot, and D.M.J.S. Bowman.

2001 Fire Ecology and Aboriginal Land Management in Central Arnhem Land, Northern Australia: A Tradition of Ecosystem Management. Journal of Biogeography 28:325-343. 


\section{Appendix A: List of Researcher Field Visits}

Table 3: Researcher Rapport Building and Field Visits

\begin{tabular}{|l|l|l|}
\hline Travel & Activity & Role \\
\hline $3 / 18 / 11-3 / 20 / 11$ & Stonewall Project Orientation & Intern \\
\hline $4 / 28 / 11-5 / 1 / 11$ & Stonewall Site Visit II & Intern \\
\hline $9 / 1 / 11-9 / 4 / 11$ & Stonewall Filmmaker Workshop & Intern \\
\hline $10 / 13 / 11-10 / 16 / 11$ & Stonewall Site Visit III & Intern \\
\hline $10 / 20 / 11-10 / 24 / 11$ & NKTA Pahranagat Site Visit & Assistant \\
\hline $11 / 2 / 11-11 / 4 / 11$ & Nellis AFB Native American Program Annual Meeting & Presenter \\
\hline $5 / 3 / 12-5 / 6 / 12$ & Knowledge-to-Action NWG Meeting & Assistant \\
\hline $6 / 21 / 12-6 / 24 / 12$ & Gathering for Our Mountains I & Lead Intern \\
\hline $8 / 1 / 12-8 / 3 / 12$ & Pine Nut Reconnaissance & Assistant \\
\hline $8 / 3 / 12-10 / 3 / 12$ & NKTA Fieldwork & Researcher \\
\hline $10 / 4 / 12-10 / 7 / 12$ & Gathering for Our Mountains II (Pine Nut Harvest) & Intern \\
\hline $12 / 7 / 12-12 / 9 / 12$ & Final Knowledge-to-Action NWG Meeting & Presenter \\
\hline $9 / 19 / 13-9 / 23 / 13$ & Gathering for Our Mountains III (Pine Nut Harvest) & Intern \\
\hline
\end{tabular}




\section{Appendix B: Nuwuvi Informed Consent Script}

Project Title: Nuwuvi (Southern Paiute) ethnohydrology: Ecological and management knowledge of water and perceptions of restoration in two southern Great Basin protected areas

Hello. My name is Kendra Wendel. I am a graduate student in Anthropology from Portland State University (PSU). I am conducting research that is part of the Nuwuvi Knowledge-to-Action Project, directed by Jeremy Spoon and Richard Arnold, which partners with PSU, The Mountain Institute, seven Nuwuvi Nations, the Spring Mountains National Recreation Area (U.S. Forest Service), and the Desert National Wildlife Refuge (U.S. Fish and Wildlife Service). The project seeks to document Nuwuvi knowledge of water and understand Nuwuvi perceptions of water health and restoration in the area. After I collect data, I will provide water management recommendations for both areas based on information from these interviews.

I am approaching you because you were recommended as a key individual with expert knowledge related to the project. If you are willing to participate, I would like to ask you some questions about your knowledge related to water in the Spring and Sheep mountains. With your permission, I would like to record what you say by both taking notes and with this recorder. You may refuse to have it recorded or may ask me to turn it off at any time. The notes and recordings are intended for project use to help me accurately remember everything that you say. The recorded information that I obtain from interviews will be kept secure at all times either on my person or locked in my luggage. You will receive an audio CD of this interview to keep. Your identity will be kept confidential in written reports will be protected with pseudonyms unless you provide consent for use. Information regarding the location of sacred sites will be kept confidential unless you agree that it is important to include as part of project report. If family members are present for your interview, the confidentiality of your statements cannot be guaranteed. I also request that I am able to take your photo so that we can have a visual record of you with the important information that you provide us.

I understand that this interview may take you away from your work or domestic tasks. For your participation, you will receive a $\$ 150$ stipend. If any of the questions upset you, please tell me and we can pause the interview or move on to the next question. I want you to be an active collaborator in the project, so please give me feedback and advice on all stages of the research and writing processes.

Your participation in this project is completely voluntary and you can withdraw your involvement or statements at any time during or after the interview, or refuse responses to any questions. If you have any questions or concerns at any time, please contact me, Kendra Wendel, the researcher, or Cathleen Gal, at the Human Subject Research Review Committee, Portland State University, using the provided contact information.

***Permission will be given or denied; the interview will also be conducted without recording or photos if necessary***

Researcher:

Kendra Wendel Department of Anthropology Portland State University

P.O. Box 751

Portland, Oregon 97213

(425) 750-0677

kwendel@pdx.edu
Human Subject Research Review Committee:

Cathleen Gal

Research and Strategic Partnerships 1600 SW Fourth Ave, Suite 620

Portland State University

Portland, Oregon 97201

(503) 725-4288

cgal@pdx.edu 


\section{Appendix C: Agency Informed Consent Form}

Project Title: Nuwuvi (Southern Paiute) ethnohydrology: Ecological and management knowledge of water and perceptions of restoration in two southern Great Basin protected areas

You are invited to participate in a research project conducted by Kendra Wendel, a graduate student in Anthropology from Portland State University. The researcher hopes to learn the character of ecological knowledge of water, hydrological management techniques, and perceptions of restoration held by select Nuwuvi (Southern Paiutes), and USFS and USFWS land managers. This project is being conducted in partial fulfillment of the requirements for a master's degree under the supervision of Jeremy Spoon, PhD. You were selected as a possible subject in this study because of your position and knowledge regarding hydrological management and/or restoration in either the Spring Mountains National Recreation Area or the Desert National Wildlife Refuge.

If you decide to participate, you will be asked to take part in an interview at your office or a convenient location in the Las Vegas area for a period of 1-2 hours. The interview will be recorded and will consist of a series of questions regarding hydrological features, management techniques, and approaches to hydrological restoration. I am not aware of any risks that you will be exposed to. You may not receive any personal benefit from taking part in this study, but the study may help to produce management recommendations based on the dual finding from Southern Paiute and USFS/USFWS interviews.

Your identity in public reports will be protected with pseudonyms unless you provide consent for use. Although every effort will be made to keep your identify confidential, there is still a chance your comments could be identified, and confidentiality cannot be guaranteed. Audio recordings will be kept on the researcher's person at all times or locked in her luggage and will be stored on a password-protected computer. Your participation is voluntary. You may also withdraw from this study at any time without affecting your relationship with Portland State University or the researcher.

If you have concerns or problems about your participation in this study or your rights as a research subject, please contact the Human Subjects Research Review Committee, Research and Strategic Partnerships, 1600 SW Fourth Ave, Suite 620 Portland, Oregon 97201, Portland State University, or by phone at (503) 725-4288 / 1-877-480-4400. If you have questions about the study itself, contact Kendra Wendel in the Department of Anthropology, Portland State University, P.O. Box 751, Portland, Oregon 97213, or by phone at (425) 750-0677.

Your signature indicates that you have read and understand the above information and agree to take part in this study. Please understand that you may withdraw your consent at any time without penalty, and that, by signing, you are not waiving any legal claims, rights or remedies. The researcher will provide you with a copy of this form for your own records. 


\section{Appendix D: Interview Questions for Nuwuvi Participants}

\section{Demographic information}

1. What is your name?

2. What is your age?

3. What Nation or culture group are you from?

4. Where did you grow up?

5. What is your level of education?

6. Where did you go to school?

7. How long have you lived in your current location?

\section{Topical questions}

Water and management

1. What is a spring?

2. What is a seep?

3. What is a stream?

4. What is a river?

5. What is a lake?

6. Are different types of water (streams, springs, rivers, lakes) connected to one another? Please explain.

7. How is water connected to other natural features (caves, rocks, mountains)?

8. What is the importance of water to the animals?

9. What is the most important thing about water?

10. What types of plants are associated with water? Please list. For each plant:

a. Are there certain times of year these plants are available?

b. Are these plants related to any animal species?

c. What are the uses for these plants? How did you learn about these uses?

11. Are there any stories related to water? Please explain.

12. Are there any songs related to water? Please explain.

13. What does management mean to you?

14. What does it mean for springs to be healthy?

15. What does it mean for seeps to be healthy?

16. What does it mean for streams to be healthy?

17. What does it mean for rivers to be healthy?

18. What does it mean for lakes to be healthy?

19. What practices are needed to keep water healthy?

20. How often do you visit springs, streams, rivers, or lakes?

21 . Where do you go to be near water? Please describe.

22. Are there any restrictions pertaining to the use of water?

23. How does the health of water sources such as streams and springs connect with the health of the broader landscape? 
24. Is water in this area different now than it was in the past? Please explain. a. What do you think has caused these differences?

\section{Restoration}

1. Is the water here healthy now?

2. How can you tell if water is healthy?

3. Can the water here be restored to a healthier state? Please explain.

4. How do you restore water to make it healthy again?

5. What are the biggest threats to the health of water today?

6. How do increasing human populations affect water?

7. How does increased recreation in the area affect water?

8. Should Native Americans play a role in restoring water in the ancestral territory? 


\section{Appendix E: Interview Questions for Agency Participants}

\section{Demographic information}

1. What is your name?

2. What is your age?

3. Where did you grow up?

4. What is your job title?

5. What is your educational background?

6. How long have you worked in your current position and at your current agency?

\section{Topical questions}

Water, management, and restoration

1. What are the primary functions of water in these ecosystems?

2. What plants and animals do you most strongly associate with water?

3. How do you define hydrological management?

4. What types of routine hydrological management does the agency practice?

5. How is human use of the landscape factored into hydrological management plans?

6. What are some of the current trends you are seeing in the hydrological features located on USFS/USFWS land?

7. How are hydrological resources being affected by climate change? Population growth in the region? How is the agency responding to these challenges?

8. How have hydrological features changed here since you have been working in this area?

9. How are the following issues affecting water resources in these areas?

a. Climate change

b. Growing human populations

c. Tourism

d. Recreation

10. What are the most major threats to water resources today?

11. How are water sources surveyed and monitored?

12. How do you determine when a water source is in need of restoration?

13. What methods are most commonly used in hydrological restoration projects?

14. How are restoration techniques adapted to meet newly presented challenges?

15. To your knowledge, how are past ecological conditions determined for use in restoration projects?

16. How do you determine that a restoration project is finished?

17. How do you define collaboration? 


\section{Appendix F: Sample Demographic Tables}

Table 4: Sample Demographics

\section{Total Interviewees}

20

Total Primary Nuwuvi Interviewees (secondary participants not included)

Total Agency Interviewees

Nuwuvi Female to Male Interviewee Ratio

Agency Female to Male Interviewee Ratio

Age of Oldest Nuwuvi Interviewee

Age of Youngest Nuwuvi Interviewee

Median Age of Nuwuvi Interviewees

Mean Age of Nuwuvi Interviewees

\begin{tabular}{r|}
16 \\
\hline 4 \\
\hline $3: 2$ \\
\hline $1: 1$ \\
\hline 86 \\
\hline 42 \\
\hline 62 \\
\hline 60 \\
\hline
\end{tabular}

Table 5: Sample Demographics by Nation

\begin{tabular}{|c|c|c|c|c|}
\hline Nation/Band & $\begin{array}{c}\text { Number of } \\
\text { Participants }\end{array}$ & $\begin{array}{c}\text { Number of } \\
\text { Males }\end{array}$ & $\begin{array}{c}\text { Number of } \\
\text { Females }\end{array}$ & Ages \\
\hline Chemehuevi & 4 & 2 & 2 & $47,66,69,74$ \\
\hline Chemehuevi (CRIT) & 3 & 0 & 3 & $42,62,66$ \\
\hline Kaibab & 2 & 0 & 2 & 44,61 \\
\hline Las Vegas & 3 & 2 & 1 & $54,64,70$ \\
\hline Moapa & 2 & 0 & 2 & 67,72 \\
\hline Pahrump & 3 & 2 & 1 & $59,64,86$ \\
\hline
\end{tabular}


Appendix G: Demographic Charts

Figure 5: Educational Backgrounds of Nuwuvi Participants

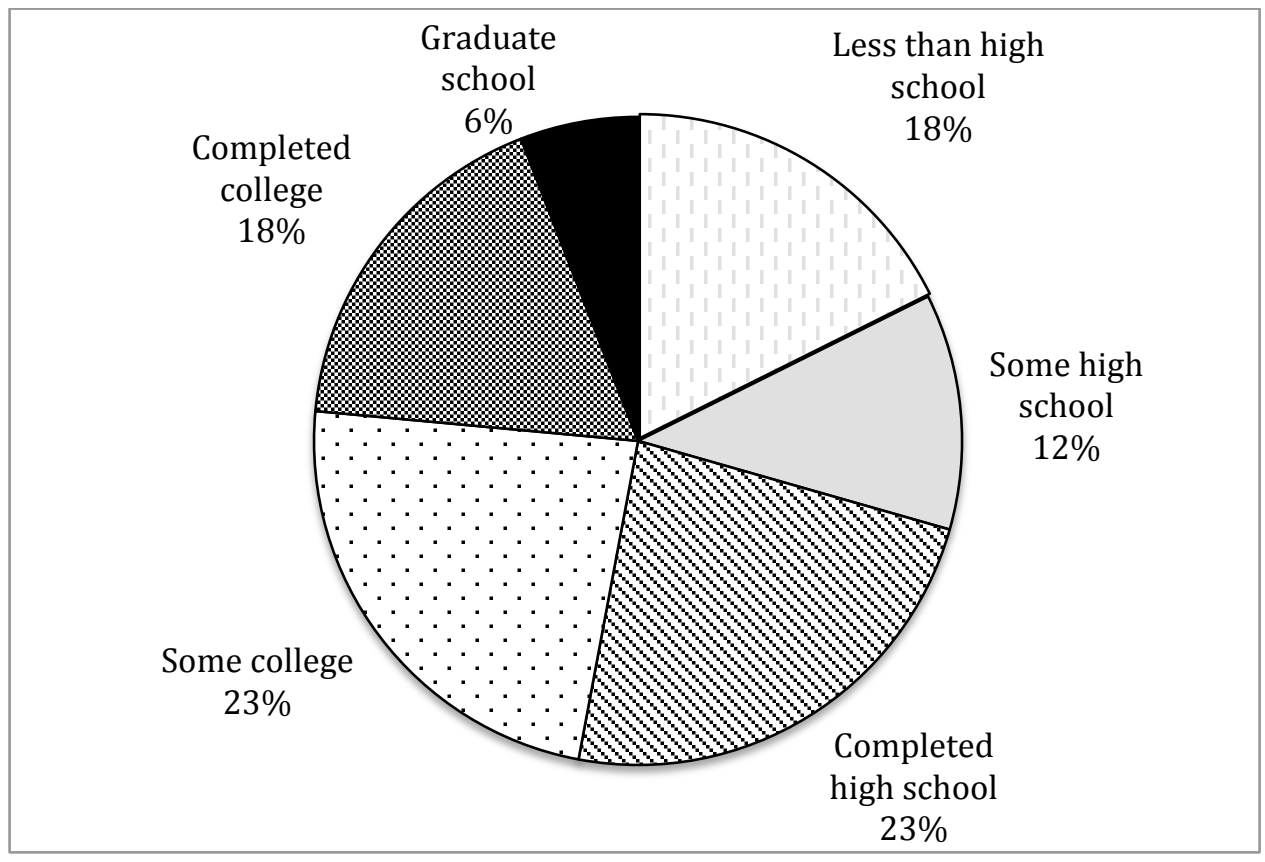

Figure 6: Residency of Nuwuvi Participants

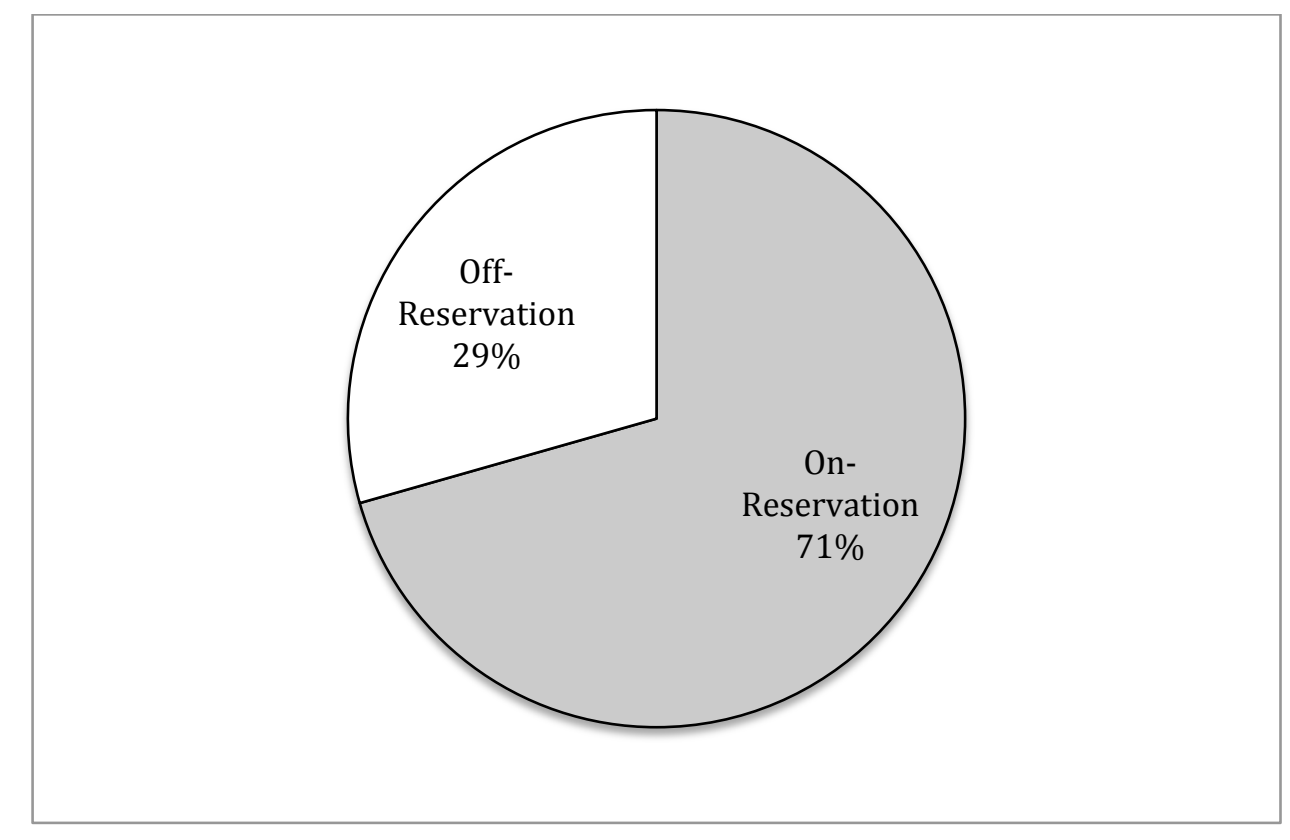

